\title{
Microstructure and Mechanical Properties of Austenitic Stainless Steels after Dynamic and Post-Dynamic Recrystallization Treatment
}

\author{
Marina Tikhonova, Rustam Kaibyshev, and Andrey Belyakov*
}

The effects of dynamic and post-dynamic recrystallization (DRX and post-DRX) on the microstructure and mechanical properties of austenitic stainless steels are critically reviewed. Particularly, the paper is focused on the grain refinement and strengthening by large strain deformation including severe plastic deformation conditions. The DRX and post-DRX microstructures are considered with close relation to the operative recrystallization mechanisms. Specific emphasis is placed upon two recrystallization mechanisms, that is, discontinuous and continuous, and their dependence on the deformation/annealing conditions. The relationships between DRX microstructures and processing conditions are summarized and their effect on post-DRX behavior is clarified. The structural strengthening mechanisms including the grain size and the dislocation density are elaborated.
Therefore, the studies dealing with microstructure control in advanced metallic material processing methods are of great practical consequence.

An important phenomenon, which can be utilized as a powerful instrument for processing of steels and alloys with desired grain sizes and dislocation substructures is a dynamic recrystallization (DRX), which occurs during plastic deformation at sufficiently large strains and at elevated temperatures. ${ }^{[7,8]}$ It is important that DRX results in the required microstructure directly during the plastic working. The final DRX microstructure and, hence, the mechanical properties of metallic materials subjected to thermo-mechanical treatment depend sensitively on the operative mechanisms of microstructure evolution, which,

\section{Introduction}

Austenitic stainless steels posses a number of beneficial properties related to technology and service. Their excellent workability and corrosion resistance along with a good weldability underlie a wide variety of diverse applications from kitchen stuff to medical devices and spaceship elements. ${ }^{[1,2]}$ One of common disadvantages of $\mathrm{Cr}-\mathrm{Ni}$ austenitic stainless steels is associated with their insufficiently high strength as compared to other structural steels and alloys. The yield strengths of conventional austenitic stainless steels lie in the range of $200-400 \mathrm{MPa} \cdot{ }^{[3]}$ Such a low strength level restricts remarkably exploitation of austenitic stainless steels as load-bearing engineering materials. Mechanical properties including strength of structural steels and alloys can be controlled by desired variation of their microstructures. ${ }^{[4]}$ Regarding the structural strengthening, the grain refinement, and the development of highly dislocated substructure are quite favorable structural changes to improve the strength properties without remarkable lose of plasticity. ${ }^{[5,6]}$ Both a decrease in the grain size (structural strengthening) and an increase in the dislocation density (substructural strengthening) can be achieved in structural steel and alloys by an appropriate thermo-mechanical treatment.

Dr. A. Belyakov, Dr. M. Tikhonova, Dr. R. Kaibyshev Belgorod State University, Belgorod, 308015, Russia E-mail: belyakov@bsu.edu.ru

The ORCID identification number(s) for the author(s) of this article can be found under https://doi.org/10.1002/adem.201700960.

DOI: 10.1002/adem.201700960 in turn, depend on the deformation conditions. ${ }^{[9]}$ The wider variety of microstructure evolution mechanisms operate during thermo-mechanical treatment, the wider diversity of structureproperty combinations could be achieved in steels and alloys. Fortunately, austenitic stainless steels exhibit various structural responses on thermo-mechanical impact, depending on deformation/annealing conditions. A face centered cubic (FCC) lattice with a relatively low stacking fault energy (SFE) in austenitic stainless steels are responsible for outstanding work hardening during cold to warm working and for dynamically stable microstructure resulting from dynamic equilibrium between strain hardening and softening during hot working. Thus, desired microstructures and properties can be easily obtained in austenitic stainless steels by an appropriate thermo-mechanical treatment. It is worth noting that the DRX microstructures evolved in large scale semi-products during thermo-mechanical treatment are frequently affected by post-deformation annealing. It has been recently reported that post-DRX annealing behavior, that is, the grain grow and softening kinetics, in various metallic materials depends significantly on the operative DRX mechanisms. ${ }^{[10]}$ Regarding austenitic stainless steels, the DRX mechanisms control the grain boundary distribution that evolve during deformation and subsequent annealing ${ }^{[11]}$ that affects corrosion resistance and fatigue behavior and is a subject of grain boundary engineering. ${ }^{[12]}$ The DRX phenomenon was carefully summarized in several recently published reviews, ${ }^{[10,13]}$ although just reported studies on the DRX effect on grain boundary character distribution and mechanical properties were not reviewed.

The present paper reviews the recently published research works on the regularities of microstructure evolution in 
austenitic stainless steels during plastic deformation to rather large strains, which are sufficient for DRX development under various deformation conditions. The major aim of the present review is to clarify the general DRX mechanisms operating under various processing conditions and to summarize their effect on the DRX microstructures, deformation behavior, and strengthening austenitic stainless steels. Since the DRX phenomenology and relevant terminology can be found in recently published reviews, ${ }^{[10,13]}$ the present paper starts from comparative analysis of DRX mechanisms operating in austenitic stainless steels followed by quantification of the resultant DRX microstructures in Section 2, specifying the condition for ultrafine grain development. Then, the effect of DRX mechanisms on the post-DRX behavior upon subsequent annealing treatment is resumed in Section 3. The grain boundary distributions and the strengthening mechanisms in austenitic stainless steels subjected to DRX treatment are quantified in individual Sections 4 and 5, respectively, due to insufficient attention paid for these topics in previous papers. Finally, prospective investigations and applications of DRX and related phenomena are outlined.

\section{DRX Regularities}

\subsection{Stress-Strain Curves during Warm to Hot Working}

Series of typical true stress-strain curves obtained by isothermal compression tests of a 304-type austenitic stainless steel under various temperature/strain-rate conditions are represented in Figure 1. ${ }^{[14,15]}$ According to the deformation mechanisms, two types of deformation behavior can be easily recognized, that is, dynamic recrystallization (DRX) type and dynamic recovery (DRV) type. The deformation behavior at relatively high temperatures $(T)$ or low strain rates $(\dot{\varepsilon})$ is characterized by a strain softening. Namely, the flow stress rapidly increases to its maximum at a relatively small strain and then gradually decreases with increasing strain and finally approaches a steady state level corresponding to dynamic equilibrium between strain hardening and softening. The strain softening is associated with the DRX development, when newly nucleated DRX grains growth out and consume work hardened surroundings with high dislocation density. The respective deformation conditions correspond to low values of Zener-Hollomon parameter (temperature compensated strain rate),

$Z=\dot{\varepsilon} \exp (Q / R T)$

where $Q$ and $R$ are the activation energy and universal gas constant, respectively, below approx. $10^{12} \mathrm{~s}^{-1}$ that can be considered as a hot deformation domain for austenitic stainless steels. Here, the activation energy for self diffusion is used as $Q$ for sake of simplicity. ${ }^{[16,17]}$ In some cases, several attenuating peaks on the stress-strain curves followed by a steady state deformation behavior can be observed (the lowest strain rate in Figure 1a). The appearance of either single or multiple peak behavior depends on the relative values of the critical strain for DRX onset and the strain for completion of one DRX cycle as originally proposed by Luton and Sellars. ${ }^{[18]}$ The single peak

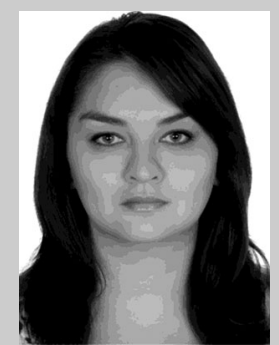

Marina Tikhonova, Ph.D., Research Associate of the Laboratory of Mechanical Properties of Nanostructured Materials and Superalloys, Belgorod State University, Belgorod, Russia, from 2014. The research interest is focused on the mechanisms of microstructure evolution, their dependence on thermo-mechanical processing conditions and effect on the mechanical properties of austenitic stainless steels. The current researches are concentrated on the dynamic and static recrystallization mechanisms, the grain refinement, and strengthening by large strain deformation.

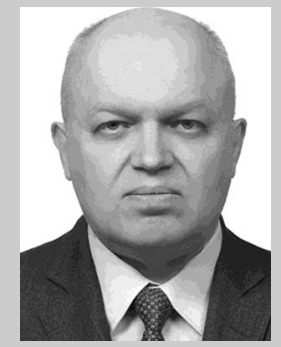

Rustam Kaibyshev, Ph.D., D.Sc., Professor, Head of the Laboratory of Mechanical Properties of Nanostructured Materials and Superalloys, Belgorod State University, Belgorod, Russia, from 2007. Research interest includes dynamic recrystallization, evolution of ultrafine grains during intense plastic straining, mechanisms of plastic deformation, creep and superplasticity of metal matrix composite, aluminum alloys, and steels.

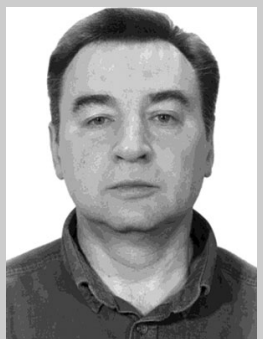

Andrey Belyakov, Ph.D., D.Sc., Leading Research Associate of the Laboratory of Mechanical Properties of Nanostructured Materials and Superalloys, Belgorod State University, Belgorod, Russia, from 2007. Research interests are mainly concerned with the mechanisms of microstructural changes in various metallic materials, subjected to large strain plastic deformation including hot and cold working as well as heat treatments. Scientific expertise incorporates deformation behavior and microstructure evolution including static, dynamic, and post dynamic recrystallization.

behavior takes place, when the strain for one cycle DRX completion is larger than the strain for DRX startup. On the other hand, the multiple peaks can be observed, if the strain for DRX cycle development is much smaller than that one for DRX initiation. For instance, an increase in the deformation temperature accelerates significantly the growth of DRX grains, while the nucleation of DRX grains is less affected by the temperature/strain rate conditions, leading to a strain for DRX cycle completion being smaller than that for DRX initiation that results in multiple stress peak behavior. Therefore, decreasing $Z$ parameter promotes the multiple peak behavior. The initial grain 
(a)
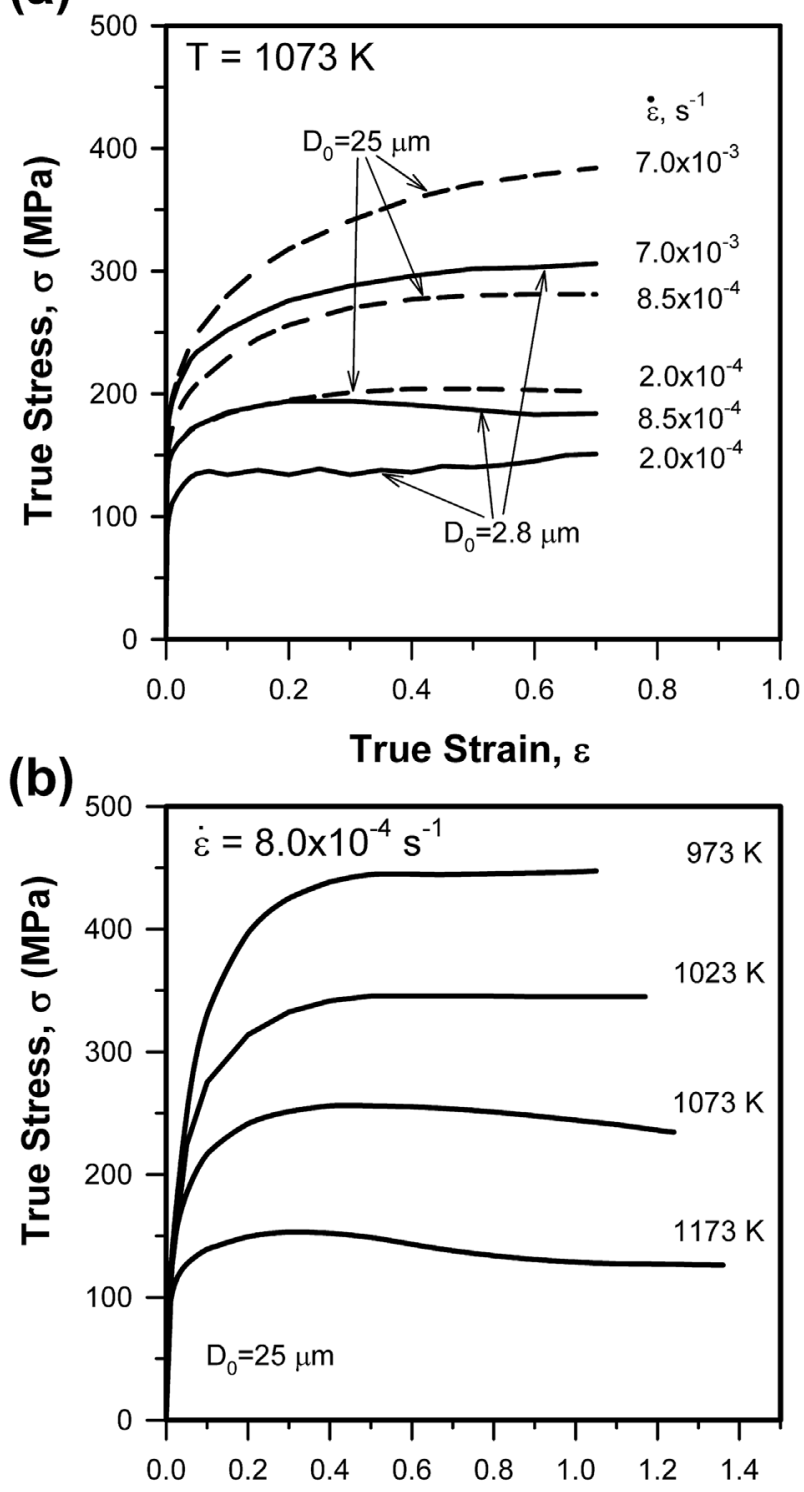

True Strain, $\varepsilon$

Figure 1. Typical stress-strain curves for warm to hot working of a 304type austenitic stainless steel. Effect of compression strain rate a) and temperature b) on deformation behavior. ${ }^{[14,15]}$

size reduction may also be favorable for multiple peak appearance, as will be considered in Section 2.4.

Another type of true stress-strain curves is observed at fairly low temperatures and/or rather high strain rates, when the true flow stress continuously increases during deformation. The rate of flow stress increase gradually slows down during deformation and, in some cases, approaches almost zero at large stains followed by a steady state deformation behavior. These deformation conditions correspond to high values of Zener-Hollomon parameter above approx. $10^{13} \mathrm{~s}^{-1}$ and can be considered as a warm deformation domain. The deformation behavior under conditions of warm working is generally affected by dynamic recovery as the main restoration process operating during plastic deformation..$^{[7,17,19-21]}$ A steady state deformation can take place, when the softening owing to dynamic recovery is large enough to balance the strain hardening. Recent studies on the microstructure evolution during large strain warm to hot working suggest that the misorientations between the straininduced subgrains, which evolve through dynamic recovery, progressively increase up to values inherent in ordinary highangle grain boundaries, leading to new grain development, that is, in situ (continuous) DRX. [22-31] $^{\text {[ }}$

The difference in the deformation behavior between warm and hot deformation is clearly reflected on the temperature/ strain rate dependence of flow stress (Figure 2). ${ }^{[14,32]}$ The flow
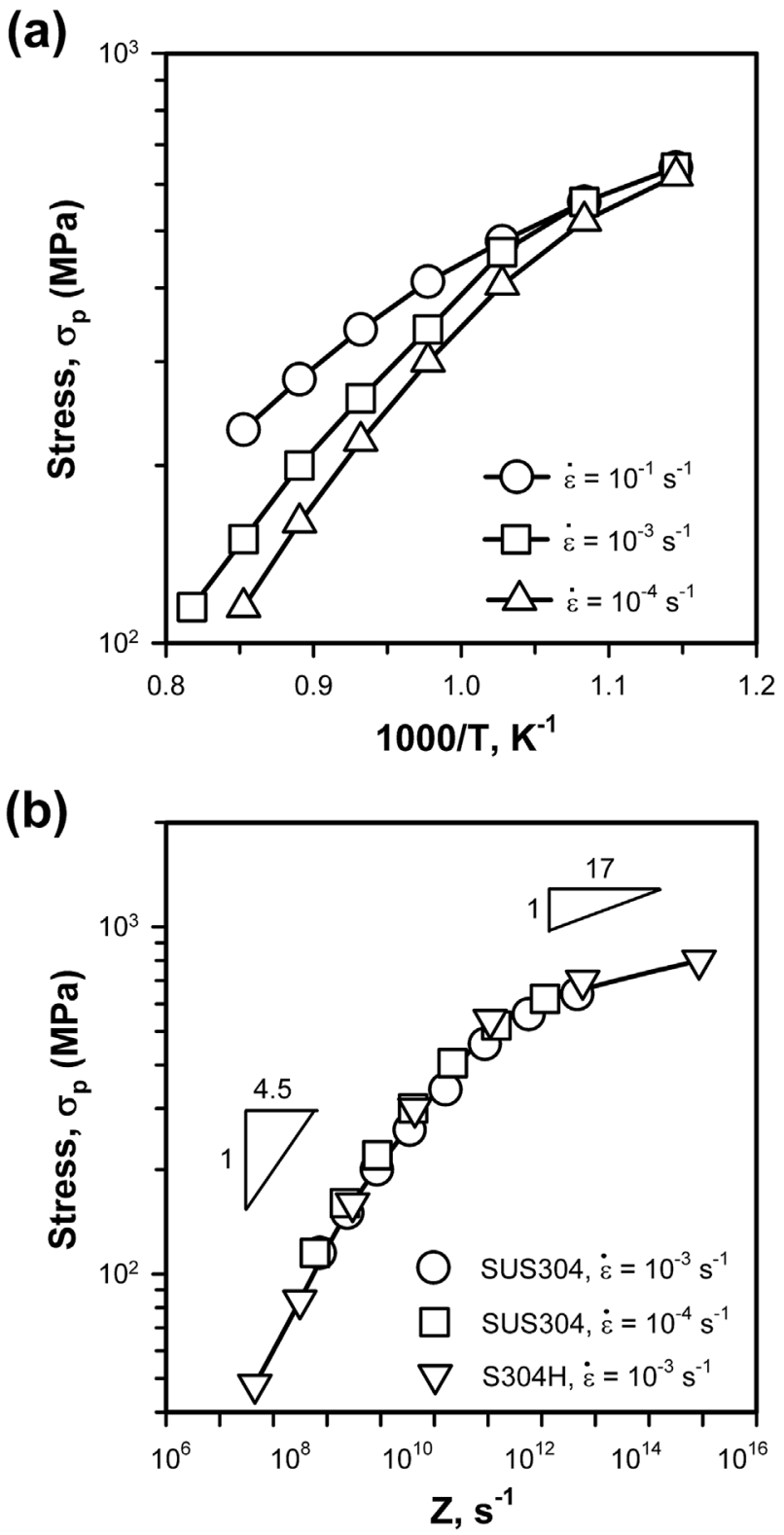

Figure 2. Effect of deformation temperature a) and temperature compensated strain rate b) on the peak flow stress upon warm to hot compression of 304-type austenitic stainless steels. ${ }^{[14,32]}$ 
stress depends substantially on the deformation temperature and/or strain rate under hot deformation conditions (the deformation domain below about $400 \mathrm{MPa}$ in Figure 2a). On the other hand, the temperature/strain rate dependence of the flow stress weakens as the stress increases. Correspondingly, power law relationships are held between the flow stresses and deformation conditions expressed by $Z$ (Figure $2 b$ ). Commonly, the flow stress of austenitic stainless steels can be expressed as $\sigma_{p}^{4.5} \approx Z$ in the hot deformation domain corresponding to $Z<10^{12} \mathrm{~s}^{-1}$ or $\sigma_{p}^{17} \approx Z$ under the warm deformation at $Z>10^{12} \mathrm{~s}^{-1}$. The different deformation behavior under hot and warm working conditions is associated with a transition from discontinuous DRX mechanism to continuous DRX one with a decrease in the deformation temperature (increasing $Z$ ).

\subsection{Microstructure Evolution}

\subsubsection{Discontinuous $D R X$}

The most elaborated DRX mechanism is discontinuous DRX, which occurs in various metallic materials with low to medium SFE during hot working, when the rapid DRX progress is accompanied by strain softening. ${ }^{[7,8,18,33-38]}$ This type of DRX has been being studied for more than 50 years and, therefore, frequently considered as conventional or classical DRX in contrast to other somewhat special mechanisms. The terminology of discontinuous DRX is used to reflect its periodic/cyclic behavior including several specific sequential stages. The discontinuous DRX grain evolution involves a nucleation by local grain boundary bulging, a growth of the DRX nucleus, which is driven by deformation stored energy in neighbor grains, and a grain growth stagnation resulting from both the DRX grain impingement and diminishing the driving growth force because of work hardening of the growing DRX grains. Then, the new DRX grain can nucleate in the existing and work hardened DRX grain that means a new cycle of discontinuous DRX. There are, therefore, different structural elements coexisting at any stage of the discontinuous DRX development. Those are the nuclei, the growing grains, and work hardened grains as expected nucleation sites, which are also indicative of discontinuous manner of this DRX type.

The grain nucleation and growth during discontinuous DRX are similar to those in primary static recrystallization (SRX), which occurs upon heating of cold worked metallic materials. ${ }^{[20,39-41]}$ Recovery assisted bulging of a grain boundary portion is commonly considered as the main mechanism of discontinuous DRX nucleation. ${ }^{[8,10,14,20,40]}$ Dynamic recovery readily develops near the grain boundaries, which serve as sink sites for lattice dislocations and promote the dislocation rearrangement, forming the potential DRX nucleus as a subgrain with lowered dislocation density. Such subgrain is partially bounded by an ordinary grain boundary, which is able to migrate toward the high dislocation density in work hardened surroundings. The difference in local dislocation densities is commonly considered as a driving pressure for the grain boundary migration toward high dislocation density and corresponding growth of DRX nuclei. In contrast to primary SRX, the grain boundaries are frequently corrugated during hot working. Therefore, the grain boundary bulging easily occurs at corrugated grain boundaries. Figure 3 shows two typical examples of the discontinuous DRX nuclei that developed by the local bulging of grain boundaries. ${ }^{[42]}$ It is evident from Figure 3 that the DRX nuclei contain much lower dislocation density than work hardened surroundings and these nuclei are separated from the highly dislocated substructures by the low-angle dislocation subboundary (left-side nucleus) or the twin boundary (right-side nucleus). The frequent development of annealing twins during discontinuous DRX at elevated temperatures is sometimes discussed as special DRX mechanism in low SFE materials. ${ }^{[43,44]}$ Similar to primary SRX, the growth of discontinuous DRX nuclei is driven by the difference in deformation stored energy (accumulated in dislocation substructures including individual dislocations and dislocation subboundaries) between the nucleus and work hardened surroundings. However, this difference (and the corresponding driving force) gradually diminishes during hot working because of increasing the dislocation density in the growing DRX grain that may result in a cessation of the DRX grain grow and that cannot occur on primary SRX.

A grain boundary sliding commonly takes place in austenitic stainless steels, as well as in other various metallic materials during hot working. ${ }^{[45-48]}$ The latter promotes the rotation of the bulged DRX nuclei, increases the misorientation between the nucleus and parent grain and, therefore, advances the discontinuous DRX development in vicinities of grain boundaries. The discontinuous DRX nuclei rapidly evolve at grain boundaries of initially coarse grains and results in the evolution of necklace-like microstructure, in which the chains of fine DRX grains locate between original grains. ${ }^{[49,50]}$ Then, the DRX layers thicken upon the DRX progress leading to a kind of bimodal microstructure composed of rather coarse non-recrystallized remnants surrounded by the fine DRX grains. Finally, the DRX portions propagate throughout the worked piece, resulting in the uniform microstructure consisting of fine DRX grains. An

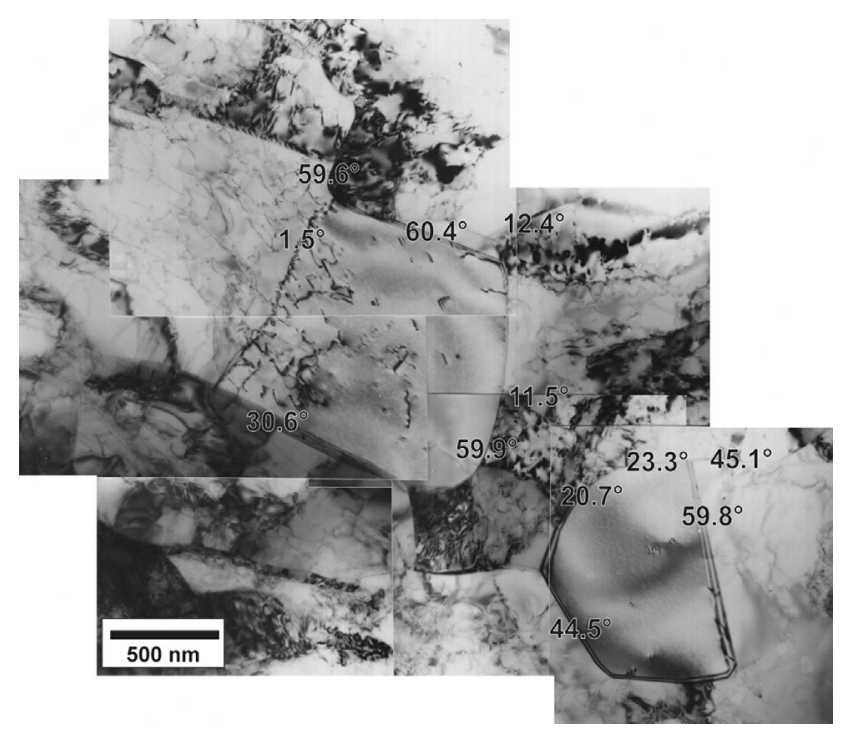

Figure 3. Discontinuous DRX nuclei in a 304-type austenitic stainless steel subjected to compression at $1073 \mathrm{~K}$ at a strain rate of $10^{-3} \mathrm{~s}^{-1} \cdot{ }^{[42]}$ 
increase in deformation temperature promotes the recoveryassisted nucleation and diffusion-controlled growth of new grains and, thus, accelerates the DRX kinetics (Figure 4). ${ }^{[51]}$

\subsubsection{Continuous $D R X$}

Phenomenon of continuous DRX was first recorded during deformation of aluminum alloys and ferritic stainless steels

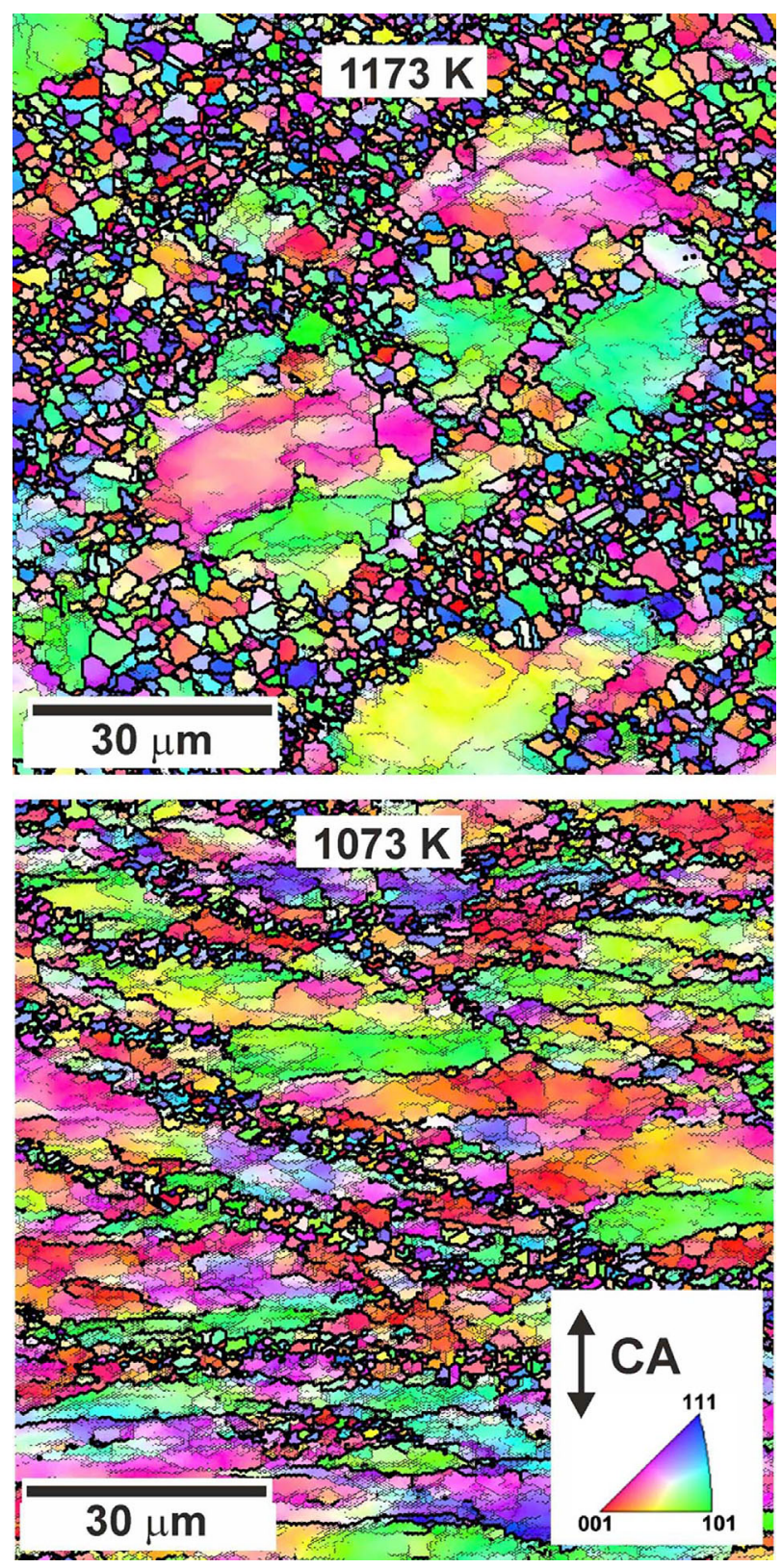

Figure 4. Necklace-type microstructure during discontinuous DRX in a $22 \mathrm{Cr}-10 \mathrm{Ni}$ austenitic stainless steel subjected to hot compression at indicated temperatures to a strain of 1.2 at a strain rate of $10^{-3} \mathrm{~s}^{-1} \cdot .^{51]}$ High-angle and low-angle boundaries are indicated by thick and thin black lines, respectively. The colors indicate the crystallographic direction along the compression axis (CA). under conditions of hot working. ${ }^{[22-24,52-54]}$ These materials are highly susceptible to dynamic recovery (DRV), which provides rapid dislocation rearrangement forming uniform polygonized substructures. Therefore, the fast dynamic recovery prevents the development of local strain gradients and corresponding heterogeneities in dislocation densities, which generate the driving force for discontinuous DRX nucleation by a local grain boundary bulging. Since, the necessary conditions for discontinuous DRX are not created in DRV materials, these materials can be continuously deformed to large strains, which are not accompanied by the nucleation and growth of new DRX grains. On the other hand, large strain deformations of DRV materials are accompanied by the dislocation buildup within deformation subboundaries and the corresponding lattice rotation among strain-induced subgrains, leading to an increase in the subboundary misorientations. Then, new strain-induced grain boundaries can be developed at large strains, when the (sub) boundary misorientation exceeds some critical value (typically $15^{\circ}$ ) separating low-angle subboundaries and high-angle grain boundaries. Thus, original grains are split into deformation subgrains followed by an increase in the subboundary misorientations with straining resulting in the development of new grains in place of subgrains at sufficiently large strains. This process of new grain evolution develops in continuous manner and, hence, frequently referred to as continuous DRX.

A low SFE is a common feature of austenitic stainless steels. Therefore, these steels experience substantial strain hardening during hot working. An increase in the flow stress caused by an increase in the dislocation density during deformation creates the high driving pressure for DRX nucleation by grain boundary bulging followed by growth out of DRX grains, which are characterized by quite low dislocation densities at an early stage of the DRX development, that is essential feature of discontinuous DRX. The growing DRX grains consume the deformation substructures, the evolution of which could result in the development of new grains at large strains (continuous DRX). Thus, small critical strains for the development of discontinuous DRX eliminates the possibility of continuous DRX in austenitic stainless steels during hot working, as schematically illustrated in Figure $5 .^{[55]}$ On the other hand, the grain boundary mobility slows down as the deformation temperature decreases. Under conditions of warm deformation, therefore, the grain boundary bulging requires much higher driving pressure as compared to hot working conditions, that is, the critical strain for the initiation of discontinuous DRX becomes very large. In this case, the new DRX grains can appear as a result of progressive subgrain evolution, when the misorientations of the straininduced subboundaries increase and attain values of ordinary high-angle grain boundaries during large strain deformation, that is, continuous DRX.

Typical deformation microstructures and substructures that evolve during warm multiple multiaxial forging are represented in Figure $\mathbf{6}$ and 7 , respectively. ${ }^{[56,57]}$ Commonly, plastic deformations of austenitic stainless steels with low SFE is accompanied by a rapid increase in the dislocation density, which may exceed $10^{15} \mathrm{~m}^{-2}$ even at small strains during warm working at temperatures of approx. $0.5 \mathrm{Tm}$. Increasing the strain promotes the dislocation rearrangement and the development of dislocation cell/subgrain substructure consisting of dislocation 


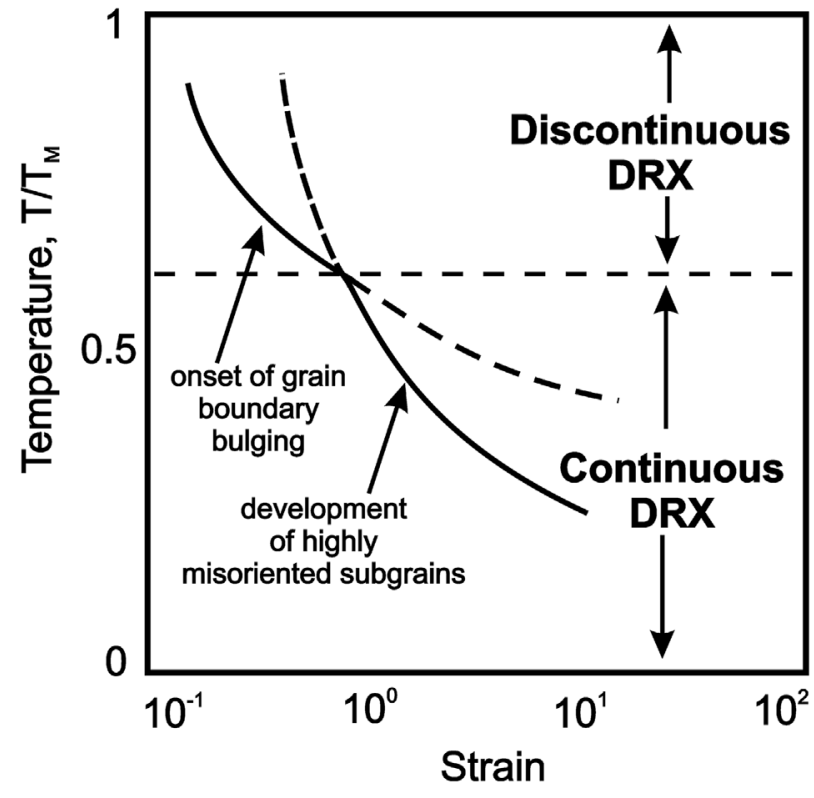

Figure 5. Schematic relationship between discontinuous and continuous DRX..$^{[55]}$

cell blocks bearing large lattice curvatures that are subdivided by strain-induced subboundaries (Figure 6a). These strain-induced subboundaries are commonly characterized by relatively lowangle misorientations upon their appearance at early deformation. The misorientations of strain-induced subboundaries may quickly increase during deformation, leading to the development of new high-angle grain boundaries. The strain-induced subboundaries, which have a high potential for an increase in their misorientations, locate frequently near original grain boundaries or boundary triple junctions (Figure 7a). Such rapidly developing strain-induced boundaries can be considered as geometrically necessary ones. These boundaries are necessary to appear between microvolumes, which experience some differences in plastic flow, for example, different combination of slip systems or different local strains. ${ }^{[58,59]}$ A distinctive attribute of the deformation microstructures that develop under conditions of warm working is the deformation microbands (or microshear bands), which pass over original grains (Figure 6a). The strain localization was considered as an important contributor to the development of continuous DRX in austenitic stainless steels during warm rolling. ${ }^{[17,60,61]}$ The misorientations across the deformation microbands readily increase during warm deformation, leading to rapid grain subdivision. Continuous character of the development of new strain-induced grain boundaries can be clearly revealed by the observations of many incomplete grain boundaries in Figure 6a (pointed by the arrow heads). These boundaries appear as local portions along the lowangle subboundaries. Namely, the portions of strain-induced subboundaries are indicated as high-angle grain boundaries on the OIM images when the local boundary misorientation exceed the critical angle between low-angle and high-angle boundaries. The appearance of crystallites bounded by low-to high-angle boundaries is an essence of the continuous DRX development, when the misorientations between crystallites separated by
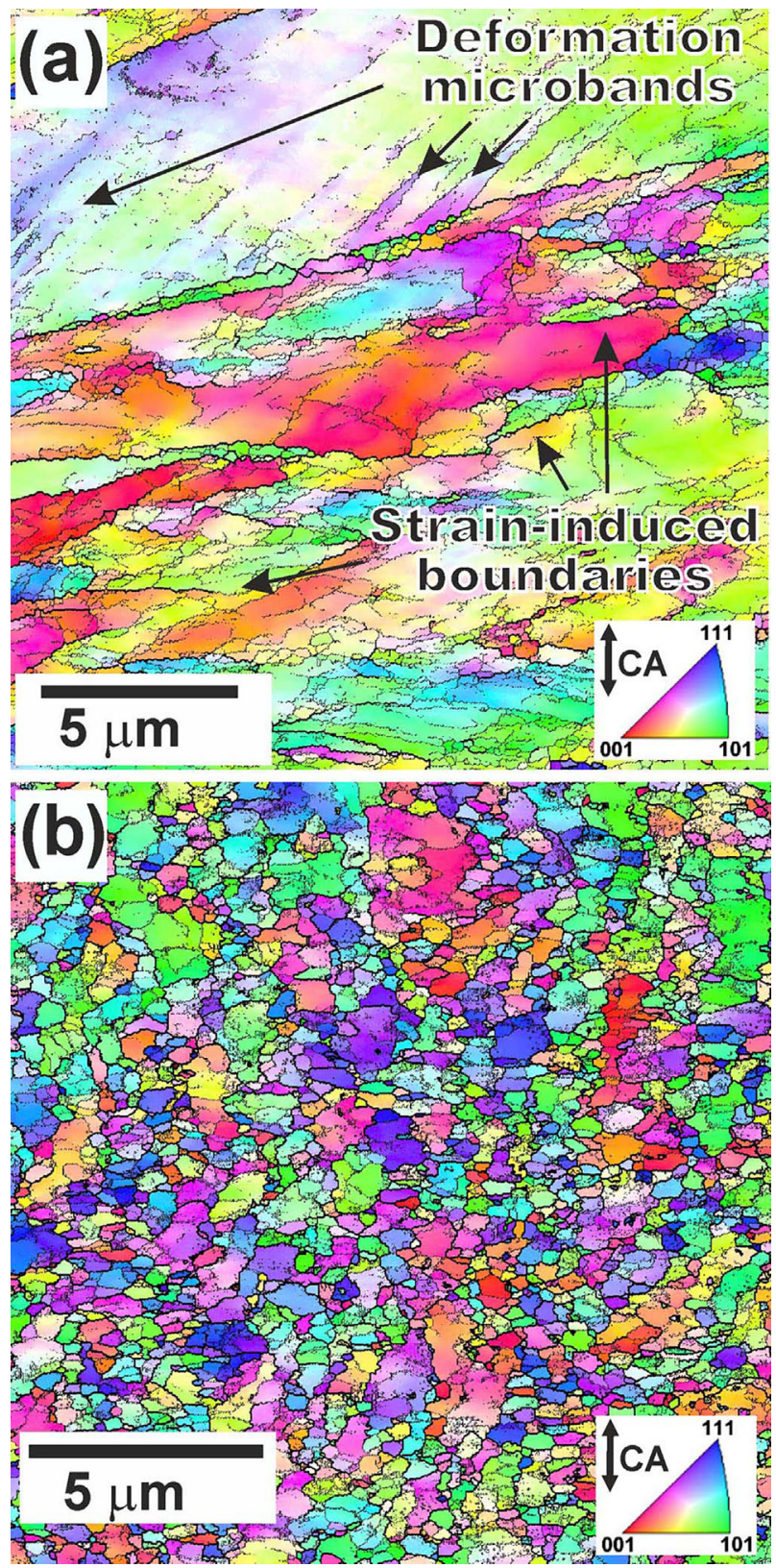

Figure 6. Typical deformation microstructures evolved in a 304-type austenitic stainless steel during multiple multiaxial forging at $873 \mathrm{~K}$ to a total strain of 0.8 a), 4.0 b). High-angle and low-angle boundaries are indicated by thick and thin black lines, respectively. The colors correspond to the crystallographic direction along the last pass forging axis $(\mathrm{CA}) .^{[57]}$

strain-induced subboundaries progressively increase during deformation leading to a gradual increase in the high-angle boundary portions at expense of low-angle ones. ${ }^{[10,30,47]}$

The number density of deformation microbands and the orientation gradient along them increase with an increase in strain. The new ultrafine grains gradually develop during deformation in a consequence of progressive evolution of strain-induced subboundaries into high-angle grain boundaries. The high-angle boundaries readily develop at deformation microbands, which 


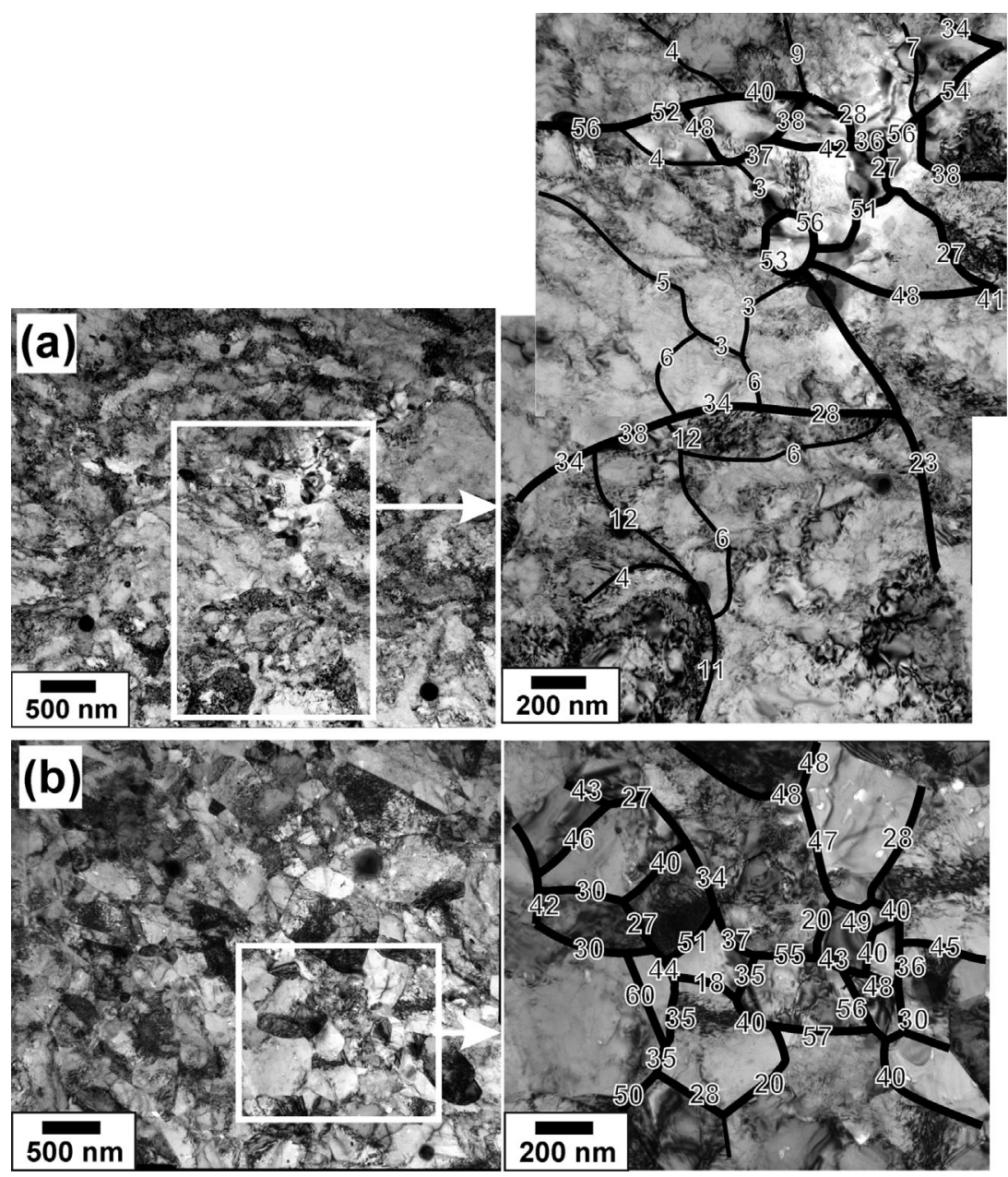

Figure 7. Representative fine microstructures evolved in a 304-type austenitic stainless steel during multiple multiaxial forging at $973 \mathrm{~K}$ to total strains of $0.8 \mathrm{a}$ ) and $4.0 \mathrm{~b}$ ). The numbers indicate the boundary misorientations in degrees. ${ }^{[56]}$

during warm deformation of austenitic stainless steels, because the rate of continuous DRX grain evolution depends on local strain gradients, which rapidly develop near the grain boundaries, at triple junctions, along deformation microbands and their intersections. The heterogeneous development of ultrafine grains in an austenitic stainless steel subjected to warm multiple multidirectional deformation is clearly reflected in the evolution of grain size distributions during the progress of continuous DRX (Figure 8) $\cdot{ }^{[62]} \mathrm{A}$ huge peak corresponding to rather coarse original grains is gradually scaled down while another peak gradually grows against ultrafine grain sizes as the total strain increases. It is interesting to note that a kind of bimodal grain size distribution with two peaks against small and large grain sizes evolves at intermediate strains similar to that in necklace microstructure in course of discontinuous DRX. Finally, a peak corresponding to the new ultrafine grains stands up in the grain size distribution evolved at sufficiently large total strains.

In contrast to geometric DRX, which has been originally proposed as a kind of continuous DRX for new grain evolution in aluminum alloys after large rolling reductions at elevated temperatures, ${ }^{[20,23,63-65]}$ the development of deformation microbands plays an important role in the grain refinement in austenitic stainless steels under conditions of unidirectional large strain warm rolling. ${ }^{[61]}$ Typical examples of the transition bands, that is, the boundaries separating the deformation microbands, are indicated by the arrow heads in Figure 9a. Some portions of these boundaries in Figure 9a exhibit high-angle misorientations that testify to the formation of

serve as preferential sites for the fast development of strain-induced boundaries because of corresponding large strain gradients. The frequently corrugated original grain boundaries and their triple junctions are also preferential sites for the fast development of strain-induced boundaries because of large strain gradients evolved in vicinity of grain boundaries. Thus, the ultrafine grains first develop along the deformation microbands and original grain boundaries. Any changes in the direction of applied load during multiple deformations, for example, multiple multidirectional forging, should assist the activation of a number of variable slip systems and promote the development of high density of deformation microbands running in various directions. Therefore, following somewhat heterogeneous appearance of the first ultrafine grains at relatively small strains, almost uniform ultrafine grains with the size approaching the size of preceding subgrains evolve at large total strains (Figure 6b, 7b).

Continuous DRX means progressive evolution of deformation subgrains that leads to their gradual conversion into new fine grains during deformation to sufficiently large strains. However, the new ultrafine grains appear heterogeneously strain-induced grain boundaries as geometrically necessary ones at relatively small strains. Further deformation leads to development of lamellar-type microstructures, where high-angle boundaries (original and strain-induced ones) are aligned in the direction of metal flow. The distance between the high-angle boundaries decreases with straining, approaching the size of deformation subgrains. Therefore, the ultrafine grained microstructure consisting of fine grains/subgrains elongated toward the rolling axis is evolved after sufficiently large strains (Figure 9b). The effect of strain-induced boundaries on the grain refinement kinetics during warm bar rolling is illustrated in Figure $10 .{ }^{[61]}$ In the range of relatively small strains $(\varepsilon<1$ in Figure 10), a decrease in the transverse grain size is ahead of that predicted by rolling reduction. Therefore, this strain range can be considered as a region of grain refinement when the grain size decreases owing to the development of new straininduced high-angle grain boundaries. On the other hand, the number of grains along the direction crosswise to the metal flow decreases as strain increases in the range of large strains $(\varepsilon>1$ in Figure 10). Such an apparent grain coarsening 


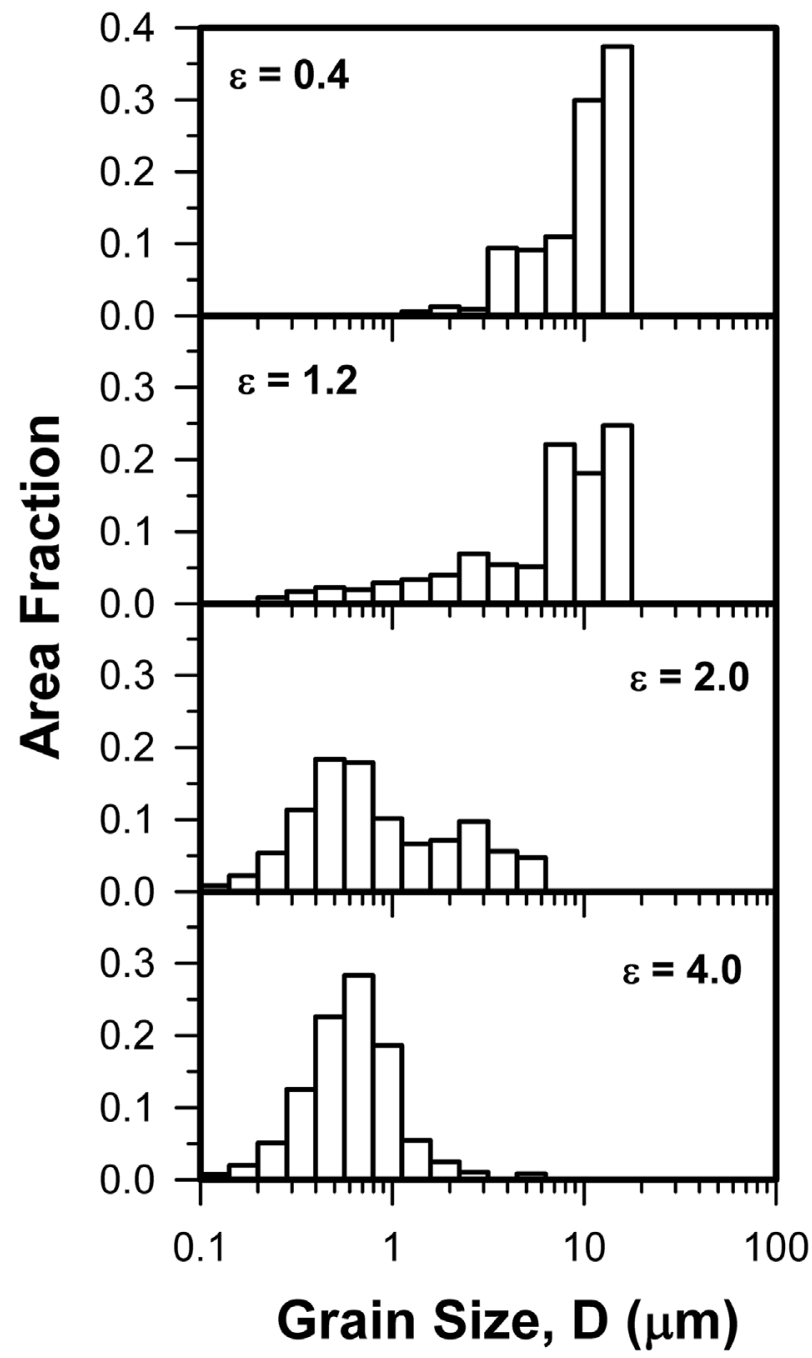

Figure 8. Grain size distributions in a 304-type austenitic stainless steel subjected to multiple multidirectional forging at $973 \mathrm{~K} .{ }^{[62]}$

results from the DRX grains, the size of which approaches a constant value depending on the deformation conditions and no more depends on the total strains after sufficiently large deformation.

\subsubsection{Severe Plastic Deformation}

Substantial grain refinement in austenitic stainless steels down to nanocrystalline state can be achieved by severe plastic deformation, that is, large strain deformation at relatively low temperatures, which is currently considered as one of the most powerful techniques for development of ultrafine grained metals and alloys. ${ }^{[65-81]}$ It has been suggested that ultrafine grains appear during severe plastic deformation in place of deformation cells/subgrains, which were evolved at small to moderate strains. ${ }^{[65,73,74]}$ The ultrafine grained structures that develop at large strains are considered, therefore, as a result of gradual transformation of dislocation cells/subgrains
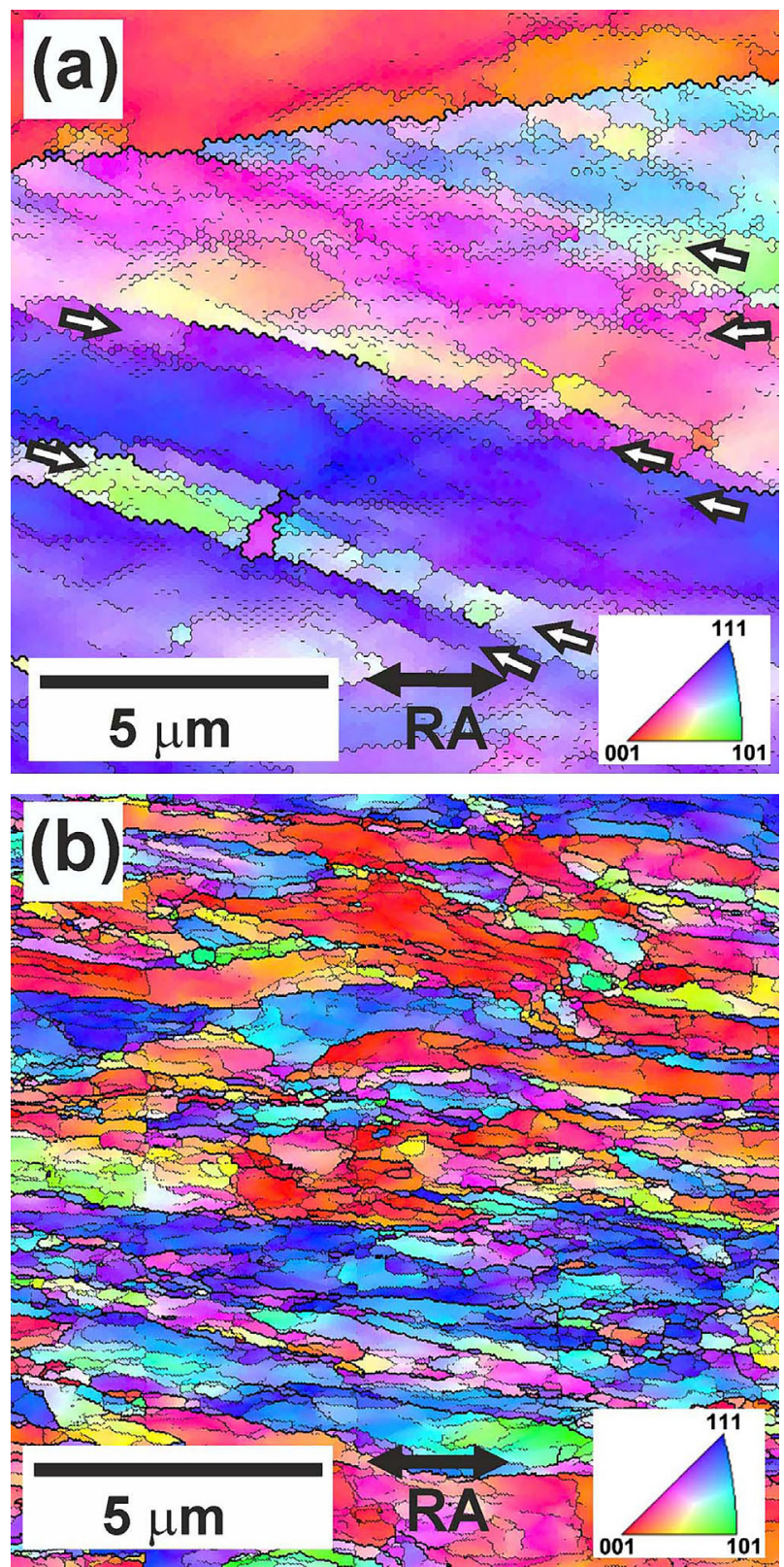

Figure 9. Typical deformation microstructures evolved in a 304L-type austenitic stainless steel during warm bar rolling at $773 \mathrm{~K}$ to strains of 0.5 a) and $2.0 \mathrm{~b}$ ). High-angle and low-angle boundaries are indicated by thick and thin black lines, respectively. The colors indicate the crystallographic direction along the rolling axis (RA).$^{[9]}$

into largely misoriented crystallites, that is, new grains. The dislocation density in cell walls/subboundaries progressively increases during deformation, leading to an increase in the misorientations between dislocation cells. This model assumes that subboundaries with low-angle misorientations introduced at low strains can progressively transform into high-angle grain boundaries through the accumulation of high density dislocations during deformation, finally leading to the homogeneous evolution of an ultrafine grained structure at large strains. Therefore, the process of ultrafine grain evolution during severe 


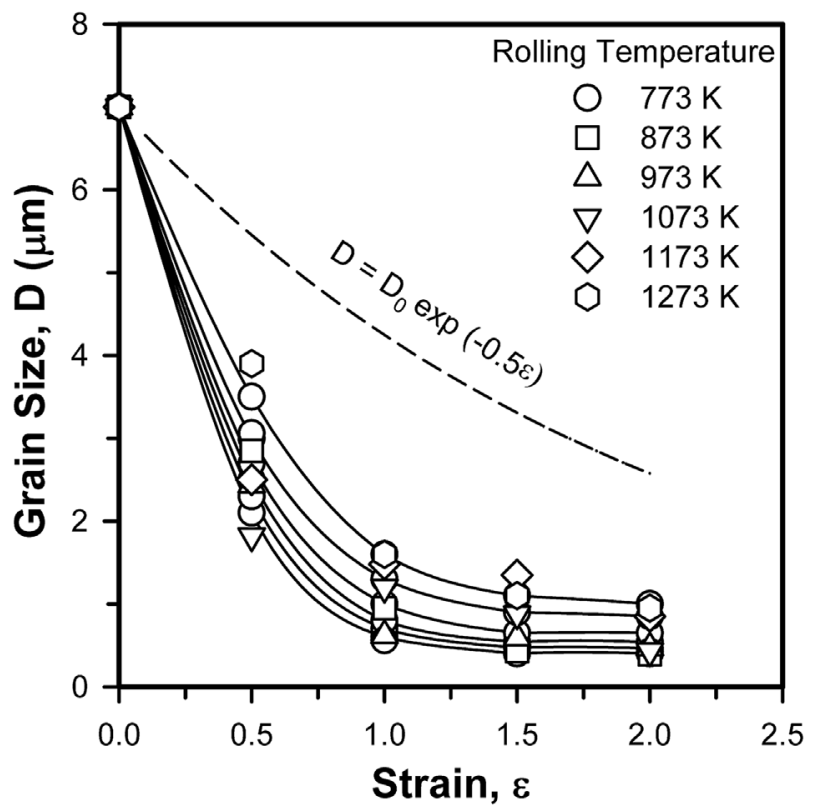

Figure 10. Decrease in the transverse grain size in a 304-type austenitic stainless steel during warm to hot rolling at indicated temperatures. ${ }^{[61]}$

plastic deformation can be considered as a kind of continuous DRX.

It is worth noting that the dislocation substructures evolved during cold working are characterized by certain heterogeneity. ${ }^{[58,59,82-86]}$ An early deformation involves high dislocation density, leading to the development of substructure in the form of dislocation cell blocks. An increase in strain is accompanied with a localization of plastic flow leading to the development of deformation micro-bands and/or microshear-bands with transition bands as strain-induced geometrically necessary boundaries, splitting the original grains into individual fragments bounded by high-angle boundaries. The microstructural evolution during severe plastic deformation, therefore, is sometimes considered in terms of grain subdivision or fragmentation. ${ }^{[59,85]}$ Anyway, the strain localization in various micro-bands is an essential feature of structural changes during severe plastic deformation. Similar to continuous DRX during warm working, the new ultrafine grains primarily develop within the portions of deformation substructures with large strain gradients, such as intersections of the deformation micro-bands and/or microshear-bands, vicinities of grain boundaries and, especially, the grain boundary triple junctions, followed by the new grain development along the micro-bands under conditions of severe plastic deformation. ${ }^{[10,74,87-89]}$ The fraction of ultrafine grains gradually increases as the number and thickness of various micro-bands increase during the straining that results in progressive propagation of the ultrafine grains throughout the processed material. Correspondingly, the mean grain size decreases gradually approaching some constant value at sufficiently large strains.

The efficiency of severe plastic deformation for production of nanocrystalline steels and alloys depends on the grain refinement kinetics, which is associated with material susceptibility to grain fragmentation upon cold working. Austenitic stainless steels are highly susceptible to grain fragmentation during cold deformation because of specific deformation mechanisms. Low SFE in these steels leads to the operation of deformation twinning. ${ }^{[90-96]}$ Moreover, chromium-nickel austenitic stainless steels are meta-stable at room temperature. Therefore, cold working of austenitic stainless steels is accompanied by straininduced martensitic transformation. ${ }^{[93-106]}$ Both the deformation twinning and the strain-induced martensitic transformation significantly accelerate the grain refinement, leading to the fast development of spatial network of multiple crossed high-angle
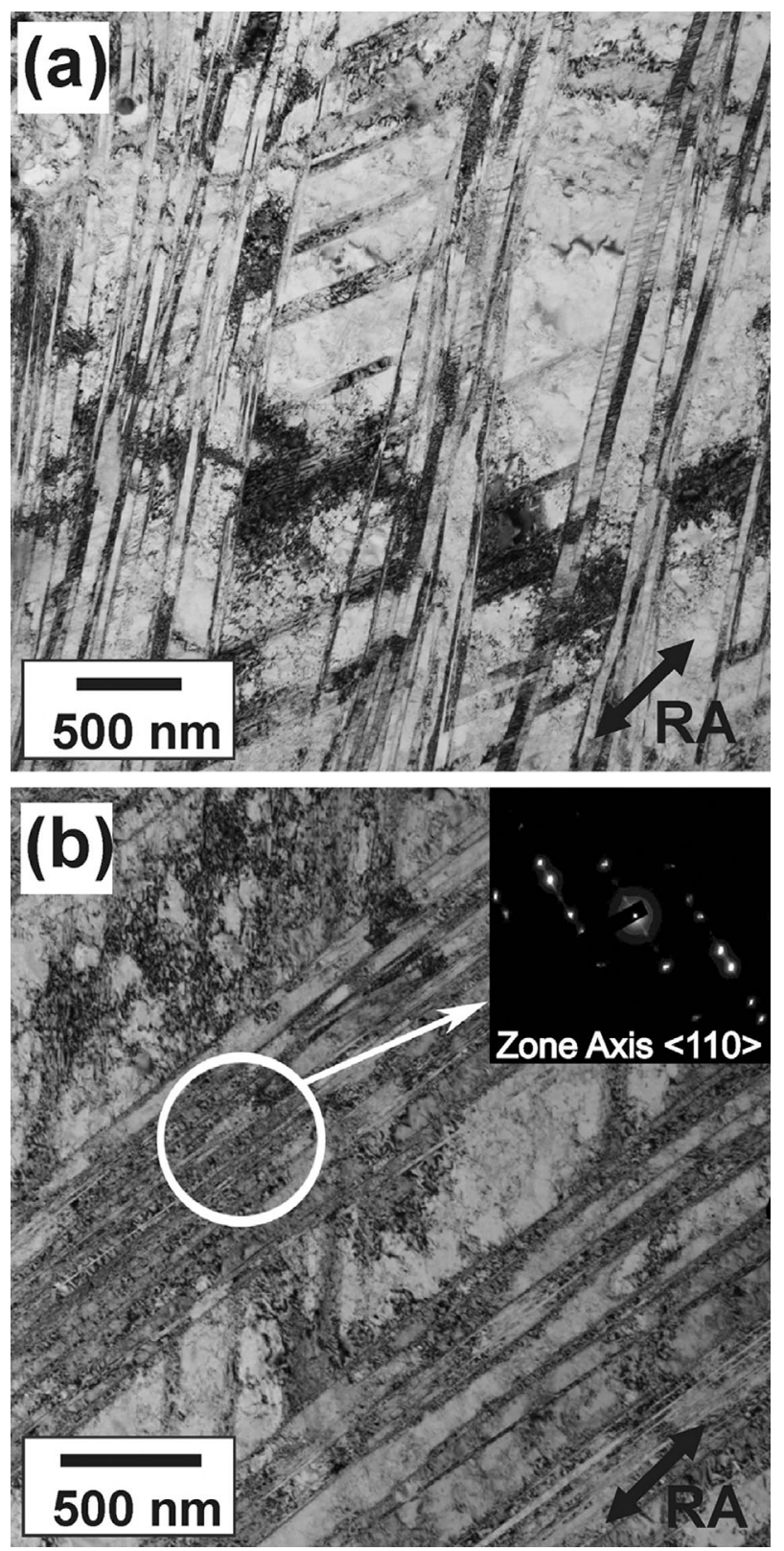

Figure 11. Deformation twinning in 304-type a) and 316L-type b) austenitic stainless steels after cold rolling to a strain of 0.4 . The RA indicates the rolling

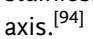



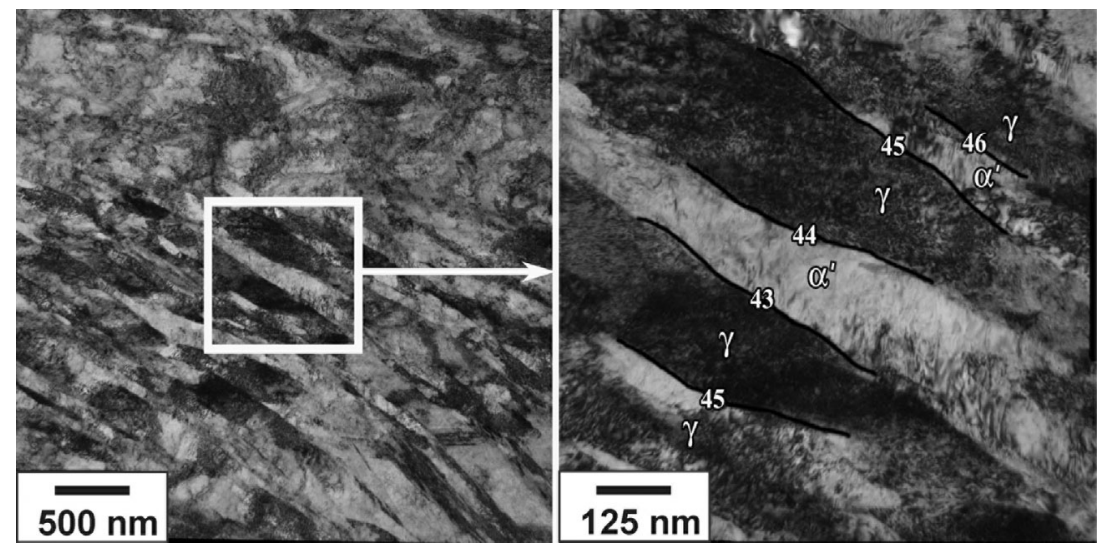

Figure 12. Representative deformation microstructure developed in a 316L-type austenitic stainless steel after bar rolling at ambient temperature to a strain of 1.2. The numbers indicate the nominal misorientations angles between neighboring cubic crystallites in degrees. ${ }^{[107]}$ experience large rotations during subsequent deformation and their orientations may significantly deviate from the predicted relationships. ${ }^{[93,95]}$ The vicinities of grain boundaries are also characterized by large strain gradients and serve as preferable sites for strain-induced martensite appearance (Figure 13). ${ }^{[110]}$ The strain-induced martensitic transformation continuously develops during cold deformation leading to an increase in the volume fraction of deformation martensite (Figure 14). ${ }^{[111]}$ An increase in the martensite fraction $\left(F_{M}\right)$ can be expressed by a sigmoid function of strain $(\varepsilon)$ as proposed by Olson and Cohen for heterogeneous nucleation of strain-induced martensite, ${ }^{[112]}$ that is,

$$
F_{\mathrm{M}}=1-\exp \left(-A_{1}\left(1-\exp \left(-A_{2} \varepsilon\right)\right)^{A}\right),
$$

strain-induced grain boundaries, and corresponding new grains at relatively small strains.

The sequence of structural changes, which are responsible to the development of nanocrystalline structures in austenitic stainless steels during large-strain cold deformation, can be discussed as follows. An increase in the dislocation density at early deformation is followed by the deformation twinning, which subdivides initial grains into platelet fragments with high-angle twin boundaries (Figure 11) ${ }^{[94]}$ Further straining is accompanied by the formation of deformation microbands/microshear bands. The formation of frequently twinned structures with large strain gradients in deformation microbands promotes the initiation of strain-induced martensitic transformation. ${ }^{[104,106]}$ An example of the microshear band consisting of alternating martensite and austenite crystallites with their transverse sizes of about $50 \mathrm{~nm}$ is shown in Figure 12. ${ }^{[107]}$ The strain-induced martensite appears with orientation relationships to austenite matrix within $5^{\circ}$ from those suggested by Kurdjumov-Sachs or Nishiyama-Wasserman, ${ }^{[93,108,109]}$ although martensite grains with constants of $A, A_{1}, A_{2}$ depending on austenite stability and processing method (Figure 15, 16)..$^{96,107]}$ The latter seems to suppress the strain-induced martensite formation, if it involves a high hydrostatic pressure. ${ }^{[107,113]}$ Typical nanocrystalline structures in stainless steels processed by severe plastic deformations at ambient temperature are shown in Figure 17. ${ }^{[13,114]}$ Both the 10 torsion revolutions under pressure and the multiple multiaxial forging to a total strain of 4 resulted in nanocrystalline microstructures consisting of austenite (after high pressure torsion) or austenite/martensite grains (after multiaxial forging) with almost the same transverse grain size of about $50 \mathrm{~nm}$ in 304-type stainless steels. Also, more or less equiaxed nanocrystalline microstructure consisting of austenite and strain-induced martensite in a 321-type stainless steel was evolved during the equal channel angular pressing (4 passes in Figure 17c). Thus, the nanocrystalline structural state can be easily obtained in austenitic stainless steels by using simple methods of metal working like multiple forging because of rapid kinetics of grain refinement inherent in austenitic stainless steels upon cold deformation.
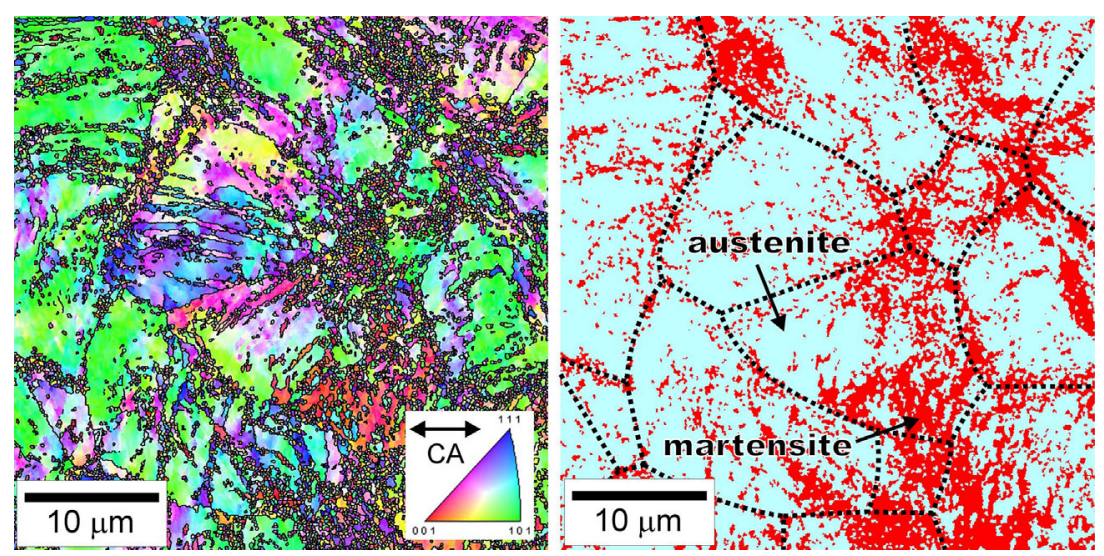

Figure 13. Deformation microstructure in a 304-type steel after multiple forging to a total strain of 1.2 at room temperature. The colors in the left-hand image correspond to the crystallographic direction along the last pass forging axis (CA); high-angle boundaries are indicated by black lines. In the right-hand image, the red and blue colors indicate strain-induced martensite and austenite, respectively; the dotted lines roughly outline original grains. ${ }^{[10]}$

\subsection{DRX Grain Size}

The grain size in austenitic stainless steels subjected to hot deformation accompanied by discontinuous DRX depends on the rates of nucleation and growth of DRX nuclei/ grains. ${ }^{[8,18-20]}$ The mean dynamic grain size that evolves at steady state of hot deformation, when the dynamic equilibrium between strengthening and softening processes is established, is controlled by deformation conditions, mainly by temperature and strain rate. A decrease in the deformation temperature and/or an increase in the strain rate results in a decrease in the grain size and vice versa. Quantitatively, the dynamic grain size $(D)$ can be expressed in the form of a power dependence on the temperature-compensated strain-rate, that is, $D^{n} \approx Z .^{[17,38,57,115]}$ The 

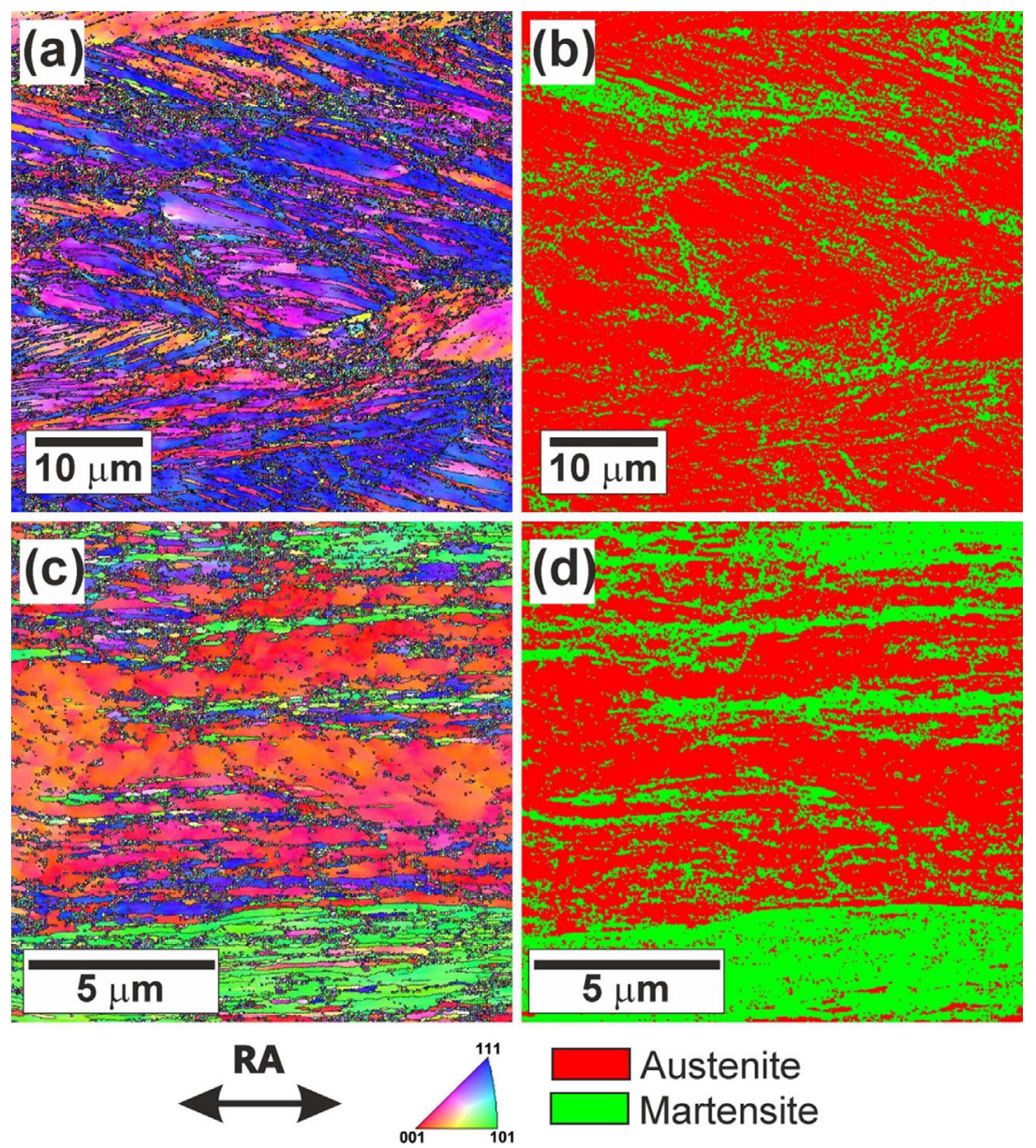

\section{$5 \mu \mathrm{m}$}

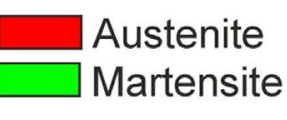

Figure 14. Deformation microstructures a), c) and the corresponding phase maps b), d) of a $316 \mathrm{~L}$-type stainless steel subjected to cold rolling to strains of $1.2 \mathrm{a}$ ), b) and $4 \mathrm{c}$ ), d). High-angle boundaries are indicated by black lines. The colors in a and c correspond to the crystallographic direction along the rolling axis (RA). ${ }^{[11]}$

steady state deformation behavior means that the flow stress becomes strain invariant and entirely controlled by deformation temperature and strain rate. The steady state flow stress can also be expressed by a power law relationship of the temperaturecompensated strain-rate. Therefore, a power-law relationship is held between the flow stresses and the size of DRX grains, ${ }^{[8,14,38,42,57]}$

$\sigma=K D^{-N}$

For various metallic materials including fine grained austenitic stainless steels that exhibit discontinuous DRX under hot working conditions, the grain size exponent $(N)$ is about 0.7. ${ }^{[8-10,14,57,116-118]}$

Under conditions of warm working at relatively low deformation temperatures, the rate of all diffusion-controlled process including the grain boundary migration and corresponding grain growth slows down. The new grains develop during warm working as a result of continuous DRX, when the misorientations between deformation subgrains increase above some critical value (commonly, $15^{\circ}$ ) separating low-angle subboundaries and high-angle grain boundaries. Therefore, the size of continuously DRX grains at large strains should finally approach the size of deformation subgrains evolved at preceding strains. ${ }^{[10,42,47,48,54-57,61,74,118]}$ Similar to discontinuous DRX under hot working conditions, continuous DRX under warm working conditions is also characterized by a power law relationship between the DRX grain size and the flow stress, but with different exponent $(N)$ of about $0.3 .^{[10,21,42,48,57,118]}$ In other words, the change in the DRX behavior upon the change in the deformation conditions from hot to warm working is reflected on the relationship between DRX grain size and flow stress as the change in the grain size exponent.

The power law relationship between the flow stress and the DRX grain size evolved in a 304-type austenitic stainless steel is represented in Figure 18 from cold to hot working. ${ }^{[119]}$ The size of deformation subgrains is also indicated in Figure 18 for reference. Three deformation domains with different grain size exponents are clearly distinguished. (Note here that similar three-stage relationship between flow stress and dynamic grain size evolved at large strains has been recently observed in a titanium. ${ }^{[120]}$ ) The grain size exponent varies from -0.7 in the hot working domain I to -0.3 in the warm working domain II and then to -1.0 in the cold working domain III (corresponds to severe plastic deformation) as the flow stress increases with decreasing the deformation temperature. The different stress - grain size relationships correspond to variation in the operating DRX mechanisms. In contrast, the size of deformation subgrains varies in inverse proportion to the flow stress irrespective of the range of deformation conditions. This unique relationship accounts for the dislocation strengthening (work hardening), which predicts striking correlations between the flow stress, dislocation density and cell/subgrain size. ${ }^{[121-125]}$ The dynamic grain size developed by discontinuous DRX is attributed to the growth of new grains and, therefore, should be much larger than the size of DRX nucleus, which is comparable to the subgrain size. The rate of grain growth decreases with decreasing the deformation temperature. Therefore, the size of DRX grains under warm working conditions rapidly approaches the size of deformation subgrains as the flow stress increases. Then, a decrease in the grain size should be limited by the cell/subgrain size, leading to the same inverse proportion to the flow stress under conditions of the cold deformations, although the grain size smaller than cell/subgrain size was observed in microshear bands evolved by severe plastic deformation. ${ }^{[87]}$

\subsection{DRX Kinetics}

The DRX kinetics in austenitic stainless steels depends significantly on deformation conditions and initial microstructures. 


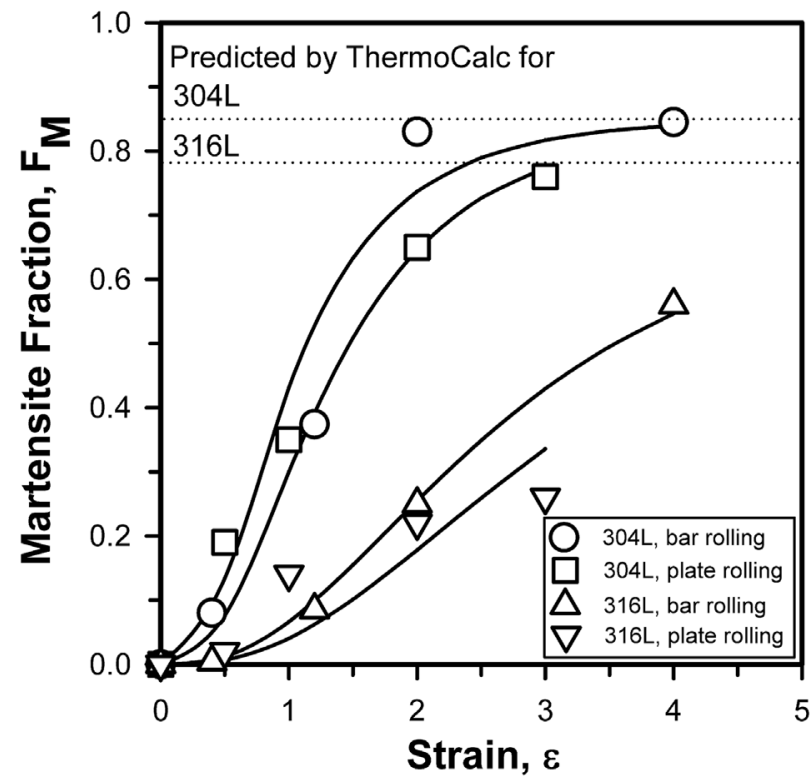

Figure 15. The strain effect on the martensite fraction in $304 \mathrm{~L}$ and $316 \mathrm{~L}$-type stainless steels subjected to bar rolling or plate rolling at room temperature. ${ }^{[96]}$
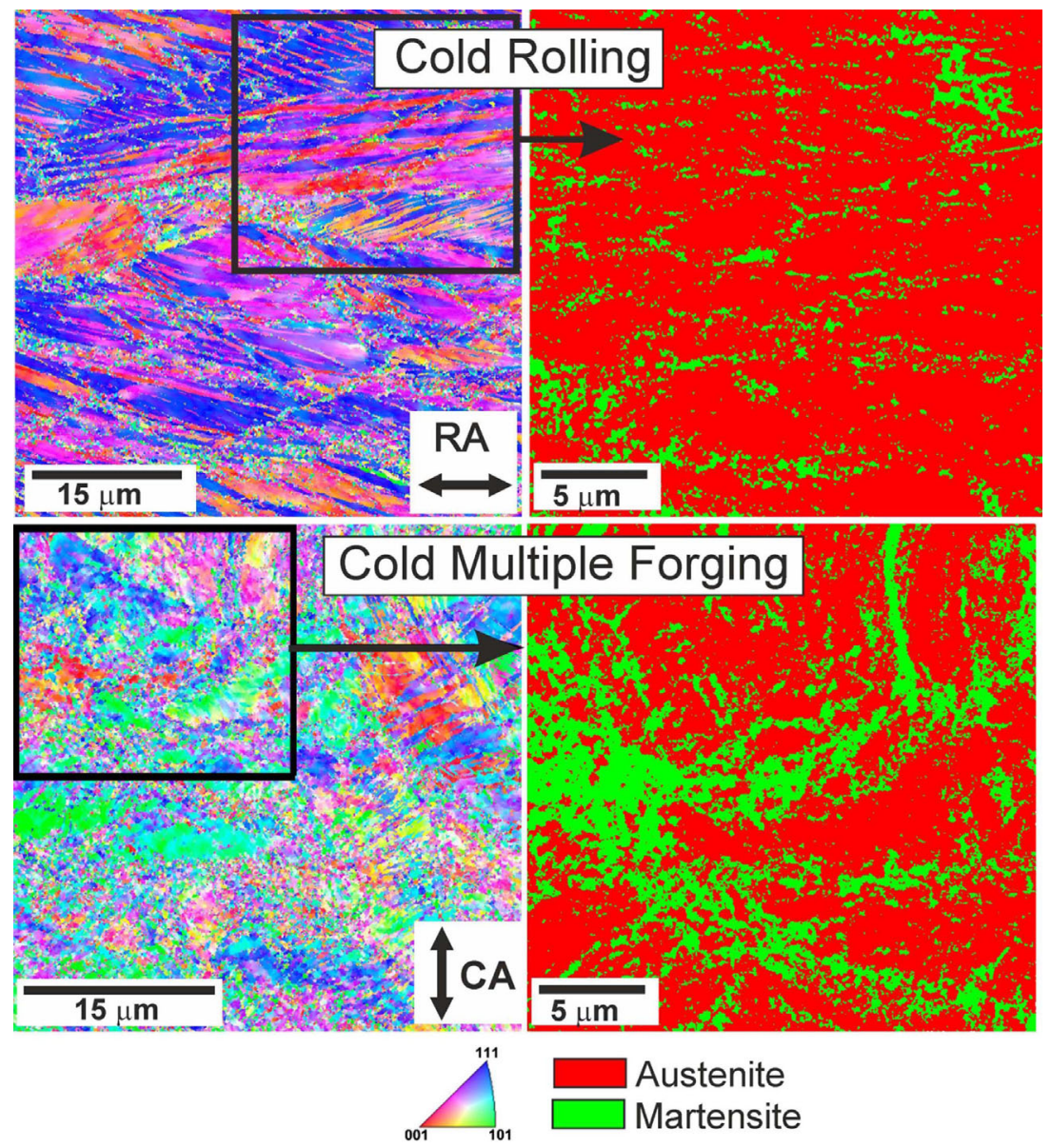

Figure 16. Representative microstructures and phase maps for a 316L-type stainless steel subjected to cold bar rolling or multidirectional forging to a strain of 1.2. The inverse pole figures are shown for the rolling axis (RA) or the axis for the last forging pass (CA). ${ }^{[107]}$
Generally, an increase in deformation temperature accelerates the nucleation and growth of new grains in various steels and alloys that experience discontinuous DRX during hot working, that is, initiation and completion of each discontinuous DRX cycle occur at smaller strains. ${ }^{[7,8,14,33-38]}$ A decrease in the strain rate within the range of conventional hot working conditions also leads to the discontinuous DRX development in smaller strains. Similar to primary SRX, the discontinuous DRX development requires some critical strain, which is followed by nucleation and growth of DRX grains, and an increase in the stored energy increases the recrystallization kinetics. The strain for the discontinuous DRX cycle completion depends significantly on the temperaturecompensated strain rate $(Z)$. On the other hand, the critical strain for discontinuous DRX initiation is less affected by the deformation conditions. Hence, the multiple stress peaks can be observed at flow curve with decreasing $Z$. It should be noted that discontinuous DRX with attenuating multiple stress peaks is accompanied by an increase in the mean dynamic grain size. Such DRX behavior has encouraged Sakai et al. to elaborate the adequate mechanism explaining the relationship between the shape of the flow curve and the relative grain size. ${ }^{[34,126-128]}$ The model predicts single stress peak behavior when the dynamic grain size is less than half of the initial grain size. In this case, the hot working results in grain refinement. In contrast, the multiple peak behavior and grain coarsening take place if the dynamic grain size exceeds half of the initial one. The influence of initial grain size on discontinuous DRX nucleation was further elaborated taking into account the change in the grain boundary energy with decreasing the grain size. ${ }^{[129]}$ Therefore, a decrease in the initial grain size promotes the discontinuous DRX development. Since various solutes retard the grain boundary migration, a decrease in the solute concentrations also accelerates the discontinuous DRX kinetics. ${ }^{[130]}$

Beneficial effects of the initial grain refinement on the discontinuous DRX kinetics can be utilized to enhance an efficiency of conventional hot working for production of ultrafine grained austenitic stainless steels. Figure 19 represents typical stress-strain curves obtained during multiple compressions, which were carried out rotating the specimen over $90^{\circ}$ with a respect of the loading direction and decreasing the deformation temperature from 1223 to $1023 \mathrm{~K}$ with a step of $50 \mathrm{~K}$ from pass to pass, with reference to ordinary single pass compression.$^{[14,42]}$ It is clearly seen that the flow stress in the course of multiple deformations rapidly increases to a peak followed by a strain softening finally approaching a steady-state flow in each compression pass, indicating complete discontinuous DRX throughout the multiple deformation. The initial grain size in each multiple compression pass was developed by preceding deformation. This sequential decrease in the grain size promotes the discontinuous DRX resulting in the full development of ultrafine 

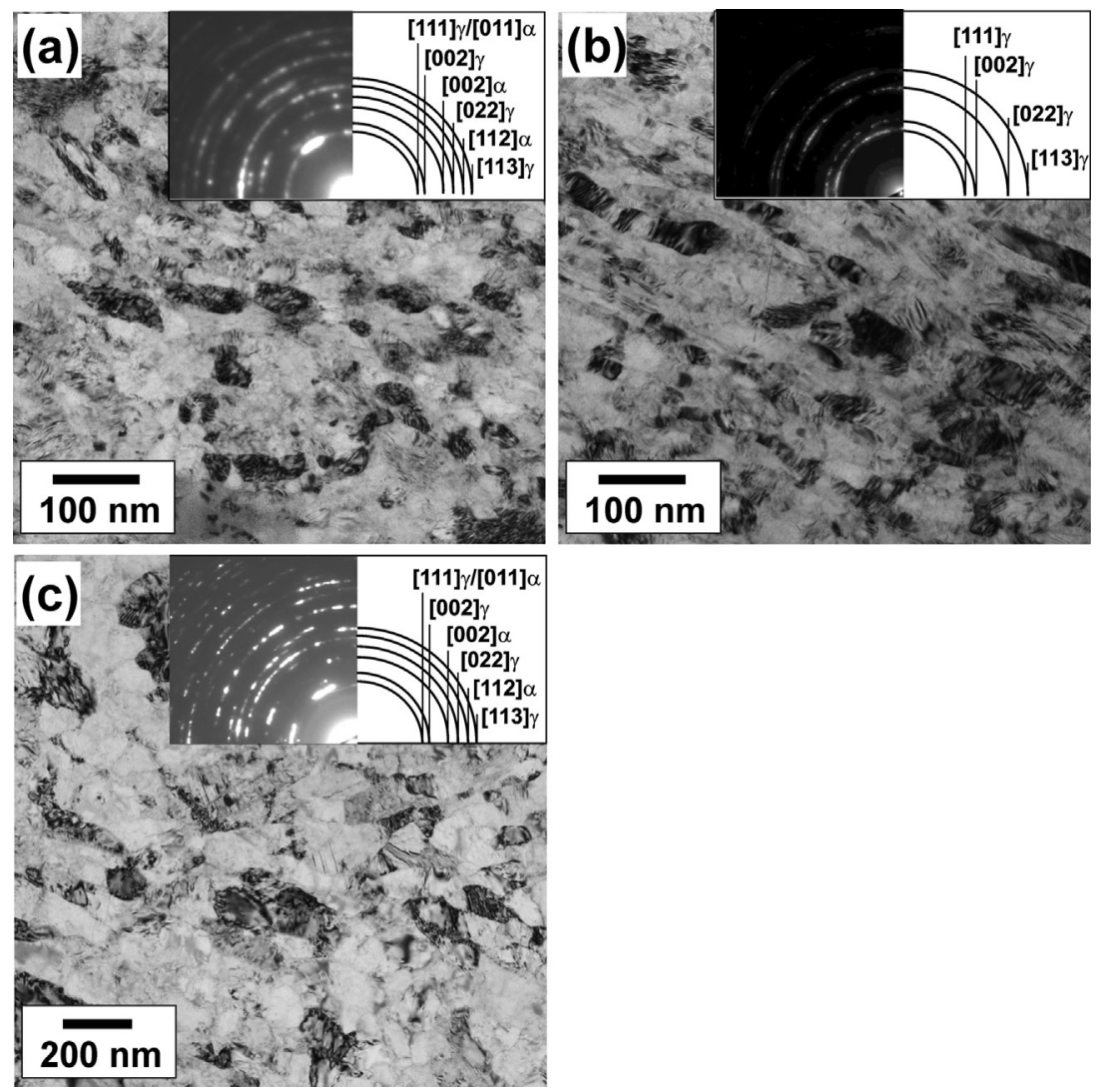

Figure 17. Typical fine microstructures in stainless steels subjected to severe plastic deformation at room temperature; multiple multidirectional forging of a 304-type steel a), torsion under high pressure of a 304-type steel b), equal channel angular pressing of a 321-type steel c). ${ }^{[13,114]}$

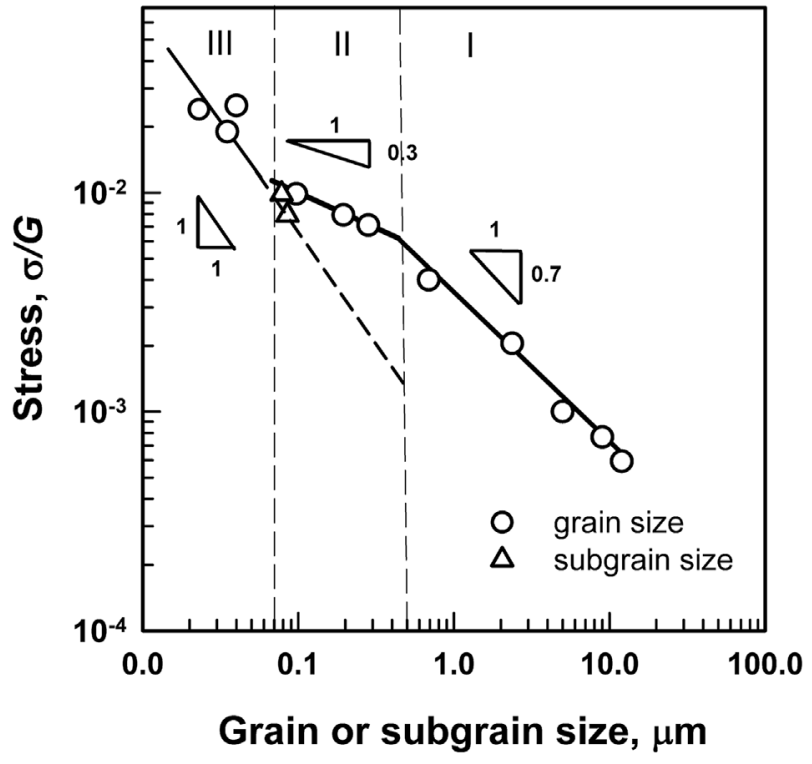

Figure 18. Relationship between the flow stress normalized by shear modulus and the deformation grain/subgrain size in a 304-type austenitic stainless steel. ${ }^{[119]}$

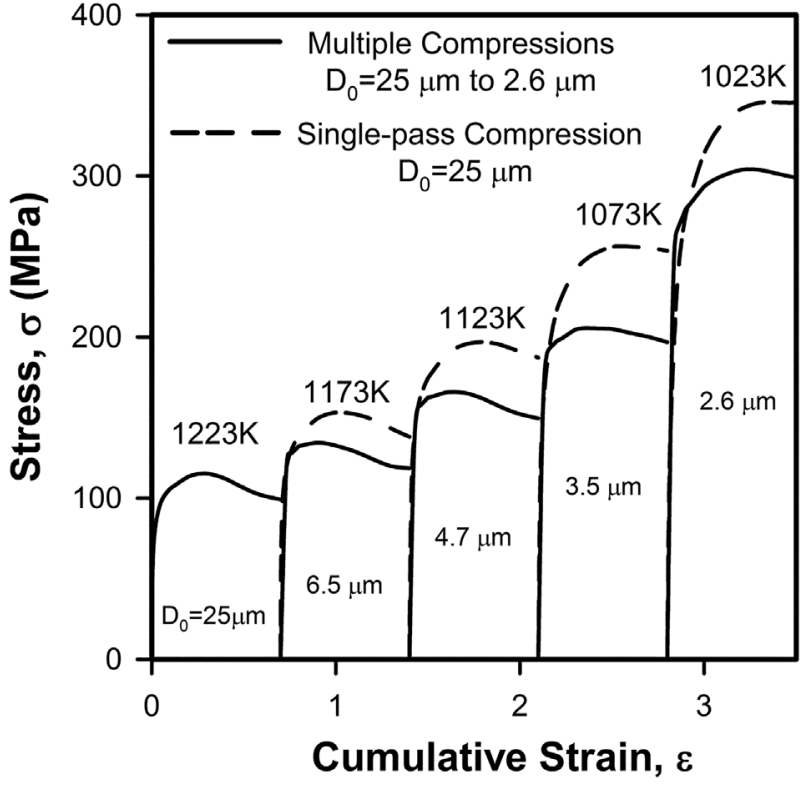

Figure 19. Effect of initial grain size in a 304-type austenitic stainless steel on the stress-strain curves obtained during multiple compressions with temperature decreasing from 1223 to $1023 \mathrm{~K}$ or single pass isothermal compression at indicated temperatures. ${ }^{[14,42]}$ 

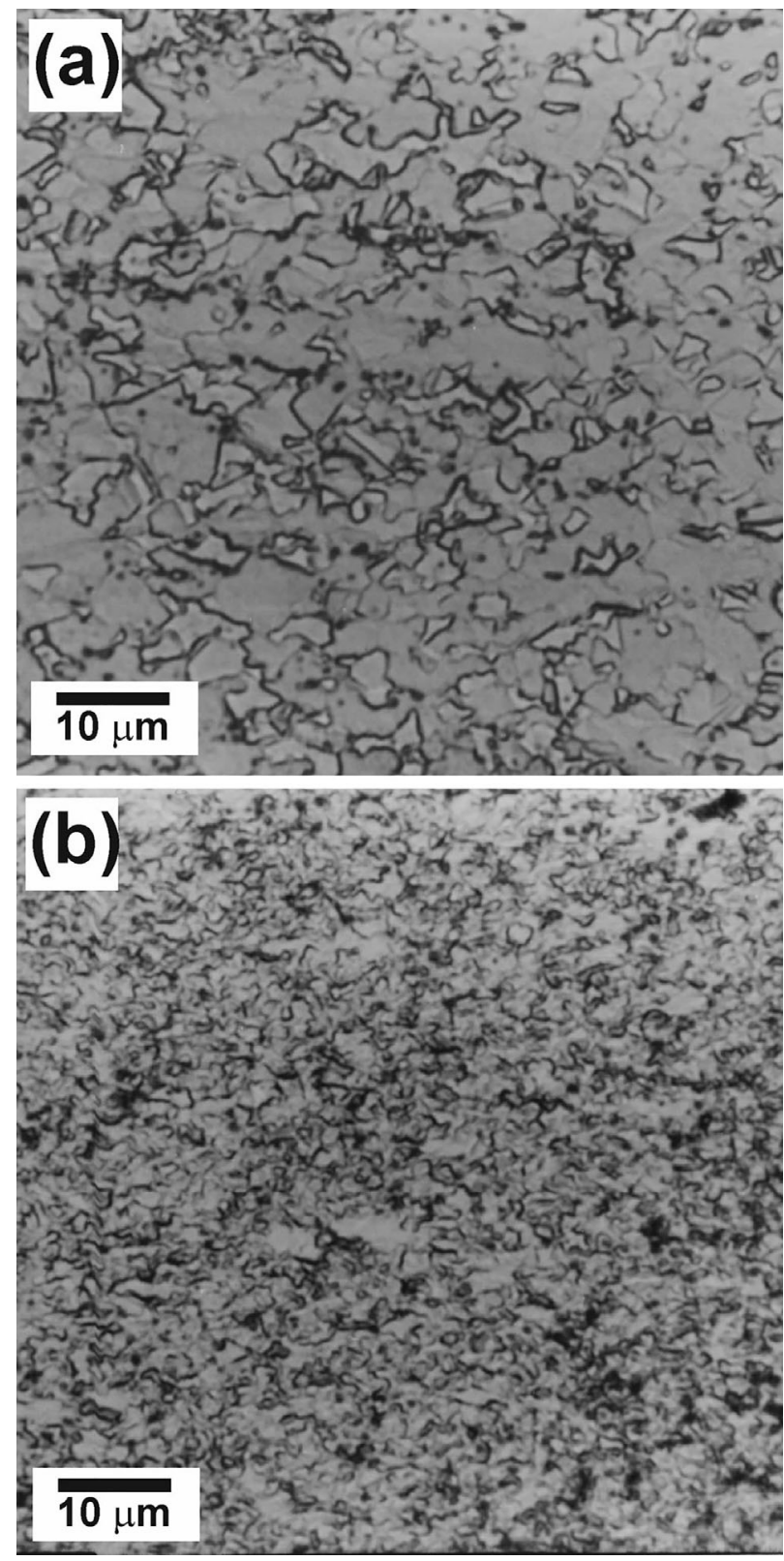

Figure 20. Fine grained microstructures evolved in a 304-type austenitic stainless steel after multiple compressions with temperature decreasing from 1223 to $1123 \mathrm{~K}$ a) and $1023 \mathrm{~K} \mathrm{~b}) \cdot{ }^{[42]}$

with a decrease in the deformation temperature (Figure 21). It is worth noting that rather weak temperature dependence for the occurrence of discontinuous DRX at high temperatures becomes stronger and stronger with a decrease in the deformation temperature. In contrast, the change in the continuous DRX kinetics demonstrates opposite temperature dependence. Namely, the strong effect of the temperature on the development of continuous DRX at relatively high temperatures in the range of warm working remarkably weakens as the temperature decreases.

The change in the DRX kinetics with temperature is associated with a change in the combination of activated DRX mechanisms.

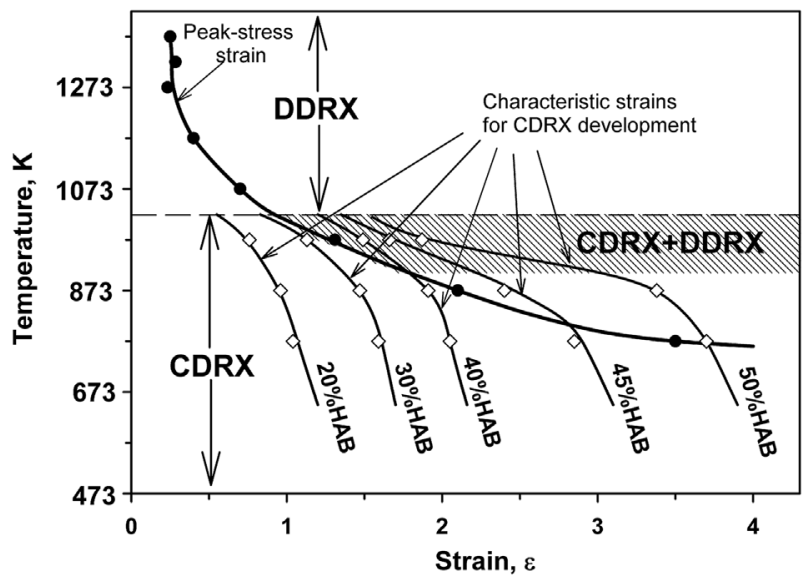

Figure 21. Effect of deformation temperature on the kinetics of discontinuous DRX (DDRX) and continuous DRX (CDRX) in an austenitic stainless steel. ${ }^{[57]}$

In the range of hot working, discontinuous DRX solely controls the new grain evolution, because any strain-induced boundaries periodically consumed by growing new grains. On the other hand, the development of continuous DRX does not prohibit the onset of discontinuous DRX, when the stored deformation energy, that is, driving pressure, becomes large enough to initiate the grain boundary bulging. Therefore, the progress in the new fine grain development in the high temperature range of warm working can be accelerated by an additional effect of discontinuous DRX when the total strain attains the onset of discontinuous DRX. The effect of temperature on the kinetics of continuous DRX can be discussed with reference to the mechanisms responsible for the development of strain-induced high-angle grain boundaries. ${ }^{[10,28,29,74,85,132-139]}$ Gourdet and Montheillet developed a model for continuous DRX, which might take place during hot working. ${ }^{[28,134]}$ They elaborated the Laasraoui-Jonas equation combining the strain hardening and dynamic recovery ${ }^{[132]}$ and obtained the increasing rate of strain-induced subboundary misorientations as function of the recovery parameter (recovery rate) and the flow stress. ${ }^{[137]}$ According to the model, the DRX kinetics accelerates with an increase in deformation temperature because of acceleration of dynamic recovery, which promotes the rearrangement of lattice dislocations into dislocation subboundaries, leading to increasing misorientations among homogeneous deformation substructures. On the other hand, the formation of strain-induced boundaries owing to the development of deformation microbands was attributed to the stress-strain gradients, which are mainly accumulated at grain boundaries, and was treated in terms of partial disclinations. ${ }^{[85,133,138]}$ These stressstrain gradients should increase when the rate of dislocation storage exceeds the rate of dislocation recovery/annihilation during deformation ${ }^{[139]}$ that suggests a promotion of straininduced boundary formation with decreasing the deformation temperature. Therefore, kinetics of grain refinement by recovery assisted gradual increase in the subboundary misorientations in uniform deformation substructures is slowed down, whereas the development of strain-induced boundaries associated with the deformation microbands is promoted with a decrease in the deformation temperature. Concurrent operation of these 
continuous DRX mechanisms in austenitic stainless steels results in a weak temperature dependence of the grain refinement kinetics in a wide range of warm working conditions. Regarding the development of strain-induced grain boundaries, it should be noted that the grain fragmentation (subdivision) itself is not enough for the fine grain evolution through continuous DRX; recovery-assisted dislocation rearrangement is also necessary condition for the dynamic grain formation. For instance, continuous DRX scarcely develops in high-Mn austenitic steels, in which dynamic recovery is suppressed by very low SFE, although warm working of these steels certainly brings about a high dislocation density and leads to grain fragmentation by straininduced high-angle boundaries. ${ }^{[140]}$

Similar to discontinuous DRX during hot working, a decrease in the initial grain size accelerates the kinetics of continuous DRX during cold-to-warm working. ${ }^{[118,141]}$ Vicinities of the initial grain boundaries were shown as preferential sites for the development of deformation subboundaries with rapidly increasing misorientations during warm working because of strain incompatibilities and related constraints aroused by the neighboring grains. ${ }^{[47,118]}$ An increase in the grain boundary fraction by decreasing the initial grain size increases the volume, which can be readily occupied by new fine grains, and, thus promotes the grain refinement kinetics. A decrease in the initial grain size to about $3 \mu \mathrm{m}$ resulted in rapid grain refinement in a 304-type stainless steel during warm multidirectional forging at $873 \mathrm{~K}$; more than $60 \%$ of high-angle strain-induced boundaries could be achieved at relatively small total strains below $2 .{ }^{[118]}$ On the other hand, the effect of initial microstructure on continuous DRX kinetics weakened with further grain refinement (Figure 22). Under conditions of warm working, therefore, the dimension of such preferential sites for the fast development of new fine grains near original grain boundaries

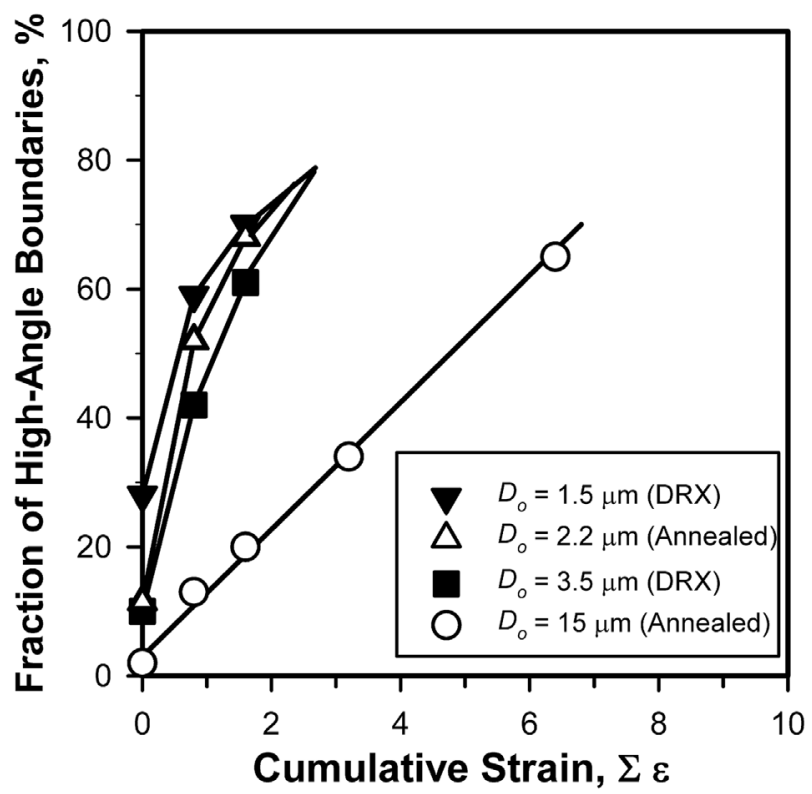

Figure 22. Effect of the initial microstructures on the development of strain-induced high-angle boundaries during warm multiple deformation of a 304 stainless steel. ${ }^{[18]}$ may comprise about $1 \mu \mathrm{m}$ in conventional austenitic stainless steels. ${ }^{[18]}$

The new grains during both hot and warm working appear after some critical strains. Then, the DRX grain fraction increases at quickened pace with straining followed by stunted growth, finally approaching a saturation at large strain. Thus, the discontinuous and continuous DRX kinetics can be related to the total strain through a sigmoid shape function. The fraction of DRX grains $\left(F_{\mathrm{DRX}}\right)$ has been successfully related to the strain $(\varepsilon)$ through a modified Johnson-Mehl-Avrami-Kolmogorov (JMAK) equation, ${ }^{[20,62,142-145]}$

$F_{\mathrm{DRX}}=1-\exp \left(-k\left(\varepsilon-\varepsilon_{c}\right)^{n}\right)$

where $k, n$, and $\varepsilon_{c}$ are constants, which depend on material and processing conditions. Since the deformation microbands and their intersections are preferable sites for the new ultrafine grain appearance in austenitic stainless steels under conditions of continuous DRX, the fraction of continuous DRX grains can be also expressed by Equation 2 that has been originally proposed by Olson and Cohen ${ }^{[112]}$ for strain-induced martensite in metastable austenitic stainless steels subjected to cold working.

\section{Post-DRX Annealing Behavior}

\subsection{Annealing Softening}

The softening behavior during annealing of DRX microstructures is schematically shown in Figure 23 in comparison with ordinary SRX of cold worked metallic materials. ${ }^{[10,20,128]}$ The softening upon heating of cold worked materials proceeds in three stages $\left(\mathrm{I}_{\mathrm{SRX}}\right.$ to $\mathrm{III}_{\mathrm{SRX}}$ in Figure 23). The first stage corresponds to incubation period, when recovery creates the

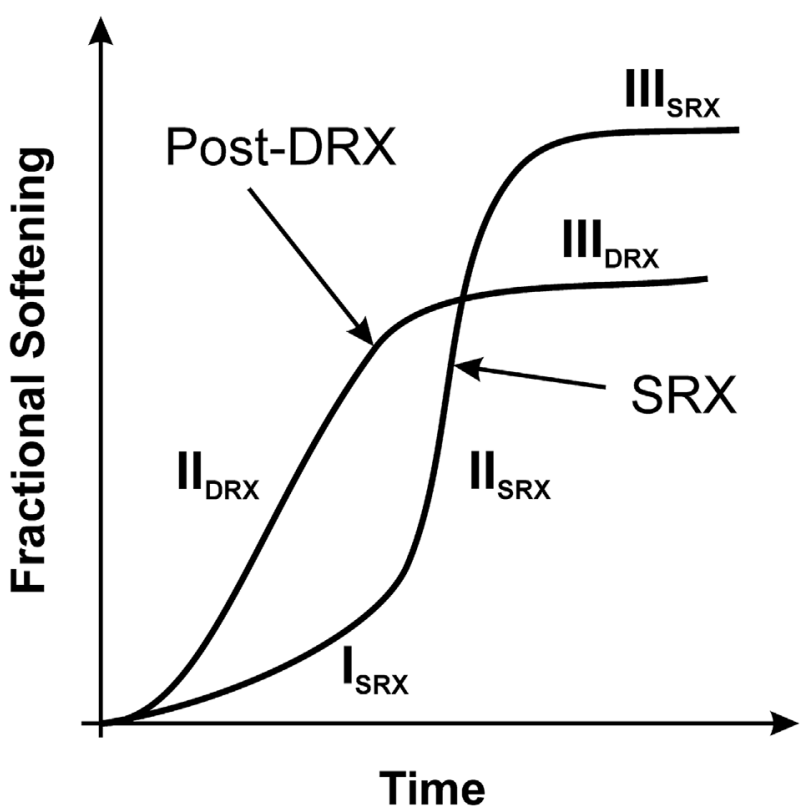

Figure 23. Comparative scheme for softening behavior during primary static recrystallization (SRX) and post-DRX annealing. 
recrystallization nuclei, which are able to growth. Then, the growing recrystallized grains provide an almost complete softening (stage $\mathrm{II}_{\mathrm{SRX}}$ ). Finally, the softening is controlled by a normal grain growth (stage III $_{S R X}$ ). The main difference of post-DRX annealing behavior from primary SRX is the absence of the incubation period. The hot worked microstructures that developed trough discontinuous DRX consist of DRX nuclei, growing DRX grains, and work hardened grains. The DRX nuclei start to growth and the growing DRX grains restart to growth, leading to significant instantaneous softening just upon reheating or holding at the temperature of hot deformation (stage $\left.\mathrm{II}_{\mathrm{DRX}}\right) \cdot{ }^{[146-148]}$ Another feature of post-DRX annealing behavior is apparently incomplete softening at the end of the rapid grain growth (cf. stages $\mathrm{II}_{\mathrm{DRX}}$ and $\left.\mathrm{II}_{\mathrm{SRX}}\right)$. This is attributed to the presence of growing DRX grains containing dislocation substructures, which were evolved during previous hot deformation. These grains experience recovery during postDRX annealing and cannot be such softened as dislocation free SRX grains.

Austenitic stainless steels with continuous DRX microstructures exhibit apparently the same softening behavior during post-DRX annealing as those processed by hot working accompanied by discontinuous DRX, although the softening mechanism during stage $\mathrm{II}_{\mathrm{DRX}}$ is somewhat different. A series of softening curves for ultrafine grained 304-type stainless steel processed by multidirectional forging at $873 \mathrm{~K}$ followed by annealing at various temperatures is shown in Figure $24 .{ }^{[146]}$ The uniform ultrafine grained microstructures with relatively high internal stresses are developed during large strain warm deformation. Following a release of the internal stresses by a rapid recovery along the strain-induced grain boundaries just upon post-deformation heating, the ultrafine grains readily grow

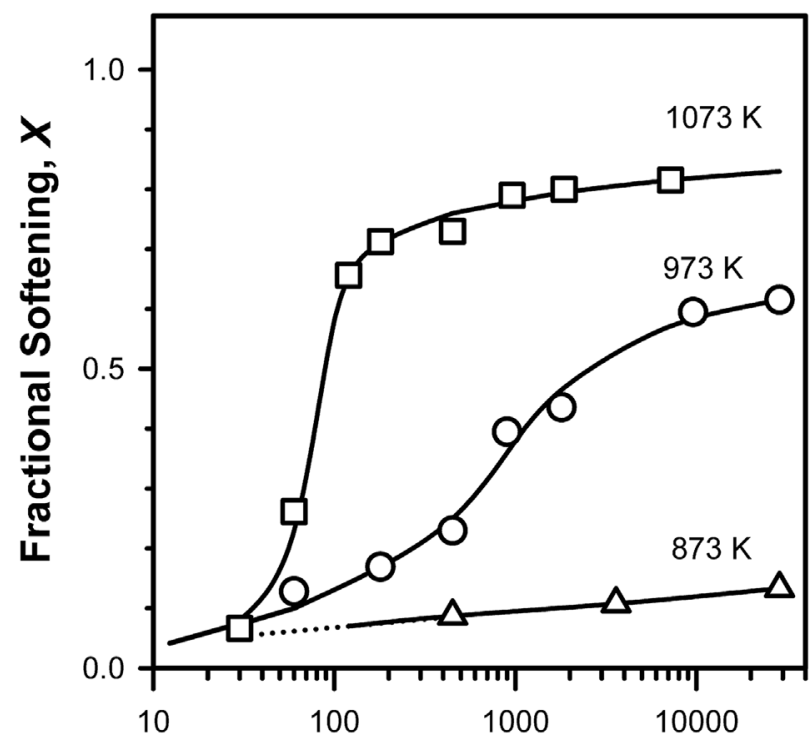

\section{Annealing Time, $\mathbf{t}(\mathbf{s})$}

Figure 24. Fractional softening during annealing of a 304-type austenitic stainless steel with an ultrafine grained microstructure developed by large strain warm deformation. ${ }^{[146]}$ (stage $\mathrm{II}_{\mathrm{DRX}}$ ) during annealing. The corresponding softening depends on annealing temperature, which controls the grain size. The rapid grain growth during post-continuous DRX annealing takes place homogeneously throughout the continuous DRX microstructures and was discussed as a kind of continuous SRX. ${ }^{[10,147]}$ This fast growth of ultrafine grains is driven by not only grain boundary energy, but also high dislocation densities and some substructural heterogeneities that are inherent in continuous DRX structures developed during large strain warm deformation. The rapid grain growth results in unification of microstructures and diminishes the driven force for further grain coarsening. Therefore, long time post-continuous DRX annealing is accompanied by a gradual softening much similar to that associated with normal grain growth, although dislocation substructures can exist in DRX microstructures during a long time annealing.

The annealing softening of a 304-type stainless steel subjected to large strain plate rolling at ambient temperature or $573 \mathrm{~K}$ is represented in Figure 25. ${ }^{[149]}$ Annealing at $873 \mathrm{~K}$ does not lead to significant fractional softening, which comprises about $0.1-0.2$ after $30 \mathrm{~min}$ annealing, followed by sluggish softening upon further annealing. In contrast, an increase in the annealing temperature significantly affects the softening. The rapid grain growth during annealing for $30 \mathrm{~min}$ at 973 and $1073 \mathrm{~K}$ provides substantial fractional softening of $0.4-0.5$ and $0.7-0.8$, respectively. Following the rapid softening during $30 \mathrm{~min}$ annealing, the steels gradually soften with an increase in the annealing duration. Therefore, the softening by a rapid grain growth during annealing of ultrafine grained steels depends mainly on the annealing temperature, whereas the temperature of previous large strain deformation has insignificant effect (s. Figure 24, 25).

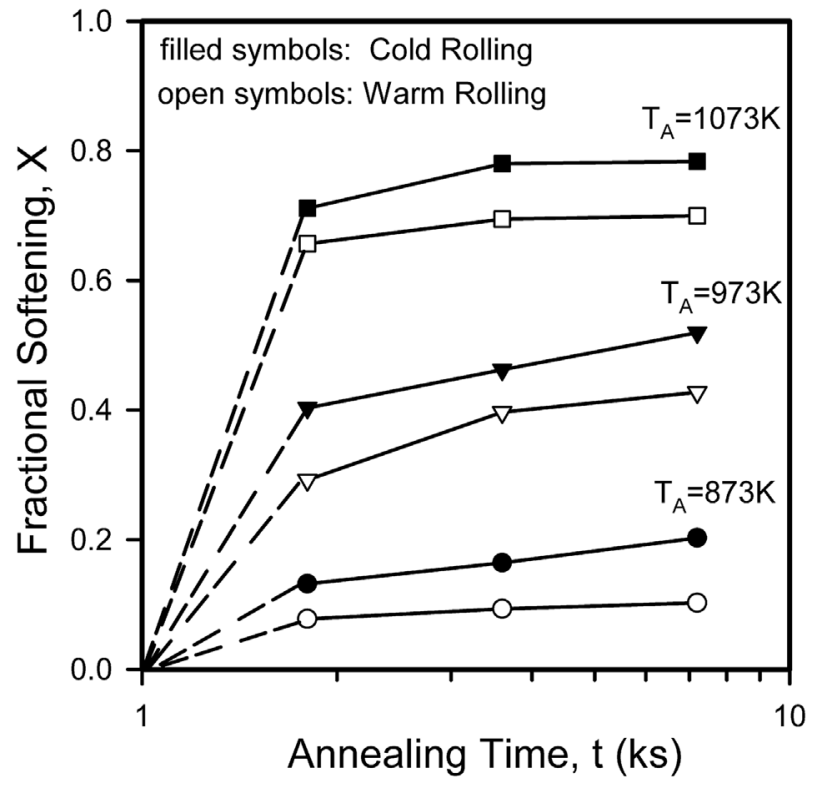

Figure 25. Effect of annealing temperature/time on the fractional softening of a 304L-type stainless steel processed by warm or cold rolling. ${ }^{[149]}$ 


\subsection{Grain Coarsening}

The grain coarsening in austenitic stainless steels during postDRX annealing correlates with softening. Commonly, the rapid grain growth occurs at annealing stage $\mathrm{II}_{\mathrm{DRX}}$ followed by a gradual grain coarsening similar to normal grain growth at stage III $_{\text {DRX }}$ (Figure 23). The annealing behavior following discontinuous DRX was considered as a kind of discontinuous post-DRX, when the DRX nuclei and growing grains start/restart growth at expense of work hardened grains at stage $\mathrm{II}_{\mathrm{DRX}}{ }^{[10,128]}$ Then, the growth rate decreases at stage III $_{\mathrm{DRX}}$ following impingement of growing grains. In contrast, the grain coarsening after continuous DRX was discussed as a kind of continuous postDRX. ${ }^{[10,147]}$ In this case, the grain growth takes place homogeneously, although the deformation stored energy after large strain warm working that provides high driving force results in relatively fast grain growth at stage $\mathrm{II}_{\mathrm{DRX}}$ followed by a decrease in the grain coarsening kinetics at stage III $_{\mathrm{DRX}}$ similar to discontinuous post-DRX behavior.

The effect of deformation temperature on the grain growth in a 304-type ultrafine grained austenitic stainless steel processed by large strain multidirectional warm forging is shown in Figure 26. ${ }^{[11]}$ The stage $\mathrm{II}_{\mathrm{DRX}}$ corresponding to rapid grain growth shifts toward shorter annealing time as the temperature of previous warm deformation, at which the ultrafine grained microstructure was developed, decreases. Decreasing the deformation temperature leads to increasing the dislocation density and structural/substructural heterogeneity that accelerates the grain growth kinetics. The grain growth exponent that averaged over a whole studied annealing duration comprises approx. 2 (Figure 26). It is worth noting that the grain growth exponent of 2 has been originally predicted by Burke and Turnbull, ${ }^{[39]}$ whereas much larger grain growth exponents up to

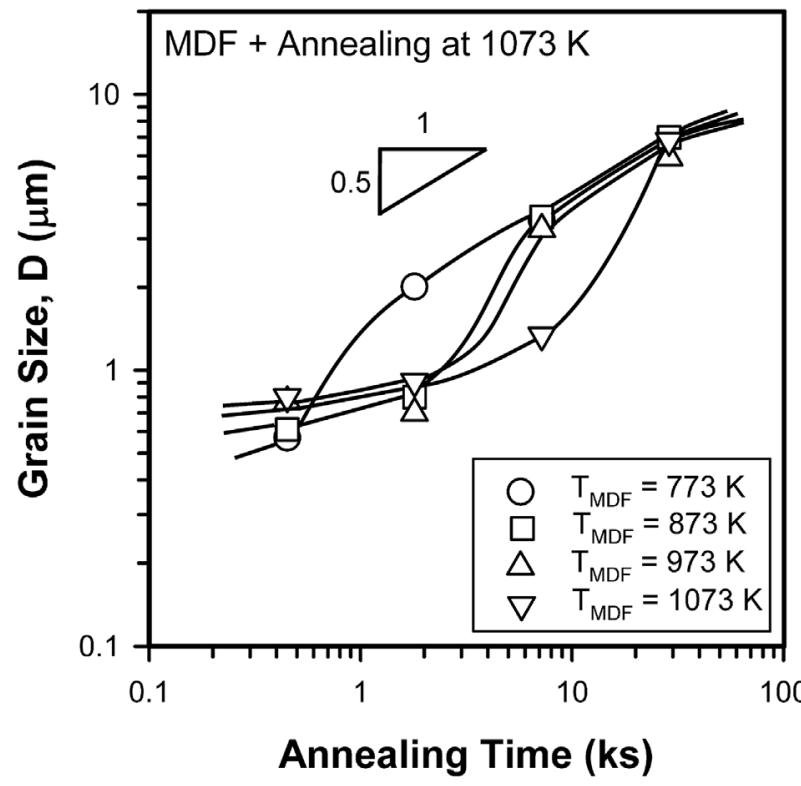

Figure 26. Grain coarsening during annealing at $1073 \mathrm{~K}$ of a 304-type ultrafine-grained austenitic stainless steels processed by warm multidirectional forging (MDF) at indicated temperatures $\left(T_{M D F}\right) .^{[1]}$
10 were obtained in numerous experimental studies. ${ }^{[20,149-152]}$ The grain growth exponents of about 2 were observed in pure metals during annealing at high temperatures. ${ }^{[20,150]}$

The grain growth behavior with a grain growth exponent of 4 at the late annealing stage was also observed during annealing of nanocrystalline austenitic stainless steels processed by large strain cold rolling (Figure 27). ${ }^{[1,149]}$ Note here that the cold rolled steels included large fractions of strain-induced martensite, which quickly transformed to austenite upon heating and then experienced grain growth along with cold worked nanocrystalline austenite. The cold rolled steels exhibit annealing behavior, which is much similar to continuous recrystallization irrespective of partial austenite reversal, because the austenite reversal occurs by a shear mechanism. ${ }^{[149]}$ Therefore, upon a heating, the strain-induced martensite rapidly transforms to ultrafine grained austenite, which is almost the same as the cold worked austenite. Then, the uniform ultrafine grained austenite microstructure, which is quite similar to those frequently observed in other metals and alloys subjected to severe plastic deformation, ${ }^{[73]}$ exhibits a kind of continuous recrystallization during annealing. The development of continuous post-DRX during annealing of nanocrystalline and ultrafine grained austenitic stainless steels processed by large strain cold to warm working allows us obtaining the a range of uniform annealed microstructures with desirable grain size. Examples of ultrafine grained annealed microstructures in austenitic stainless steels are shown in Figure 28. ${ }^{[149]}$

Post-DRX softening and grain growth frequently occur during the intervals between hot working operations in a course of multiple deformations at elevated temperatures, leading to the development of a special microstructure, which is considered as a result of so-called metadynamic recrystallization (MDRX). ${ }^{[10,20,148,153-156]}$ The MDRX mechanism involves several concurrent processes including a rapid growth of DRX nuclei, polygonization/coalescence of dislocation substructure,

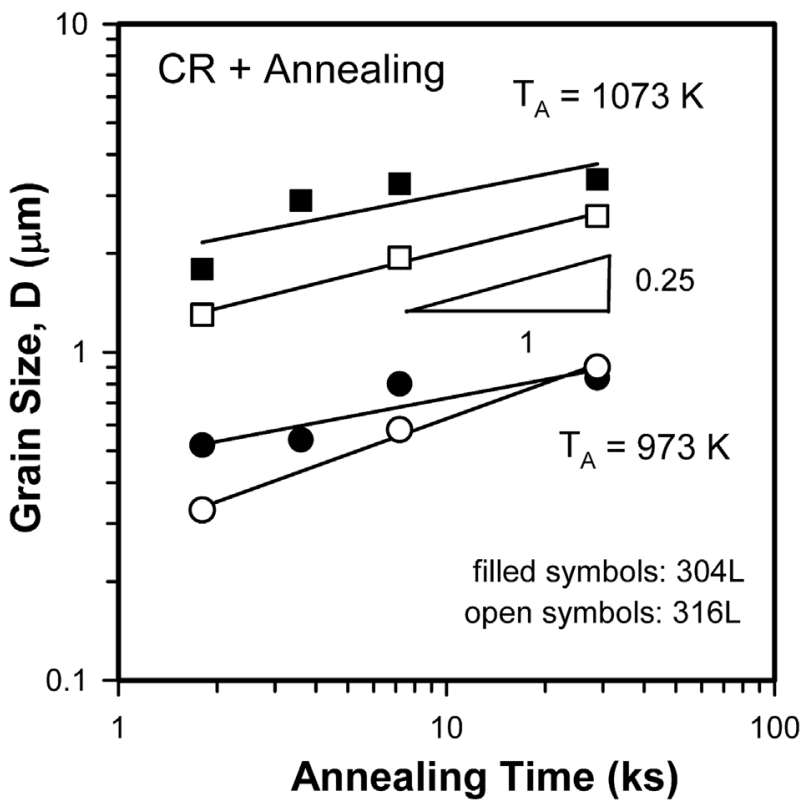

Figure 27. Grain coarsening in stainless steels subjected to cold-rolled (CR) followed by annealing at indicated temperatures $\left(T_{A}\right){ }^{\left[{ }^{11]}\right.}$ 

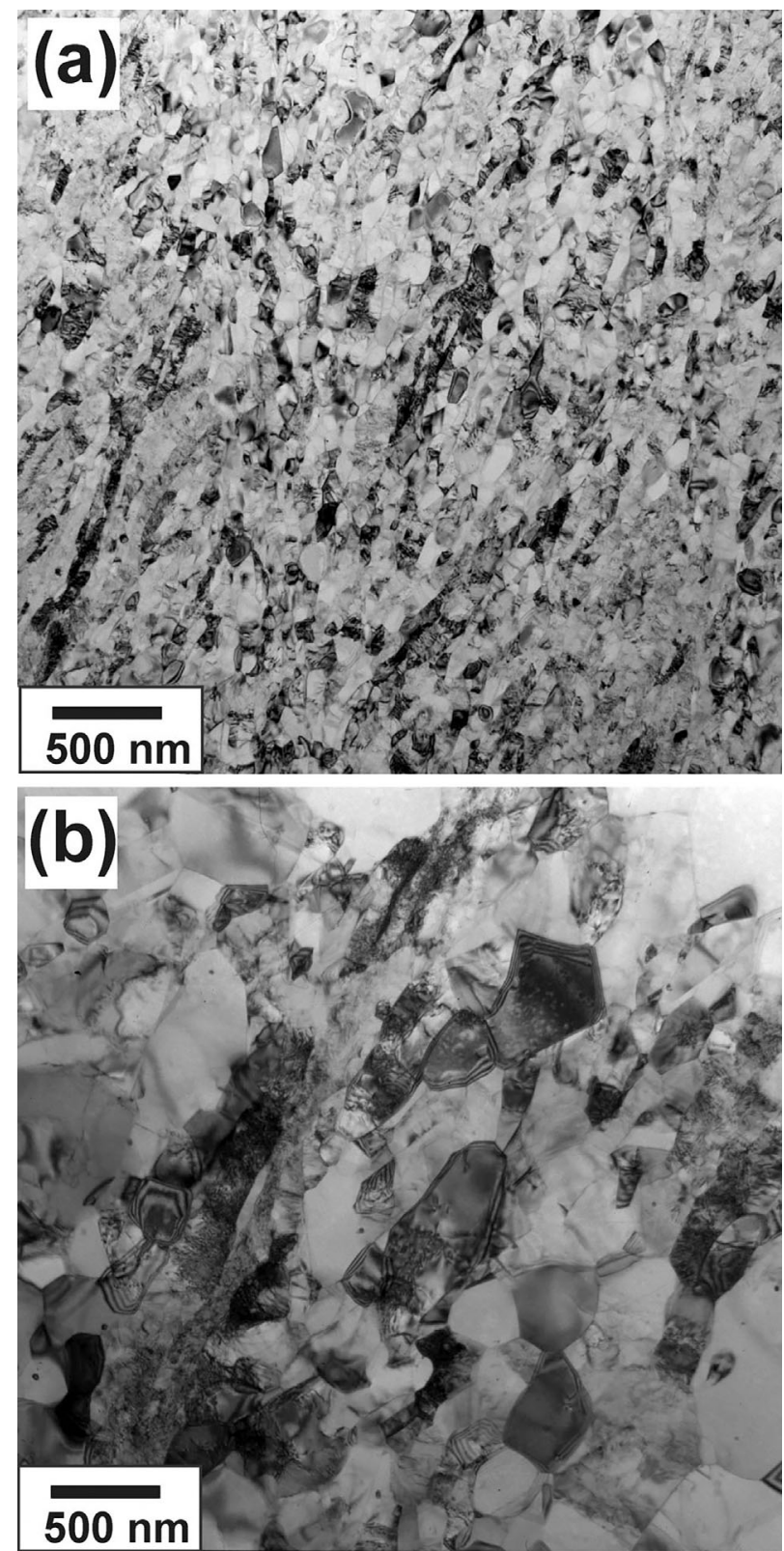

Figure 28. Ultrafine grained structures in a 304L-type stainless steel subjected to cold rolling and annealing for $30 \mathrm{~min}$ at $873 \mathrm{~K} \mathrm{a}$ ) and $973 \mathrm{~K} \mathrm{~b}$ ). ${ }^{[149]}$

and a dislocation recovery at grain boundaries. ${ }^{[10,148]}$ The MDRX kinetics can be described on the base of JMAK analysis much similar to conventional SRX. ${ }^{[10,153,155]}$ An increase in the strain and/or strain rate markedly promotes the MDRX development. A decrease in the grain size also accelerates the MDRX kinetics, although the grain size effect is not so pronounced. ${ }^{[153]}$

\section{Grain Boundary Misorientation Distribution}

\subsection{DRX Grain Boundaries}

Typical grain boundary networks and corresponding grain boundary misorientation distributions in austenitic stainless steels with DRX microstructures are shown in Figure 29 and 30, respectively. ${ }^{[51,157,158]}$ The deformation microstructure evolved through discontinuous DRX (hot working conditions) consists of various boundaries, including a number of low-angle subboundaries and twin-related $\Sigma 3^{n}$ CSL boundaries in addition to ordinary high-angle grain boundaries (Figure 29a). Corresponding boundary misorientation distribution can be considered as a summation of three specific misorientation distributions, which are associated with different structural elements (Figure 30a). These distributions include the misorientation distribution with
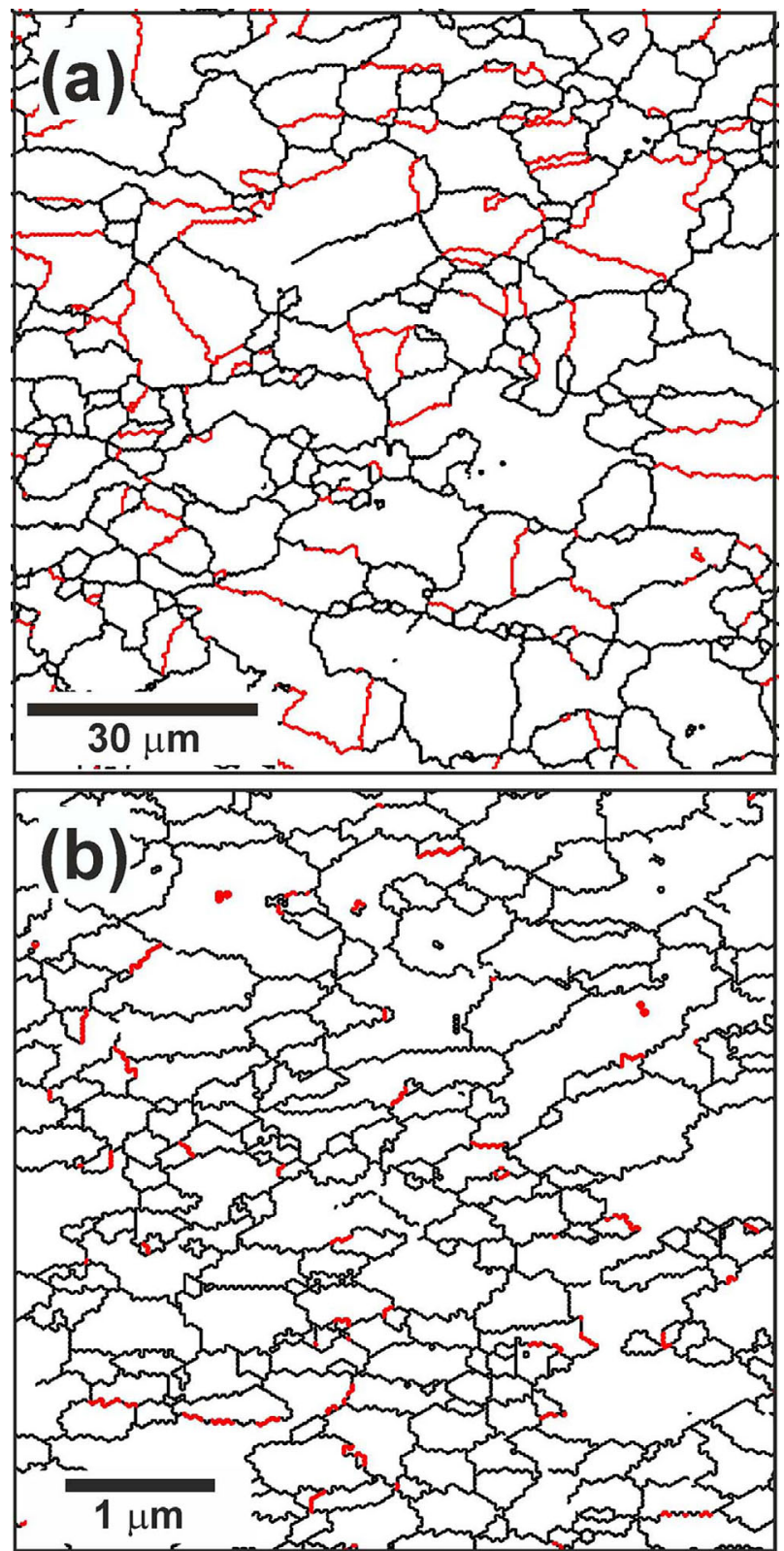

Figure 29. Typical microstructures evolved in a $22 \mathrm{Cr}-10 \mathrm{Ni}$ austenitic stainless steel subjected to hot compression to a strain of 1.2 at $1323 \mathrm{~K} \mathrm{a}$ ) and 304-type austenitic stainless steel subjected to multidirectional forging to total strain of 4 at $773 \mathrm{~K}$. The red and black lines correspond to the CSL $\Sigma 3$ boundaries and ordinary grain boundaries, respectively. ${ }^{[51,158]}$ 


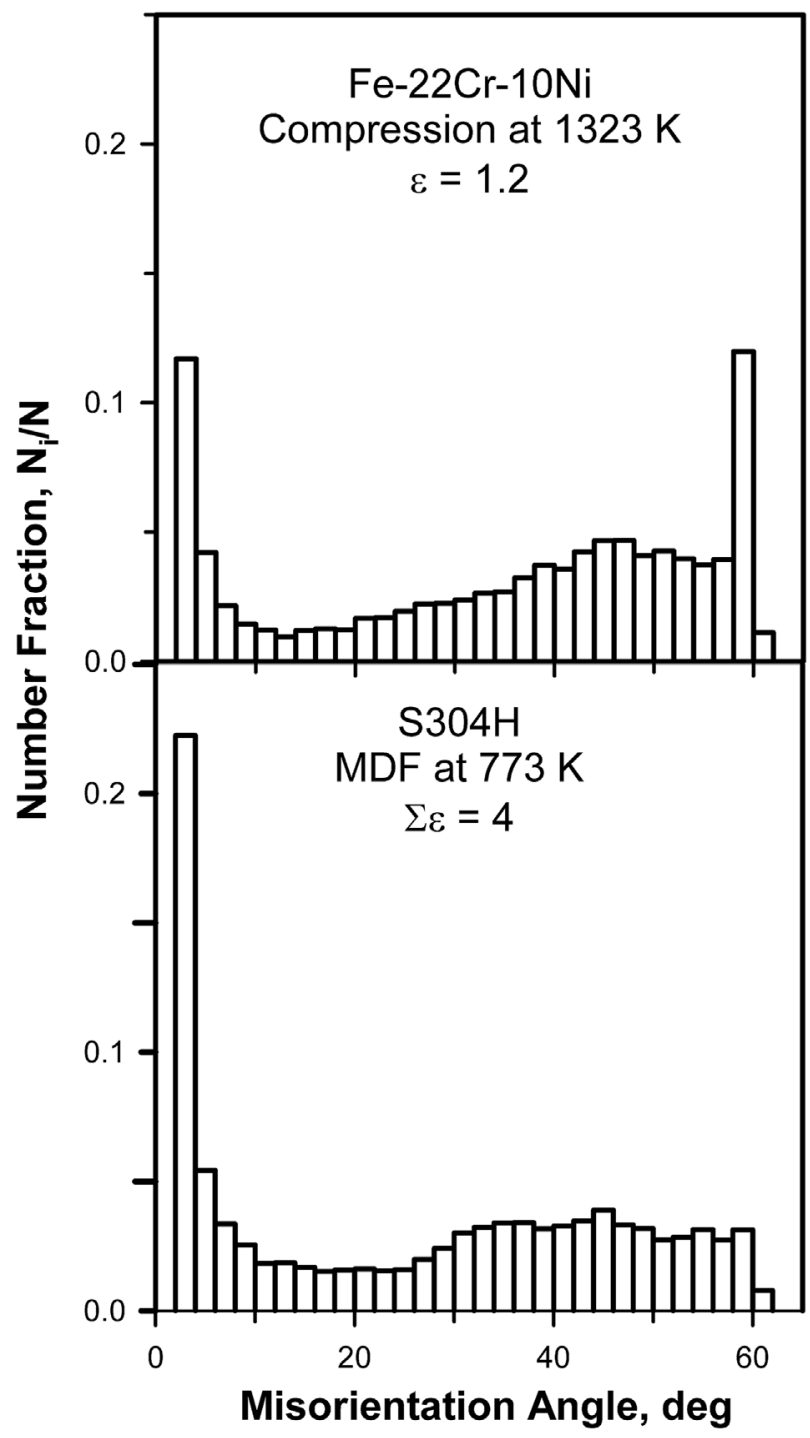

Figure 30. Grain boundary misorientation distributions in a $22 \mathrm{Cr}-10 \mathrm{Ni}$ austenitic stainless steel subjected to hot compression to a strain of 1.2 at $1323 \mathrm{~K}$ and a 304-type austenitic stainless steel subjected to multidirectional forging to total strain of 4 at $773 \mathrm{~K}^{[51,158]}$

a large peak against small angles that is typical of well developed deformation substructures, a random misorientation distribution with a broad peak at $45^{\circ}$ (Mackenzie distribution ${ }^{[159]}$ ) and the misorientation distribution with a sharp peak at $60^{\circ}$ corresponding to annealing twins. The latter ones form by a migrating boundary as a result of growth accidents during discontinuous DRX. ${ }^{[160-163]}$

In contrast to discontinuous DRX, the ultrafine grained microstructure evolved during warm working accompanied by continuous DRX is characterized by a network of low- to high-angle (sub)grain boundaries with a quite few twin-related boundaries (Figure 29b). The distribution of the boundary misorientations developed by continuous DRX includes a sharp peak corresponding to low-angle deformation subboundaries (Figure 30b). It is worth noting that the strain-induced high-angle boundaries with misorientations above $15^{\circ}$ are characterized by almost the same fractions for different misorientations. Similar misorientation distributions were frequently observed for strain-induced grain boundaries evolved through continuous DRX under conditions of warm working or severe plastic deformation. ${ }^{[10,57,61,74,118,164-166]}$

Generally, the effect of DRX mechanism on the development of ordinary high-angle grain boundaries $\left(F_{\mathrm{HAB}}\right)$ and twin-related $\Sigma 3^{n}$ boundaries $\left(F_{\mathrm{CSL}}\right)$ in austenitic stainless steels can be discussed as follows (Figure 31). Three DRX mechanisms correspond to different power law functions with grain size exponents of about -0.7 for discontinuous DRX during hot working, -0.3 for continuous DRX during warm working, and -1.0 for grain refinement during severe plastic deformation. On the other hand, the size of deformation subgrains can be related to the flow stress through a unique inverse function irrespective of deformation temperature (s. Figure 18). Therefore, the fraction of strain-induced high-angle grain boundaries should increase with decreasing the deformation temperature in the range of discontinuous DRX because a ratio of $D / d$ decreases. Correspondingly, a decrease in the grain boundary mobility with decreasing temperature results in a grain growth cessation and, therefore, the fraction of $\Sigma 3^{n}$ CSL boundaries decreases. Continuous DRX is characterized by the different grain size dependence on the flow stress. Namely, the grain size rapidly approaches the subgrain size with an increase in the flow stress (i.e., a decrease in the deformation temperature or an increase in $Z$ ). The fraction of high-angle grain boundaries, therefore, should approach 1, while the fraction of $\Sigma 3^{n}$ CSL boundaries becomes negligibly small. An example of the changes in the fractions of ordinary high-angle grain boundaries and twinrelated $\Sigma 3^{n}$ CSL boundaries in the DRX microstructures that develop in an austenitic stainless steel during warm to hot working is shown in Figure 32. ${ }^{[51]}$ It is clearly seen in Figure 32 that the fraction of ordinary grain boundaries increases, while

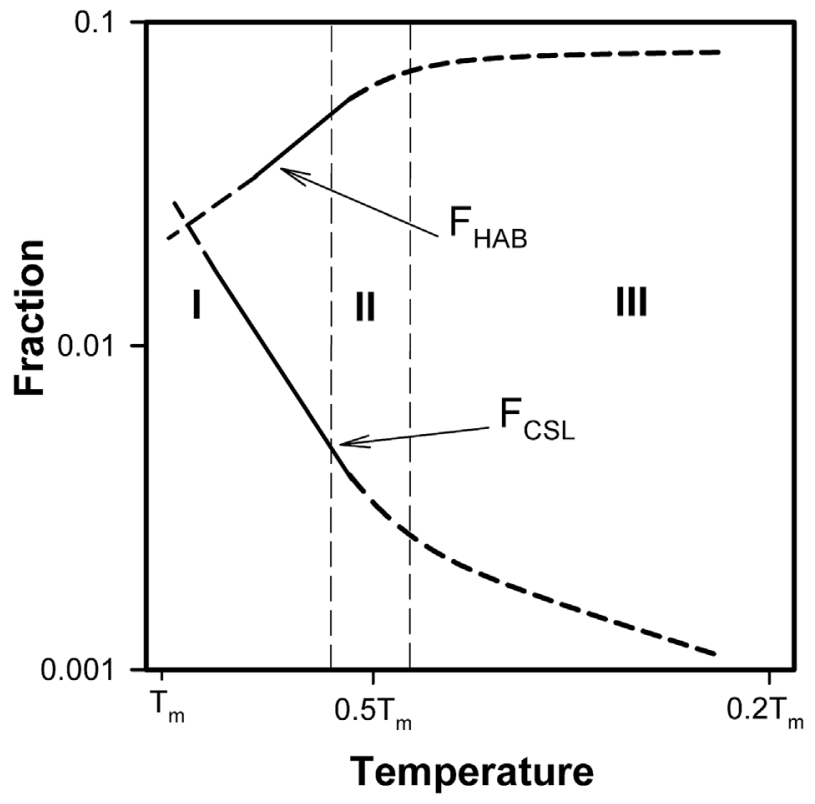

Figure 31. Schematic representation of variations in the fractions of highangle boundaries $\left(F_{\mathrm{HAB}}\right)$ and $\Sigma 3 \mathrm{CSL}$ boundaries $\left(F_{\mathrm{CSL}}\right)$ in austenitic stainless steels subjected to cold to hot deformation. ${ }^{[51]}$ 


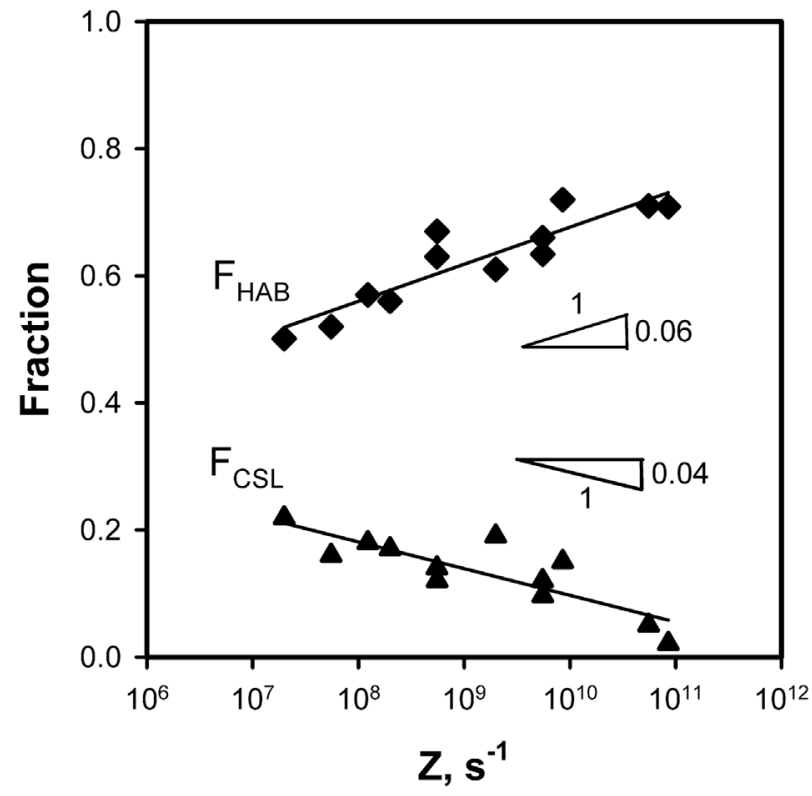

Figure 32. Fractions of high-angle boundaries $\left(F_{\mathrm{HAB}}\right)$ and $\Sigma 3 \mathrm{CSL}$ boundaries $\left(F_{\mathrm{CSL}}\right)$ in a $22 \mathrm{Cr}-10 \mathrm{Ni}$ austenitic stainless steel as functions of temperature-compensated strain rate $(Z) \cdot{ }^{[5]]}$

the fraction of $\Sigma 3^{n}$ CSL boundaries decreases to almost zero as $Z$ increases. After severe plastic deformation, the ultrafine grains seem to be entirely bounded by high-angle boundaries, ${ }^{[65,167]}$ leading to $F_{\mathrm{HAB}}$ approaching one, although ultrafine grained and nanocrystalline materials that develop by severe plastic deformation are commonly characterized by a saturation of $F_{\mathrm{HAB}}$ at $0.6-0.8$ that is below 1.0. ${ }^{[10,141]}$ Any annealing twins and related $\Sigma 3^{n}$ CSL boundaries are hard to evolve during cold working and their fraction should approach zero with a decrease in the deformation temperature, although the deformation twins can be developed during severe plastic deformation.

\subsection{Post-DRX Annealing}

Depending on the DRX microstructure, the subsequent annealing is accompanied with either discontinuous or continuous postDRX recrystallizations that commonly result in grain coarsening. ${ }^{[10,128,147]}$ The high rate of the grain coarsening at early postDRX annealing decreases during heat treatment, approaching that usually reported for normal grain growth at late annealing stages. ${ }^{[0,147]}$ Typical misorientation distributions evolved in an austenitic stainless steel during post-DRX annealing are shown in Figure 33. ${ }^{[158]}$ The changes in the grain boundary misorientation distribution are associated with a decrease in the fraction of lowangle subboundaries, which are readily consumed by growing DRX grains, and an increase in the fraction of $\Sigma 3^{n}$ SCL boundaries, which are associated with the development of annealing twins as a grain growth accidents (cf. Figure 30, 33).

\subsubsection{Annealing Twin Frequency}

The annealing twins frequently appear in austenitic stainless steels during recrystallization and grain growth. Taking the

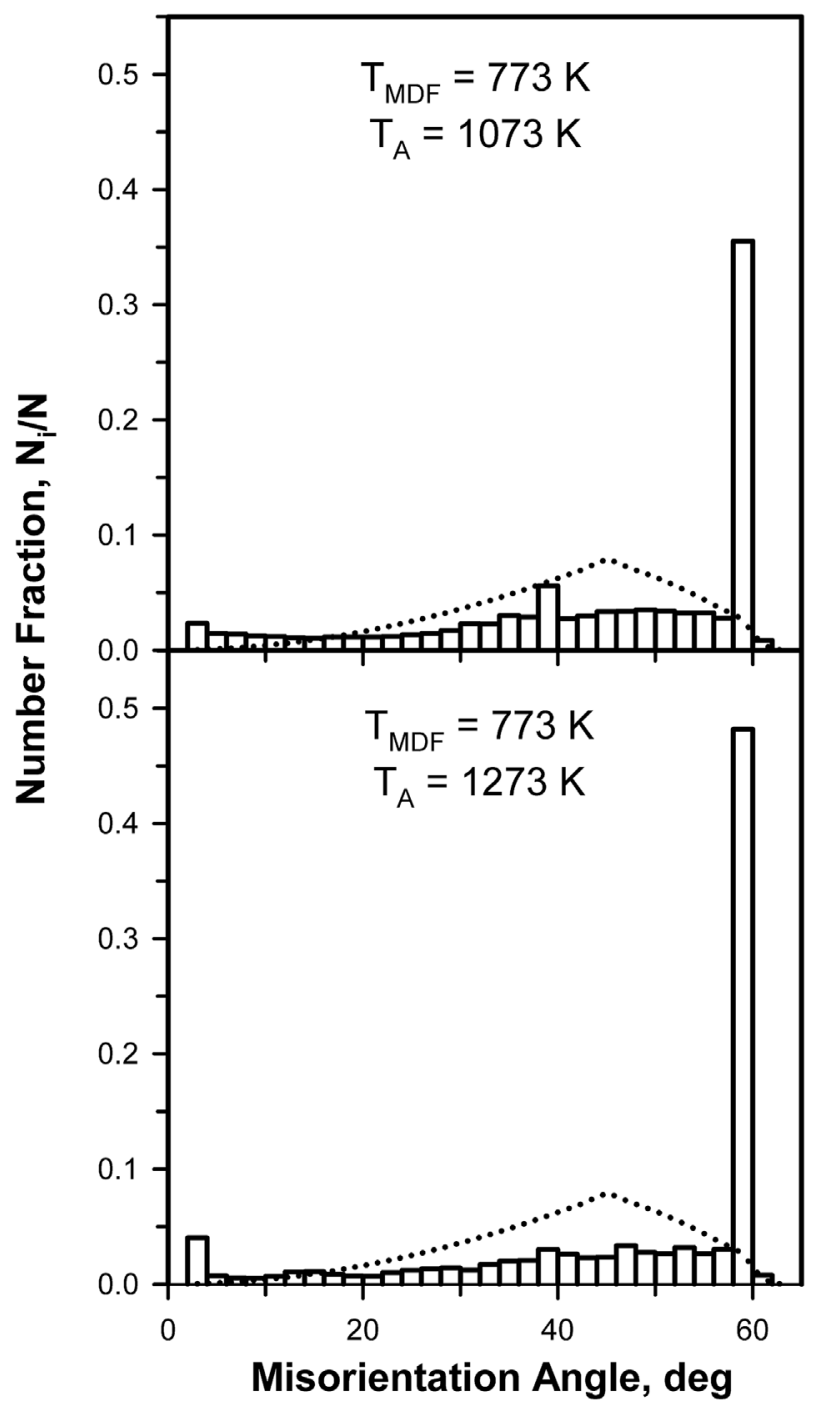

Figure 33. The grain boundary misorientation distributions developed in a 304-type austenitic stainless steel subjected to multidirectional forging at $773 \mathrm{~K}$ and annealing at $1073 \mathrm{~K}$ or $1273 \mathrm{~K}$. The random misorientation distribution is indicated by the dashed lines. ${ }^{[158]}$

probability of twin appearance as a function of the rate of boundary motion, the fraction and number of $\Sigma 3^{n}$ CSL boundaries per unit area have been shown being functions of the grain size ratio of $D / D_{0}$, where $D$ is the grain size after annealing and $D_{0}$ is the original grain size before annealing. ${ }^{[11,158]}$

$F_{\mathrm{CSL}}=\frac{N_{\mathrm{CSL}_{0}}+K \ln \frac{D}{D_{0}}}{N_{\mathrm{CSL}_{0}}+K \ln \frac{D}{D_{0}}+1}$

$p_{\mathrm{CSL}}=\frac{N_{\mathrm{CSL}}+N_{\mathrm{CSL}_{0}}}{D}=\frac{K}{D} \ln \frac{D}{D_{0}}+\frac{N_{\mathrm{CSL}_{0}}}{D}$

where $K \geq 0$ is a coefficient, $N_{\mathrm{CSL}_{0}}=\left(F_{\mathrm{CSL}_{0}}{ }^{-1}-1\right)^{-1}$, and $F_{\mathrm{CSL}_{0}}$ are the number and fractions of $\Sigma 3^{n} \mathrm{CSL}$ boundaries in an original grain, respectively. Note here, that Equation 6 
approaches that obtained by Pande et al., ${ }^{[160]}$ when the second term goes to zero, for example, in the case of primary SRX.

Equations 5 and 6 predict both $F_{\mathrm{CSL}}$ and $\rho_{\mathrm{CSL}}$ rapidly increasing at the beginning of grain growth. Then, the rate of $F_{\mathrm{CSL}}$ increase gradually decreases suggesting a monotonous increase in $F_{\text {CSL }}$ with increasing the grain size. On the other hand, $\rho_{\text {CSL }}$ quickly attains its maximum at a ratio of $D / D_{0}$ around 2.5 and, then, steadily decreases approaching zero when the grain size tends to infinity. The value of $K$ depends on SFE and the rate of boundary motion. Practically, materials with smaller SFE and/or faster boundary migration are characterized by more frequent annealing twins. Figure 34 and 35 show the experimental values of $F_{\mathrm{CSL}}$ and $\rho_{\mathrm{CSL}}$ (various symbols) as functions of $D / D_{0}$, respectively, along with those (shown by solid

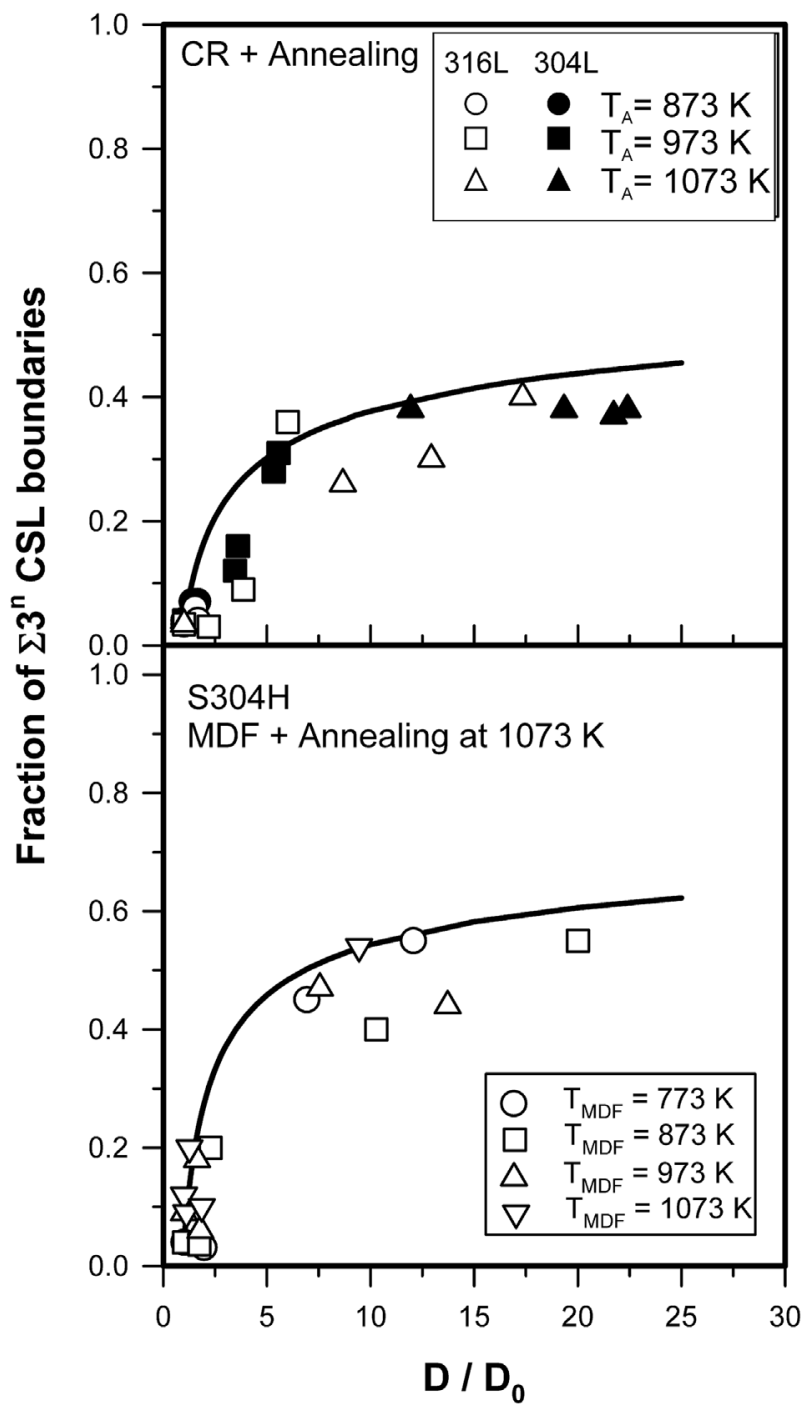

Figure 34. Relationship between the fraction of $\Sigma 3$ CSL boundaries and the grain size ratio $\left(D / D_{0}\right)$ in stainless steels subjected to cold rolling $(C R)$ or warm multidirectional forging (MDF) and then annealed at indicated temperatures. $^{[1]]}$

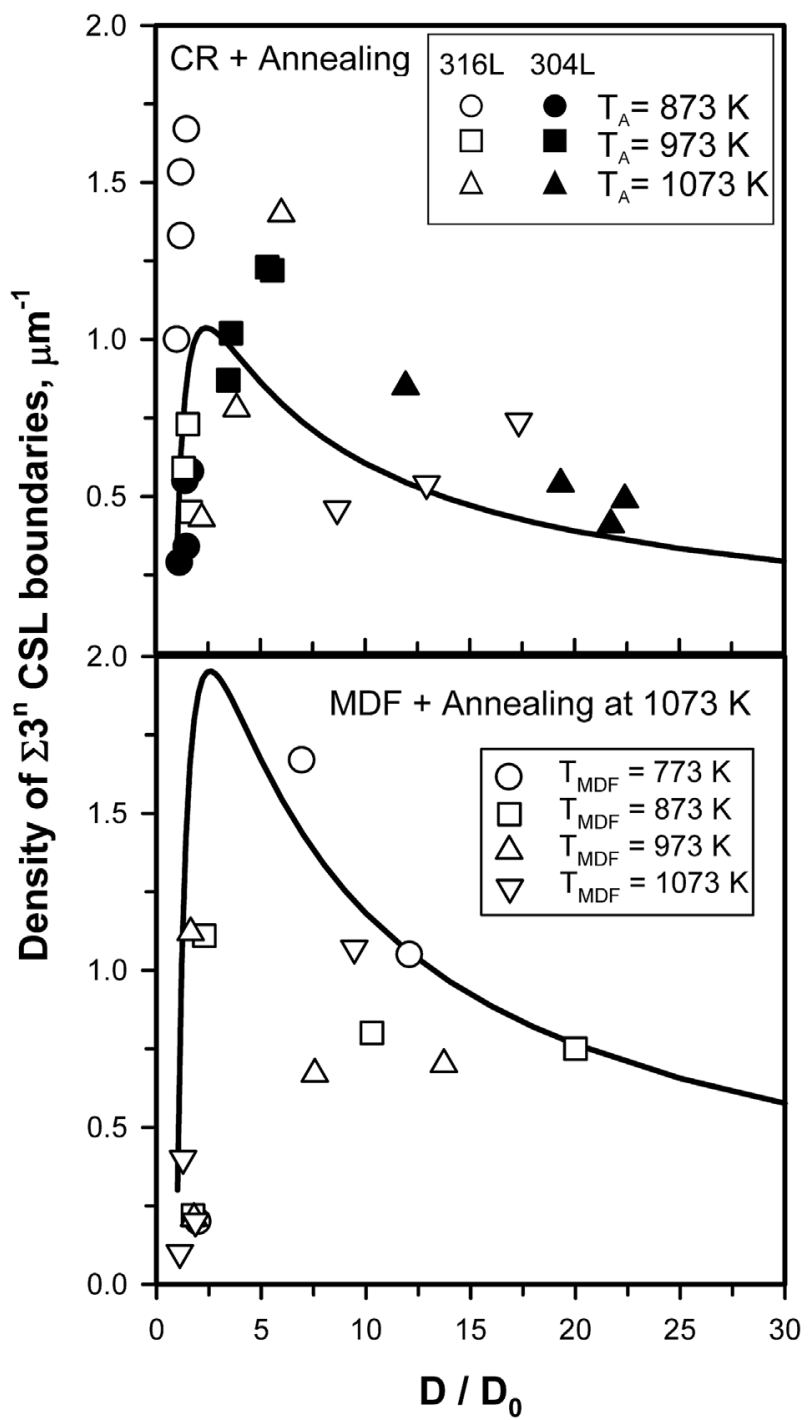

Figure 35. Relationship between the density of $\Sigma 3$ CSL boundaries and the grain size ratio $\left(D / D_{0}\right)$ in stainless steels subjected to cold rolling $(C R)$ or warm multidirectional forging (MDF) and then annealed at indicated temperatures. ${ }^{[1]}$

lines) predicted by Equations 5 and $6 .^{[11]}$ The predicted values of $F_{\text {CSL }}$ and $\rho_{\text {CSL }}$ were calculated taking the numerical factors as $K=n^{-1}$, where $n$ is the grain growth exponent, that is, $K=0.25$ for cold rolling and $K=0.5$ for multiaxial warm forging from Figure 26 and 27. It is clearly seen in Figure 34 and 35 that the tendencies predicted by Equations 5 and 6 are perfectly confirmed by the experimental measurements. Note here that similar change in the annealing twin density with the grain size and/or annealing time has been observed in various metallic materials with low SFE. ${ }^{[162,168]}$ Thus, a grain size ratio of $D / D_{0}$ can be used as an exclusive parameter, which determines the fraction and density of twin-related boundaries in austenitic stainless steels with relatively low SFE during post-DRX annealing irrespective of DRX mechanisms operated during previous deformation. 


\section{Mechanical Properties}

\subsection{DRX under Warm to Hot Working Conditions}

Decreasing the temperature in the range of warm to hot working conditions results in significant strengthening of austenitic stainless steels..$^{[9,60,61,169-171]}$ Arbitrary selected engineering stress-elongation curves obtained by tensile tests of 304 and 316-type austenitic stainless steels processed by large strain warm to hot rolling are shown in Figure 36. ${ }^{\left[{ }^{9]}\right.}$ The steels demonstrate almost the same strengthening ability upon warm to hot working. The offset yield strength after rolling at $773 \mathrm{~K}$ is more than two times higher than that for the steels processed at $1273 \mathrm{~K}$. The strengthening during plastic deformation under warm working conditions is generally accompanied by a plasticity impairment. The total elongations decrease to about $10 \%$. The high dislocation densities evolved by warm working provide significant strengthening owing to restriction of further dislocation motion and, on the other hand, limit subsequent dislocation accumulation and impair plasticity. Following yielding, the steels rolled at temperatures below 0.5 Tm (about $873 \mathrm{~K}$ ) exhibit a quite short strain hardening stage during the tensile tests, resulting in the ultimate tensile strength being close to the yield strength.

The strengthening of austenitic stainless steels subjected to large strain warm to hot working is associated with the grain refinement as well as the dislocation substructures created during plastic deformation depending on the DRX mechanisms. Therefore, the offset yield strength $\left(\sigma_{0.2}\right)$ can be related to the grain size through the modified Hall-Petch relationship taking into account the substructural (dislocation) contribution. ${ }^{\text {[172-175] }}$ The substructural strengthening, which is commonly expressed as a power law function of dislocation density $(\rho), \Delta \sigma_{\rho}=a G b \rho^{0.5}$, where $a$ is a numerical factor and $G$ and $b$ are shear modulus

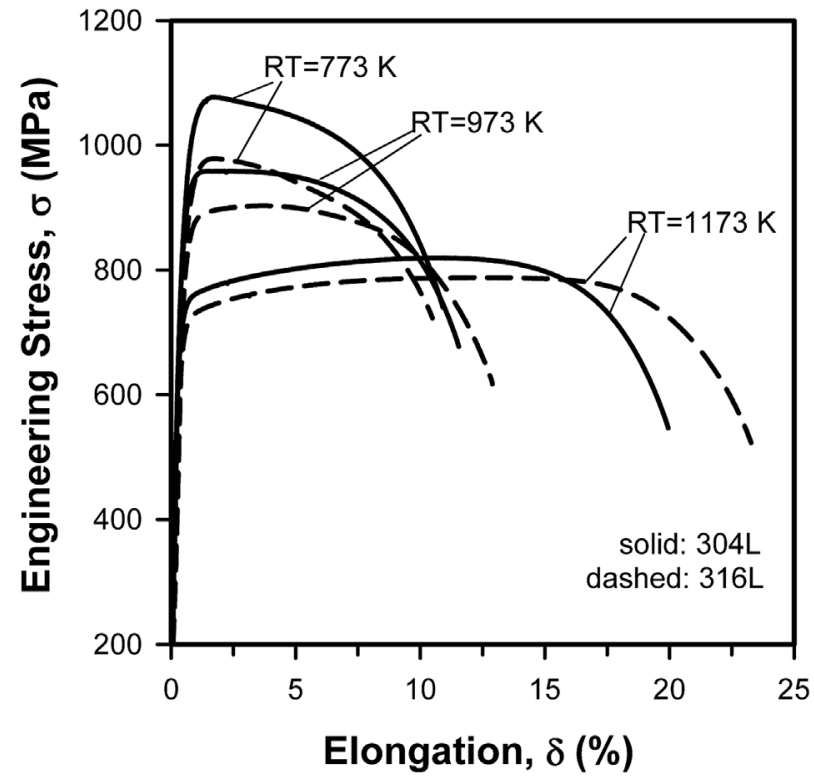

Figure 36. Tensile stress-strain curves for 316L-type and 304L-type stainless steels subjected to warm caliber rolling at different temperatures (RT). ${ }^{[9]}$ and Burgers vector, respectively, has recently been successfully used for calculation of flow stresses of various austenitic steels including those exhibiting complex inhomogeneous microstructures. ${ }^{[176-180]}$ It is commonly accepted that a unique relationship is generally held between dislocation density and subgrain (cell) size, that is, $d \approx \rho^{-0.5} \cdot{ }^{181-184]}$ Then, the substructural strengthening can be represented by either dislocation density or subgrain size. Therefore, the modified equation for the offset yield strength includes three terms:

$\sigma_{0.2}=\sigma_{0}+k_{\varepsilon} D^{-0.5}+\alpha_{1} G b\left(\rho^{0.5}+\alpha_{2} d^{-1}\right)$

Here, $\sigma_{0}$ includes Peierls stress, solid solution and dispersion strengthening, and $k_{\varepsilon}$ is a grain size strengthening factor.

The dynamic grain size that develops in various metallic materials including austenitic stainless steels during warm to hot working accompanied by DRX can be expressed by a power law function of the flow stress with a grain size exponents of approx. -0.7 or -0.3 depending on the deformation conditions, whereas a power law function with an exponent of -1 is generally held between the flow stress and subgrain size (s. Figure 18). This should lead to a unique power law relationship between the grain and subgrain sizes that developed through DRX with grain size exponents of 0.7 and 0.3 for discontinuous and continuous DRX, respectively. The mutual relationships between the grain size, the subgrain size, and the dislocation density suggest a universal approach to the strength prediction for warm to hot worked metals and alloys, that is, the strength can be evaluated by using either anyone of structural parameters or their arbitrary selected combination. ${ }^{[9,172-175,185-194]}$

\subsection{Ultrafine Grained Steels by Severe Plastic Deformation and Subsequent Annealing}

The grain refinement down to nanometer scale is one of the most advanced approaches for outstanding strengthening of austenitic stainless steels. ${ }^{[92-96,195-202]}$ The strengthening owing to the development of ultrafine grained structures in course of plastic deformation is commonly attributed to both decreased grain size (structural or boundary or grain size strengthening) and increased dislocation density (substructural or dislocation strengthening) much similar to that in the DRX microstructures after large strain warm to hot working and can be expressed by a modified Hall-Petch type relationship such as Equation 7. Since the dislocation density in largely strained steels correlates with the density of grain boundaries, the yield strength of austenitic stainless steels subjected to cold to hot working can be roughly expressed by a linear function of inverse square root of the grain size in a wide range of grain sizes from conventional micrometer scale to nanometer scale. ${ }^{[93]}$ In this case, the grain size strengthening factor should be somewhat higher than that in coarse grained statically recrystallized steels because of additional effect of high dislocation density. It is interesting to note that ultrafine grained austenitic stainless steels processed by severe plastic deformation with subsequent annealing are characterized by rather high grain size strengthening factors much similar to those obtained after large strain 
deformations. ${ }^{[93,149]}$ Such an increase in the strength of ultrafine grained steels can be attributed to dislocation substructures, which remain during continuous recrystallization and are responsible to incomplete softening of apparently recrystallized microstructures. ${ }^{[149]}$

It should be noted that an increase in strength of metallic materials is generally accompanied by degradation of their ductility. ${ }^{[93,95,175,198]}$ Therefore, the required combination of strength and ductility, can be obtained after controlled thermomechanical treatment including a post-deformation annealing resulting in beneficial microstructure. Several typical examples of achievable strength in conventional austenitic stainless steels owing to ultrafine grained microstructures developed by large strain deformations and subsequent annealing are listed in Table 1. ${ }^{[92,93,95,119,195,196,198,201,203,204}$

The development of nanocrystalline structure in austenitic stainless steels through severe plastic deformation results in outstanding strengthening with the yield strength above $2000 \mathrm{MPa} .{ }^{[92,93]}$ The most impressive results on improvement of mechanical properties by severe plastic deformation were reported for nanostructured metallic materials, which were processed by torsion under high pressure at room temperature. ${ }^{[119,196]}$ The tensile stress-strain curves obtained by using miniature tensile specimens of nanocrystalline 304-type steel processed by cold rolling and torsion under high pressure are shown in Figure 37. ${ }^{[93,119]}$ The cold rolled sample exhibits a high yield strength of $2050 \mathrm{MPa}$ and very small total elongation of $5 \%$. The stress-strain curve is characterized by a well-defined peak at small strain followed by rapidly decreasing stress until fracture. On the other hand, the sample subjected to torsion under high pressure demonstrates beneficial combination of strength and ductility, for example, high ultimate tensile strength of $1950 \mathrm{MPa}$ with rather large total elongation of $15 \%$. The enhanced ductility after torsion can be attributed to suppression of strain-induced martensite transformation by high pressure (s. Figure 17).

The nanocrystalline structures developed in austenitic stainless steels by means of severe plastic deformation are rather stable against discontinuous grain growth upon subsequent heating. ${ }^{[93,149,202,204]}$ The ultrafine grained steels subjected to large strain deformation and annealing may exhibit beneficial combination of strength and ductility. ${ }^{[203,204]}$ The improved strength-ductility relation in the ultrafine grained steels has been attributed to enhanced strain hardening owing to partial dislocation $\operatorname{slip}^{[197]}$ and/or deformation twinning. ${ }^{[204]}$ It should be noted that nanocrystalline microstructures in metastable austenitic stainless steels processed by severe plastic deformation are stabilized against annealing coarsening by straininduced martensitic transformation, which results in two phase

Table 1. Mechanical properties of ultrafine grained austenitic stainless steels subjected to large strain deformation and subsequent annealing.

\begin{tabular}{|c|c|c|c|c|c|c|}
\hline Steel & Processing & $\begin{array}{l}\text { Grain size } \\
\quad(\mathrm{nm})\end{array}$ & $\begin{array}{l}\text { Yield strength } \\
\quad(\mathrm{MPa})\end{array}$ & $\begin{array}{l}\text { Ultimate tensile strength } \\
\qquad(\mathrm{MPa})\end{array}$ & $\begin{array}{l}\text { Total elongation } \\
(\%)\end{array}$ & Ref. \\
\hline SUS3 16 & Multiple forging at room temperature & 50 & 2050 & 2075 & 10 & [92] \\
\hline SUS3 16 & Multiple forging at $73 \mathrm{~K}$ & 40 & 2100 & 2125 & 10 & [92] \\
\hline 316 & Torsion $(\varepsilon=260)$ under high pressure at room temperature & 40 & 1700 & 1800 & 7 & [196] \\
\hline 316 & Torsion $(\varepsilon=260)$ under high pressure at $673 \mathrm{~K}$ & 90 & 1720 & 1950 & 8 & [196] \\
\hline $316 \mathrm{~L}$ & Rolling $(\varepsilon=3)$ at room temperature & $\begin{array}{l}\text { Two phases: } \\
80 \text { (austenite) } \\
70 \text { (martensite) }\end{array}$ & 1680 & 1830 & 5 & [95] \\
\hline $316 \mathrm{~L}$ & Rolling $(\varepsilon=3)$ at $573 \mathrm{~K}$ & 160 & 1070 & 1175 & 10 & [95] \\
\hline $316 \mathrm{LN}$ & Rolling $(90 \%)$ +Annealing at $1173 \mathrm{~K}$ & 2000 & 994 & 1161 & 40 & [204] \\
\hline 304 & $\operatorname{ECAP}(\varepsilon=8)$ at $773 \mathrm{~K}$ & $80-100$ & 1130 & 1160 & 8 & [203] \\
\hline 304 & $\operatorname{ECAP}(\varepsilon=8)$ at $773 \mathrm{~K}+$ Annealing at $973 \mathrm{~K}$ & $100-150$ & 1045 & 1115 & 26 & [203] \\
\hline 304 & $\operatorname{ECAP}(\varepsilon=8)$ at $773 \mathrm{~K}+$ Annealing at $1023 \mathrm{~K}$ & $\begin{array}{l}\text { Bimodal: } \\
350(62 \%) \\
1400(38 \%)\end{array}$ & 725 & 930 & 40 & [203] \\
\hline $304 \mathrm{~L}$ & Rolling $(\varepsilon=3)$ at room temperature & $\begin{array}{l}\text { Two phases: } \\
145 \text { (austenite) } \\
115 \text { (martensite) }\end{array}$ & 1595 & 1785 & 4 & [198] \\
\hline $304 \mathrm{~L}$ & Rolling $(\varepsilon=3)$ at $573 \mathrm{~K}$ & 220 & 1005 & 1140 & 10 & [201] \\
\hline $\mathrm{S} 304 \mathrm{H}$ & Multiple forging $(\varepsilon=4)$ at room temperature & 30 & 1430 & 1540 & 7 & [195] \\
\hline $\mathrm{S} 304 \mathrm{H}$ & Multiple forging $(\varepsilon=4)$ at room temperature + Annealing at $773 \mathrm{~K}$ & 50 & 1420 & 1570 & 5 & [195] \\
\hline $\mathrm{S} 304 \mathrm{H}$ & Rolling $(\varepsilon=4)$ at room temperature & $\begin{array}{c}\text { Two phases: } \\
50 \text { (austenite) } \\
50 \text { (martensite) }\end{array}$ & 2050 & 2065 & 5 & [93] \\
\hline $\mathrm{S} 304 \mathrm{H}$ & Rolling $(\varepsilon=4)$ at room temperature + Annealing at $973 \mathrm{~K}$ & 170 & 1050 & 1160 & 9 & [93] \\
\hline $\mathrm{S} 304 \mathrm{H}$ & Torsion $(\varepsilon=230)$ under high pressure at room temperature & 23 & 1890 & 1950 & 17 & [119] \\
\hline $\mathrm{S} 304 \mathrm{H}$ & Torsion $(\varepsilon=230)$ under high pressure at $673 \mathrm{~K}$ & 26 & 1772 & 1828 & 12 & [119] \\
\hline
\end{tabular}




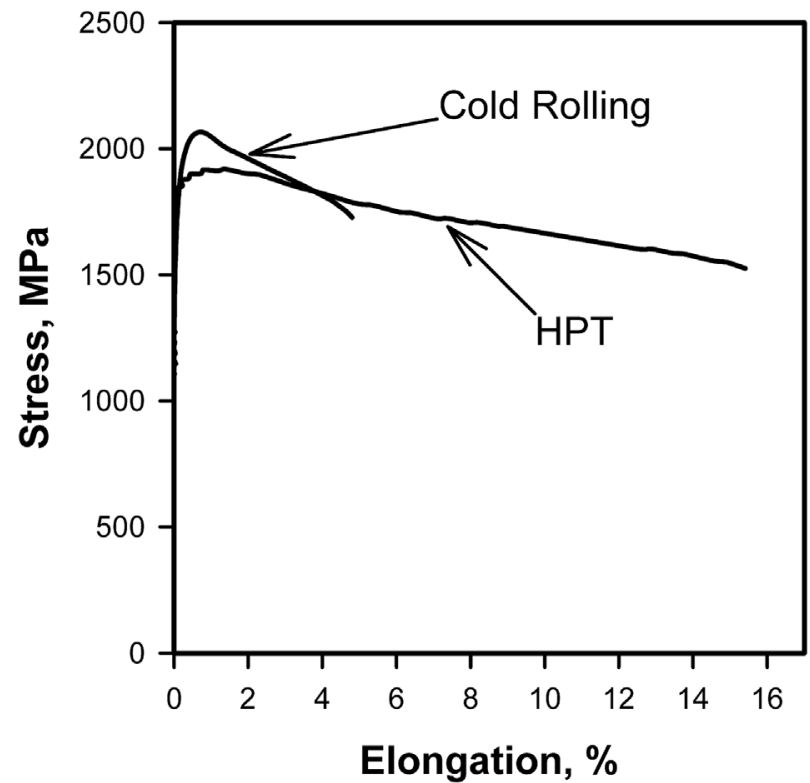

Figure 37. Tensile stress-strain curves of a 304-type stainless steel subjected to caliber cold rolling or torsion under high pressure (HPT).${ }^{[19]}$

microstructure. Such austenite-martensite/ferrite microstructure is particularly stable during subsequent annealing at temperatures up to $973 \mathrm{~K}$ because of impingement of grains of different phases. ${ }^{[3,149]}$ Besides retaining the ultrafine grains, recovery annealing leads to the annihilation of mobile dislocations and a relaxation of the grain boundaries that has been suggested to result in apparent annealing hardening. ${ }^{[205]}$ Mo-Cr-Si rich grain boundary segregations that evolve in severely strained austenite stainless steels during annealing at moderate temperatures can reportedly lead to further enhancement of the yield strength. ${ }^{[196,206]}$ Improvement of the strengthductility combination can also be achieved by means of bimodal microstructure, which can be developed in severely strained steels by subsequent heat treatment. ${ }^{[203,207-209]}$ Therefore, the ultrafine grained austenitic stainless steels with different grain sizes and various levels of residual stresses can be easily obtained by an appropriate combination of cold to warm working and annealing.

\section{Summary and Perspectives}

Austenitic stainless steels are commonly characterized by rapid kinetics of grain refinement during plastic deformation in a wide range of processing conditions from cold to hot working. Therefore, the desired microstructures with appropriate grain size can be obtained in steel semi-products through conventional processing methods. The rapid development of discontinuous DRX under conditions of hot working results from low SFE that suppresses dynamic recovery and promotes the nucleation of discontinuous DRX. On the other hand, the deformation microbands and corresponding strain gradients assist the evolution of strain-induced high-angle boundaries and advance the development of continuous DRX under conditions of warm working. Deformation twinning and strain-induced martensitic transformation in austenitic stainless steels lead to rapid grain subdivision under conditions of cold working. Thus, these steels can be easily processed in nanocrystalline state by using ordinary methods of severe plastic deformation like rolling or forging. In spite of great efforts in studying the DRX mechanisms and DRX microstructures in austenitic stainless steels, the kinetics of DRX development should be a subject of further comprehensive investigations, especially, for cold to warm working conditions, in order to incorporate the research achievements into advanced processing technologies.

The grain refinement through DRX development under conditions of cold to hot working results in substantial strengthening of austenitic stainless steels. The strengthening owing to DRX development is associated with both a decrease in the DRX grain size and an increase in the dislocation density in DRX grains. The grain size and dislocation density in DRX steels depend sensitively on deformation conditions and can be estimated using appropriate relationships with the flow stress or temperature compensated strain rate. Unique relationships that generally hold between the deformation conditions and evolved microstructure/substructure make possible predicting the strength of austenite stainless steels subjected to large strain cold to warm working. However, the quantitative evaluation of the strength of the ultrafine grained steels processed by large strain deformation requires further elaboration of the strengthening mechanisms, taking into account possible reduction of different contributions in the case of their concurrent operation. The effect of recovery annealing and grain boundary segregations on the yield strength of ultrafine grained steels subjected to severe plastic deformation is also of great importance because it may lead to unexpected extra strengthening along with ductility degradation.

Another important application of DRX and post-DRX for processing of advanced austenitic stainless steels is associated with grain boundary engineering. It should be noted that grain boundary engineering of austenitic stainless steels commonly utilizes primary static recrystallization following small strain deformation and, therefore, deals with coarse grained structures. On the other hand, the grain/subgrain boundary assemblies in the austenitic stainless steels can be directly controlled by appropriate sequences of the DRX and post-DRX treatments. Annealing twins readily evolve in the steels during recrystallization and/or grain growth owing to low SFE. Thus, the required grain/subgrain boundary distributions can be developed even in ultrafine grained steels, widening the range of mechanicalfunctional property combinations.

\section{Acknowledgement}

The financial support received from the Ministry of Education and Science, Russia, under Grant No. 11.3719.2017/PCh is gratefully acknowledged.

\section{Conflict of Interest}

The authors declare no conflict of interest. 


\section{Keywords}

austenitic stainless steels, dislocation density, dynamic recrystallization, grain size, mechanical properties, thermo-mechanical treatment

Received: November 1, 2017

Revised: January 24, 2018

Published online: February 21, 2018

[1] K. H. Lo, C. H. Shek, J. K. L. Lai, Mater. Sci. Eng. R. 2009, 65, 39.

[2] C. G. de Andres, C. Capdevila, D. San Martin, in Encycopedia of Iron, Steel, and Their Alloys, Taylor \& Francis, UK 2016, pp. 3388-3409.

[3] F. Goodwin, S. Guruswamy, K. U. Kainer, C. Kammer, W. Knabl, A. Koethe, G. Leichtfried, G. Schlamp, R. Stickler, H. Warlimont, in Springer Handbook of Condensed Matter and Materials Data (Eds: W. Martienssen, H. Warlimont), Springer, Berlin, Germany 2005, pp. 161-430.

[4] M. Kato, Mater. Trans. 2014, 55, 19.

[5] R. Z. Valiev, I. V. Alexandrov, Y. T. Zhu, T. C. Lowe, J. Mater. Res. 2002, 17, 5

[6] E. Ma, T. Zhu, Mater. Today 2017, 20, 323.

[7] H. J. McQueen, J. J. Jonas, in Treatise on Materials Science and Technology, Vol. 6 (Ed: R. J. Arsenault), Academic Press, NY 1975, pp. 393-493.

[8] T. Sakai, J. J. Jonas, Acta Metall. 1984, 32, 189

[9] Z. Yanushkevich, S. V. Dobatkin, A. Belyakov, R. Kaibyshev, Acta Mater. 2017, 136, 39.

[10] T. Sakai, A. Belyakov, R. Kaibyshev, H. Miura, J. J. Jonas, Prog. Mater. Sci. 2014, 60, 130.

[11] M. Odnobokova, M. Tikhonova, A. Belyakov, R. Kaibyshev, J. Mater. Sci. 2017, 52, 4210

[12] T. Watanabe, J. Mater. Sci. 2011, 46, 4095.

[13] K. Huang, R. E. Loge, Mater. Des. 2016, 111, 548.

[14] A. Belyakov, H. Miura, T. Sakai, Mater. Sci. Eng. A 1998, A255, 139.

[15] A. Belyakov, H. Miura, T. Sakai, Scr. Mater. 2000, 43, 21.

[16] H. J. Frost, M. F. Ashby, Deformation Mechanism Maps, Pergamon, Oxford, UK 1982, p. 62.

[17] A. Belyakov, M. Tikhonova, Z. Yanushkevich, R. Kaibyshev, Mater. Sci. Forum 2013, 753, 411.

[18] M. J. Luton, C. M. Sellars, Acta Metall. 1969, 17, 1033.

[19] J. J. Jonas, C. M. Sellars, W. J. M. Tegart, Metall. Rev. 1969, 14, 1.

[20] F. J. Humphreys, M. Hatherly, Recrystallization and Related Annealing Phenomena, Elsevier, Oxford, UK 1996, p. 363.

[21] A. N. Belyakov, Phys. Met. Metallogr. 2009, 108, 390.

[22] T. Maki, S. Okaguchi, I. Tamura, in Strength of Metals and Alloys: ICSMA 6, Vol. 1 (Ed: R. C. Gifkins), Pergamon, Oxford, UK 1983, pp. 529-534.

[23] J. K. Solberg, H. J. McQueen, N. Ryum, E. Nes, Philos. Mag. A 1989, 60, 447.

[24] S. J. Sales, T. R. McNelley, H. J. McQueen, Metall. Trans. 1991, 22A, 1037.

[25] A. Belyakov, R. Kaibyshev, Phys. Met. Metallogr. 1994, 78, 85.

[26] K. Tsuzaki, H. Xiaoxu, T. Maki, Acta Mater. 1996, 44, 4491.

[27] N. Tsuji, Y. Matsubara, Y. Saito, Scr. Mater. 1997, 37, 477.

[28] S. Gourdet, F. Monthellet, Mater. Sci. Eng. A 2000, A283, 274.

[29] A. Galiyev, R. Kaibyshev, G. Gottstein, Acta Mater. 2001, 49, 1199.

[30] T. Sakai, J. J. Jonas, in Encyclopedia of Materials: Science and Technology, Vol. 7 (Eds: K. H. Buschow, R. W. Cahn, M. C. Flemings, B. Ilschner, E. J. Kramer, S. Mahajan), Elsevier, Oxford, UK 2001, pp. 7079-7084.

[31] P. Cizek, Acta Mater. 2016, 106, 129.

[32] A. Belyakov, Z. Yanushkevich, M. Tikhonova, R. Kaibyshev, Mater. Sci. Forum 2016, 838-839, 314.
[33] D. Hardwick, C. M. Sellars, W. J. Tegart, J. Inst. Met. 1961, 90, 17.

[34] S. Sakui, T. Sakai, K. Takeishi, Trans. ISIJ 1977, 17, 718.

[35] C. M. Sellars, Philos. Trans. R. Soc. Lond. A 1978, 288, 147.

[36] H. Mecking, G. Gottstein, in Recrystallization of Metallic Materials, (Ed: F. Haessner), Riederer-Verlag, Stuttgart, Germany 1978, pp. 195-222.

[37] T. Sakai, M. Ohashi, Mater. Sci. Technol. 1990, 6, 1251.

[38] T. Maki, K. Akasaka, K. Okuno, I. Tamura, Trans. ISIJ 1982, 22, 253.

[39] J. E. Burke, D. Turnbull, Prog. Met. Phys. 1952, 3, 220.

[40] J. E. Bailey, P. B. Hirsch, Proc. R. Soc. Lond. 1962, A267, 11.

[41] R. D. Doherty, D. A. Hughes, F. J. Humphreys, J. J. Jonas, D. J. Jensen, M. F. Kassner, W. E. King, T. R. McNelley, H. J. McQueen, A. D. Rollett, Mater. Sci. Eng. A 1997, A238, 219.

[42] A. Belyakov, T. Sakai, H. Miura, R. Kaibyshev, ISIJ Int. 1999, 39, 592.

[43] D. Ponge, G. Gottstein, Acta Mater. 1998, 46, 69.

[44] X. Wang, E. Brunger, G. Gottstein, Scr. Mater. 2002, 46, 875.

[45] O. D. Sherby, J. Wadsworth, Prog. Mater. Sci. 1989, 33, 169.

[46] O. A. Kaibyshev, Superplasticity of Alloys, Intermetallics and Ceramics, Springer, Berlin, Germany 1992, p. 1.

[47] A. Belyakov, W. Gao, H. Miura, T. Sakai, Metall. Mater. Trans. A 1998, 29A, 2957.

[48] A. Belyakov, T. Sakai, H. Miura, Mater. Trans. JIM 2000, 41, 476.

[49] M. Jafari, A. Najafizadeh, Mater. Sci. Eng. A 2009, A501, 16.

[50] M. Frommert, G. Gottstein, Mater. Sci. Eng. A 2009, A506, 101.

[51] M. Tikhonova, P. Dolzhenko, R. Kaibyshev, A. Belyakov, Metals 2016, 6, 268

[52] M. D. Drury, F. J. Humphreys, Acta Metall. 1986, 24, 154.

[53] L. Qing, H. Xiaoxu, Y. Mei, Y. Jinfeng, Acta Metall. Mater. 1992, 40, 1753.

[54] A. Belyakov, R. Kaibyshev, Phys. Met. Metallogr. 1994, 78, 91.

[55] N. Dudova, A. Belyakov, T. Sakai, R. Kaibyshev, Acta Mater. 2010, $58,3624$.

[56] M. Tikhonova, V. Dudko, A. Belyakov, R. Kaibyshev, Mater. Sci. Forum 2011, 667-669, 565.

[57] M. Tikhonova, A. Belyakov, R. Kaibyshev, Mater. Sci. Eng. A 2013, A564, 413

[58] D. Kuhlmann-Wilsdorf, N. Hansen, Scr. Mater. 1991, 25, 1557.

[59] B. Bay, N. Hansen, D. A. Hughes, D. Kuhlmann-Wilsdorf, Acta Metall. Mater. 1992, 40, 205.

[60] A. Belyakov, Z. Yanushkevich, I. Shakhova, R. Kaibyshev, in Encycopedia of Iron, Steel, and Their Alloys, Taylor \& Francis, UK 2016, pp. 243-253.

[61] Z. Yanushkevich, A. Belyakov, R. Kaibyshev, Acta Mater. 2015, 82, 244.

[62] A. Belyakov, S. Zherebtsov, M. Tikhonova, G. Salishchev, Mater. Phys. Mech. 2015, 24, 224.

[63] H. J. McQueen, O. Knustad, N. Ryum, J. K. Solberg, Scr. Metall. 1985, 19, 73

[64] W. Blum, Q. Zhu, R. Markel, H. J. McQueen, Mater. Sci. Eng. A 1996, A205, 23.

[65] F. J. Humphreys, P. B. Prangnell, J. R. Bowen, A. Gholinia, C. Harris, Phil. Trans. R. Soc. Lond. A 1999, 357, 1663.

[66] N. A. Smirnova, V. I. Levit, V. I. Pilyugin, R. I. Kuznetsov, L. S. Davydova, V. A. Sazonova, Phys. Met. Metallogr. 1986, 61, 127.

[67] J. Richert, M. Richert, Aluminium 1986, 62, 604.

[68] G. A. Salishchev, O. R. Valiakhmetov, R. M. Galeyev, J. Mater. Sci. 1993, 28, 2898.

[69] Y. Kimura, S. Takaki, Mater. Trans. JIM 1995, 36, 289.

[70] C. C. Koch, Nanostruct. Mater. 1997, 9, 13.

[71] Y. Iwahashi, Z. Horita, M. Nemoto, T. G. Langdon, Acta Mater. 1997, $45,4733$.

[72] S. Saito, N. Tsuji, H. Utsunomiya, T. Sakai, R. G. Hong, Scr. Mater. 1998, 39, 1221.

[73] R. Z. Valiev, R. K. Islamgaliev, I. V. Alexandrov, Prog. Mater. Sci. 2000, 45, 103. 
[74] A. Belyakov, T. Sakai, H. Miura, K. Tsuzaki, Philos. Mag. A 2001, 81, 2629.

[75] N. Tsuji, Y. Saito, S. H. Lee, Y. Minamino, Adv. Eng. Mater. 2003, $5,338$.

[76] R. Z. Valiev, Y. Estrin, Z. Horita, T. G. Langdon, M. J. Zehetbauer, Y. T. Zhu, JOM 2006, 58, 33.

[77] A. P. Zhilyaev, T. G. Langdon, Prog. Mater. Sci. 2008, 53, 893.

[78] L. S. Toth, M. Arzaghi, J. J. Fundenberger, B. Beausir, O. Bouaziz, R. Arruffat-Massion, Scr. Mater. 2009, 60, 175.

[79] R. Z. Valiev, T. G. Langdon, Adv. Eng. Mater. 2010, 12, 677.

[80] Y. Estrin, A. Vinogradov, Acta Mater. 2013, 61, 782.

[81] L. S. Toth, C. Gu, Mater. Charact. 2014, 92, 1.

[82] J. D. Embury, A. S. Keh, R. M. Fisher, Trans. AIME 1966, 236, 1252.

[83] G. Langford, M. Cohen, Metall. Trans. A 1975, 6A, 901.

[84] J. G. Sevillano, P. van Houtte, E. Aernoudt, Prog. Mater. Sci. 1980 , $25,69$.

[85] V. V. Rybin, Large Plastic Deformations and Destruction of Metals, Metallurgia, Moscow, USSR 1987, p. 1.

[86] Q. Liu, D. Juul Jensen, N. Hansen, Acta Mater. 1998, 46, 5819.

[87] C. Kobayashi, T. Sakai, A. Belyakov, H. Miura, Philos. Mag. Lett. 2007, 87, 751.

[88] T. Sakai, A. Belyakov, H. Miura, Metall. Mater. Trans. A 2008, 39A, 2206.

[89] H. Miura, M. Kobayashi, Y. Todaka, C. Watanabe, Y. Aoyagi, N. Sugiura, N. Yoshinaga, Scr. Mater. 2017, 133, 33.

[90] T.-H. Lee, C.-S. Oh, S.-J. Kim, S. Takaki, Acta Mater. 2007, 55, 3649.

[91] T.-H. Lee, E. Shin, C.-S. Oh, H.-Y. Ha, S.-J. Kim, Acta Mater. 2010, $58,3173$.

[92] Y. Nakao, H. Miura, Mater. Sci. Eng. A 2011, A528, 1310.

[93] I. Shakhova, V. Dudko, A. Belyakov, K. Tsuzaki, R. Kaibyshev, Mater. Sci. Eng. A 2012, A545, 176.

[94] A. Belyakov, A. Kipelova, M. Odnobokova, I. Shakhova, R. Kaibyshev, Mater. Sci. Forum 2014, 783-786, 651.

[95] M. Odnobokova, A. Belyakov, R. Kaibyshev, Adv. Eng. Mater. 2015 17, 1812.

[96] A. Belyakov, M. Odnobokova, I. Shakhova, R. Kaibyshev, Mater. Sci. Forum 2017, 879, 224.

[97] K. Tomimura, S. Takaki, S. Tanimoto, Y. Tokunaga, ISIJ Int. 1991, $31,721$.

[98] K. Tomimura, S. Takaki, Y. Tokunaga, ISIJ Int. 1991, 31, 1431.

[99] D. L. Johannsen, A. Kyrolainen, P. J. Ferreira, Metall. Mater. Trans. A 2006, 37A, 2325.

[100] S. Rajasekhara, P. J. Ferreira, L. P. Karajalainen, A. Kyrolainen, Metall. Mater. Trans. A 2007, 38A, 1202.

[101] M. C. Somani, P. Juntunen, L. P. Karjalainen, R. D. K. Misra, A. Kyrolainen, Metall. Mater. Trans. A 2009, 40A, 729.

[102] M. Eskandari, A. Kermanpur, A. Najafizadeh, Metall. Mater. Trans. A 2009, 40A, 2241.

[103] F. Forouzan, A. Najafizadeh, A. Kermanpur, A. Hedayati, R. Surkialiabad, Mater. Sci. Eng. A 2010, A527, 7334.

[104] N. Nakada, H. Ito, Y. Matsuoka, T. Tsuchiyama, S. Takaki, Acta Mater. 2010, 58, 895.

[105] R. D. K. Misra, Z. Zhang, P. K. C. Venkatasurya, M. C. Somani, L. P. Karjalainen, Mater. Sci. Eng. A 2010, A527, 7779.

[106] A. Das, S. Sivaprasad, P. C. Chakraborti, S. Tarafder, Mater. Sci. Eng. A 2011, A528, 7909.

[107] M. Odnobokova, A. Kipelova, A. Belyakov, R. Kaibyshev, IOP Conf. Series: Mater. Sci. Eng. 2014, 63, 012060.

[108] H. Kitahara, R. Ueji, M. Ueda, N. Tsuji, Y. Minamino, Mater. Charact. 2005, 54, 378.

[109] H. Kitahara, R. Ueji, N. Tsuji, Y. Minamino, Acta Mater. 2006, 54, 1279.

[110] A. Belyakov, K. Tsuzaki, R. Kaibyshev, Mater. Sci. Forum 2011, 667669, 553.
[111] A. Belyakov, M. Odnobokova, A. Kipelova, K. Tsuzaki, R. Kaibyshev, IOP Conf. Series: Mater. Sci. Eng. 2014, 63, 012156.

[112] G. B. Olson, M. Cohen, Metall. Trans. A 1975, 6A, 791.

[113] M. Tikhonova, I. Shakhova, R. Kaibyshev, A. Belyakov, Mater. Sci. Forum 2017, 879, 1957.

[114] S. Dobatkin, W. Skrotzki, V. Terent'ev, O. Rybalchenko, A. Belyakov, D. Prosvirnin, E. Zolotarev, Mater. Sci. Forum 2014, 783-786, 2611.

[115] Z. Yanushkevich, A. Lugovskaya, A. Belyakov, R. Kaibyshev, Mater. Sci. Eng. A 2016, A667, 279.

[116] B. Derby, Acta Metall. Mater. 1991, 39, 955.

[117] A. Belyakov, T. Sakai, H. Miura, Mater. Sci. Eng. A 2001, 319-321, 867.

[118] A. Belyakov, K. Tsuzaki, H. Miura, T. Sakai, Acta Mater. 2003, $51,847$.

[119] M. Tikhonova, N. Enikeev, R. Z. Valiev, A. Belyakov, R. Kaibyshev, Mater. Sci. Forum 2016, 838-839, 398.

[120] A. Belyakov, S. Zherebtsov, G. Salishchev, Mater. Sci. Eng. A 2015, 628, 104.

[121] H. Mecking, U. F. Kocks, Acta Metall. 1981, 29, 1865.

[122] S. V. Raj, G. M. Pharr, Mater. Sci. Eng. 1986, 81217.

[123] E. R. Bradley, D. H. Polonis, Acta Metall. 1988, 36, 393.

[124] F. R. Castro-Fernandez, C. M. Sellars, Philos. Mag. A 1989, 60, 487.

[125] Y. Estrin, L. S. Toth, A. Molinari, Y. Brechet, Acta Mater. 1998, 46, 5509.

[126] T. Sakai, M. G. Akben, J. J. Jonas, Acta Metall. 1983, 31, 631.

[127] M. Ohashi, T. Endo, T. Sakai, J. Jpn. Inst. Met. 1990, 54, 435

[128] T. Sakai, J. Mater. Process. Technol. 1995, 53, 349.

[129] J. Favre, D. Fabrègue, A. Chiba, Y. Bréchet, Phil. Mag. Lett. 2013, 93, 631

[130] W. Gao, A. Belyakov, H. Miura, T. Sakai, Mater. Sci. Eng. A 1999, A265, 233.

[131] E. I. Poliak, J. J. Jonas, Acta Metall. Mater. 1996, 44, 127.

[132] A. Laasraoui, J. J. Jonas, Metall. Trans. A 1991, 22A, 1545.

[133] V. V. Rybin, A. A. Zisman, N. Y. Zolotorevsky, Acta Mater. 1993, 41, 2211.

[134] S. Gourdet, F. Montheillet, Acta Mater. 2003, 51, 2685.

[135] R. Kaibyshev, K. Shipilova, F. Musin, Y. Motohashi, Mater. Sci. Eng. A 2005, A396, 341.

[136] O. Sitdikov, T. Sakai, A. Goloborodko, H. Miura, R. Kaibyshev, Philos. Mag. 2005, 85, 1159.

[137] J. J. Jonas, X. Quelennec, L. Jiang, E. Martin, Acta Mater. 2009, $57,2748$.

[138] F. Musin, A. Belyakov, R. Kaibyshev, Y. Motohashi, G. Itoh, K. Tsuzaki, Rev. Adv. Mater. Sci. 2010, 25, 107.

[139] O. Bouaziz, Y. Estrin, Y. Brechet, J. D. Embury, Scr. Mater. 2010, 63, 477.

[140] P. Kusakin, K. Tsuzaki, D. A. Molodov, R. Kaibyshev, A. Belyakov, Metall. Mater. Trans. A 2016, 47A, 5704.

[141] A. Belyakov, Y. Kimura, Y. Adachi, K. Tsuzaki, Mater. Trans. 2004, 45, 2812.

[142] W. Roberts, in Strength of Metals and Alloys: ICSMA-7 (Ed: H. J. McQueen, J.-P. Bailon, J. I. Dickson), Pergamon Press, Oxford, UK, 1986, pp. 1859-1891.

[143] M.-S. Chen, Y. C. Lin, X.-S. Ma, Mater. Sci. Eng. A 2012, A556, 260.

[144] X.-M. Chen, Y. C. Lin, D.-X. Wen, J.-L. Zhang, M. He, Mater. Des. 2014, 57, 568

[145] D.-X. Wen, Y. C. Lin, Y. Zhou, Vacuum 2017, 141, 316.

[146] A. Belyakov, K. Tsuzaki, H. Miura, T. Sakai, in Proceedings of International Conference on Processing and Manufacturing of Advanced Materials, CDROM, Section A1, vol. $117 / 3$ (Eds: T. Chandra, K. Higashi, C. Suryanarayana, C. Tome), Elsevier Science, UK, 2001

[147] A. Belyakov, T. Sakai, H. Miura, R. Kaibyshev, K. Tsuzaki, Acta Mater. 2002, 50, 1547 
[148] H. Beladi, P. Cizek, P. D. Hodgson, Acta Mater. 2011, 59, 1482.

[149] M. Odnobokova, A. Belyakov, N. Enikeev, D. A. Molodov, R. Kaibyshev, Mater. Sci. Eng. A 2017, A689, 370.

[150] H. Hu, B. B. Rath, Metall. Trans. 1970, 1, 3181.

[151] P. A. Beck, M. L. Holtzworth, H. Hu, Phys. Rev. 1948, 73, 526.

[152] N. E. Hannerz, F. De Kazinczy, J. Iron Steel Inst. 1970, 208, 475.

[153] Y. C. Lin, M.-S. Chen, J. Zhong, Comput. Mater. Sci. 2008, 44, 316.

[154] Y. C. Lin, Y.-X. Liu, M.-S. Chen, M.-H. Huang, X. Ma, Z.-L. Long, Mater. Des. 2016, 99, 107.

[155] D.-G. He, Y. C. Lin, M.-S. Chen, L. Li, J. Alloys Compd. 2017, 690, 971.

[156] P. Mannan, G. Casillas, E. V. Pereloma, Mater. Sci. Eng. A 2017, A700, 116.

[157] M. Tikhonova, R. Kaibyshev, X. Fang, W. Wang, A. Belyakov, Mater. Charact. 2012, 70, 14.

[158] M. Tikhonova, Y. Kuzminova, X. Fang, W. Wang, R. Kaibyshev, A. Belyakov, Philos. Mag. 2014, 94, 4181.

[159] J. K. Mackenzie, Biometrika 1958, 45, 229.

[160] C. S. Pande, M. A. Imam, B. B. Rath, Metall. Trans. A 1990, 21A, 2891.

[161] S. Mahajan, C. S. Pande, M. A. Imam, B. B. Rath, Acta Mater. 1997, 45, 2633.

[162] C. S. Pande, M. A. Imam, Mater. Sci. Eng. A 2009, A512, 82.

[163] S. Mahajan, Scr. Mater. 2013, 68, 95.

[164] A. Belyakov, Y. Kimura, Y. Adachi, K. Tsuzaki, Mater. Trans. 2004, 45, 2812.

[165] A. Belyakov, Y. Kimura, K. Tsuzaki, Acta Mater. 2006, 54, 2521.

[166] A. Belyakov, K. Tsuzaki, Y. Kimura, Y. Kimura, Y. Mishima, Mater. Sci. Eng. A 2007, A456, 323.

[167] R. Z. Valiev, T. G. Langdon, Prog. Mater. Sci. 2006, 51, 881.

[168] X.-M. Chen, Y. C. Lin, F. Wu, J. Alloys Compd. 2017, 724, 198.

[169] S. V. Dobatkin, V. F. Terent'ev, W. Skrotzki, O. V. Rybalchenko, M. N. Pankova, D. V. Prosvirnin, E. V. Zolotarev, Russ. Met. 2012, 2012, 954

[170] S. V. Dobatkin, O. V. Rybal'chenko, A. Kliauga, A. A. Tokar', Met. Sci. Heat Treat. 2015, 57, 222.

[171] S. V. Dobatkin, O. V. Rybalchenko, N. A. Enikeev, A. A. Tokar, M. M. Abramova, Mater. Lett. 2016, 166, 276.

[172] D. A. Hughes, N. Hansen, Acta Mater. 2000, 48, 2985.

[173] N. Hansen, Scr. Mater. 2004, 51, 801.

[174] Z. Yanushkevich, A. Mogucheva, M. Tikhonova, A. Belyakov, R. Kaibyshev, Mater. Charact. 2011, 62, 432.

[175] I. Shakhova, A. Belyakov, Z. Yanushkevich, K. Tsuzaki, R. Kaibyshev, ISIJ Int. 2016, 56, 1289.

[176] C. Haase, L. A. Barrales-Mora, F. Roters, D. A. Molodov, G. Gottstein, Acta Mater. 2014, 80, 327.

[177] V. Bratov, E. N. Borodin, Mater. Sci. Eng. A 2015, A631, 10.

[178] Z. Yanushkevich, A. Belyakov, R. Kaibyshev, C. Haase, D. A. Molodov, Mater. Charact. 2016, 112, 180.

[179] P. Zhou, Z. Y. Liang, R. D. Liu, M. X. Huang, Acta Mater. 2016, $111,96$.
[180] L. Zhu, H. Ruan, A. Chen, X. Guo, J. Lu, Acta Mater. 2017, 128, 375.

[181] M. R. Staker, D. L. Holt, Acta Metall. 1972, 20, 569.

[182] S. Takeuchi, A. S. Argon, J. Mater. Sci. 1976, 11, 1542.

[183] A. W. Thompson, Metall. Trans. A 1977, 8A, 833.

[184] F. Castro-Fernandez, C. M. Sellars, J. A. Whiteman, Mater. Sci. Technol. 1990, 6, 453

[185] A. K. Miller, O. D. Sherby, Scr. Metall. 1976, 10, 311.

[186] A. W. Thompson, Metall. Trans. A 1977, 8A, 833

[187] D. J. Abson, J. J. Jonas, Met. Sci. J. 1979, 4, 24.

[188] H. Mecking, U. F. Kocks, Acta Metall. 1981, 29, 1865.

[189] C. G. Schmidt, C. M. Young, B. Walser, R. H. Klundt, O. D. Sherby, Metall. Trans. A 1982, 13A, 447.

[190] N. D. Ryan, H. J. McQueen, E. Evangelista, Mater. Sci. Eng. 1986, 81, 259.

[191] Y. Estrin, L. S. Toth, A. Molinari, Y. Brechet, Acta Mater. 1998, 46, 5509.

[192] M. Charleux, W. J. Poole, M. Militzer, A. Deschamps, Metall. Mater. Trans. A 2001, 32A, 1635.

[193] N. Isasti, D. Jorge-Badiola, M. L. Taheri, P. Uranga, Metall. Mater. Trans. A 2014, 45A, 4960 .

[194] M. J. Starink, Mater. Sci. Eng. A 2017, A705, 42.

[195] M. Tikhonova, Y. Kuzminova, A. Belyakov, R. Kaibyshev, Rev. Adv. Mater. Sci. 2012, 31, 68.

[196] M. M. Abramova, N. A. Enikeev, R. Z. Valiev, A. Etienne, B. Radiguet, Y. Ivanisenko, X. Sauvage, Mater. Lett. 2014, 136, 349.

[197] Y. F. Shen, N. Jia, Y. D. Wang, X. Sun, L. Zuo, D. Raabe, Acta Mater. 2015, 97, 305

[198] M. Odnobokova, A. Belyakov, R. Kaibyshev, Metals 2015, 5, 656.

[199] V. S. A. Challa, R. D. K. Misra, M. C. Somani, Z. D. Wang, Mater. Sci. Eng. A 2016, A649, 153.

[200] A. Kisko, A. S. Hamada, J. Talonen, D. Porter, L. P. Karjalainen, Mater. Sci. Eng. A 2016, A657, 359.

[201] M. Odnobokova, A. Belyakov, R. Kaibyshev, Mater. Sci. Forum 2017, 879,1414

[202] M. El-Tahawy, Y. Huang, H. Choi, H. Choe, J. L. Lábár, T. G. Langdon, J. Gubicza, Mater. Sci. Eng. A 2017, A682, 323.

[203] Z. J. Zheng, J. W. Liu, Y. Gao, Mater. Sci. Eng. A 2017, 680, 426.

[204] D. M. Xu, G. Q. Li, X. L. Wan, R. L. Xiong, G. Xu, K. M. Wu, M. C. Somani, R. D. K. Misra, Mater. Sci. Eng. A 2017, A688, 407.

[205] O. Renk, A. Hohenwarter, K. Eder, K. S. Kormout, J. M. Cairney, R. Pippan, Scr. Mater. 2015, 95, 27.

[206] M. M. Abramova, N. A. Enikeev, X. Sauvage, A. Etienne, B. Radiguet, E. Ubyivovk, R. Z. Valiev, Rev. Adv. Mater. Sci. 2015, 43, 83.

[207] Z. Zhang, S. K. Vajpai, D. Orlov, K. Ameyama, Mater. Sci. Eng. A 2014, A598, 106.

[208] Z. Zhang, D. Orlov, S. K. Vajpai, B. Tong, K. Ameyama, Adv. Eng. Mater. 2015, 17, 791.

[209] R. Zheng, Z. Zhang, M. Nakatani, M. Ota, X. Chen, C. Ma, K. Ameyama, Mater. Sci. Eng. A 2016, A674, 212. 